DANMARKS GEOLOGISKE UNDERSOGELSE

V. Række. Nr. 7-C

Geological Survey of Denmark. V. Series. No. 7-C

\title{
Geology of Denmark
}

aII

\section{The Development of Denmark's Nlature since the Last Glacial}

\author{
By
}

Johs. Iversen

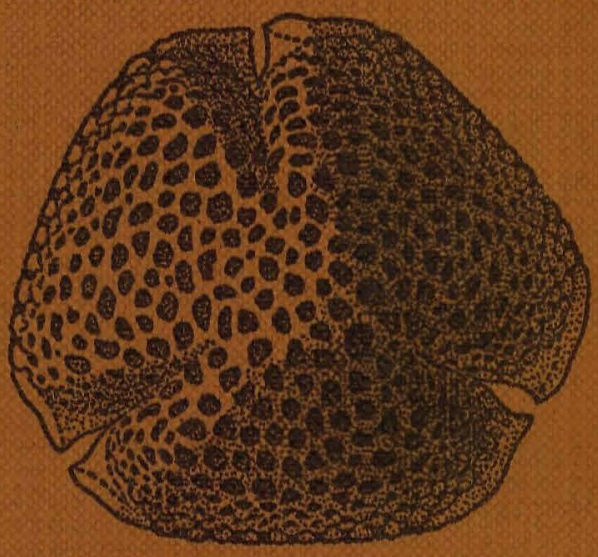

1 kommission hos C. A. Reitzels Forlag. København 1973 
The Development of Denmark's Nature since the Last Glacial 
Geology of Denmark III 
DANMARKS GEOLOGISKE UNDERS $\emptyset$ GELSE

V. RÆKKE. NR. 7-C

Geological Survey of Denmark. V. Series . No. 7-C

\title{
The Development of Denmark's Nature since the Last Glacial
}

\author{
By \\ Johs. Iversen
}

Translation from Danmarks Natur, vol. 1, pp. 345-445, 1967

by Michael Robson

I kommission hos

C. A. REITZELS FORLAG

København 1973 
D.G.U. V. rk. nr. 7-C

er sat med Linotype Times

og trykt i 2000 eksemplarer

hos F. E. Bording i København.

Bogen er trykt på glittet tryk E, $100 \mathrm{~g}$

og plancherne på krideret kunsttryk, $120 \mathrm{~g}$

fra A/S De forenede Papirfabrikker

ISBN 8742106311

Editor: Svend Th. Andersen

Pollen grain of Hedera helix

Vignet after drawing

by Ingeborg Frederiksen

in D. G. U. II rk. nr. 66

Date of publication: December 1973 


\section{CONTENTS}

Preface page

Contributions by Johs. Iversen on the vegetational history of Denmark . . . . . . . . . . . . . . . . . . . 9

The development of Denmark's nature since the last glacial . . 11

Researchers and methods . . . . . . . . . . . . . 11

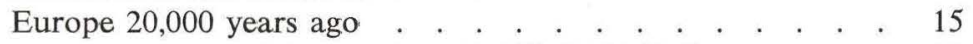

The final phase of the Ice Age, $13,000-8,300$ B. C. . . . . . . 19

Plants . . . . . . . . . . . . . . . . . . . 20

The chronology of the Late-Glacial . . . . . . . . . 28

Animal life and hunters . . . . . . . . . . . . . 33

The Late-Glacial sea . . . . . . . . . . . . . . 41

The Birch-Pine period, 8,300-7,000 B. C. . . . . . . . . 44

The forest conquers the land . . . . . . . . . . . 44

The earliest history of the Baltic Sea . . . . . . . . 51

The Hazel-Pine period, 7,000-6,000 B. C. . . . . . . . . . . 52

The Older Lime period, 6,000-3,000 B. C. . . . . . . . . . 62

The stable primeval forest arises . . . . . . . . . . 63

The tree species of the primeval forest . . . . . . . . 65

The stable primeval forest . . . . . . . . . . . . . 70

The sea . . . . . . . . . . . . . . . . . . 73

Climate . . . . . . . . . . . . . . . . . . 77

The Younger Lime period, 3,000-500 B. C. . . . . . . . . 78

The forest is transformed and exploited by man . . . . 78

The deterioration of the soil begins . . . . . . . . . 100

A portent of a climatic deterioration . . . . . . . . . 102

The Beech period. From 500 B. C. . . . . . . . . . . 105

Climatic deterioration in waves . . . . . . . . . . 105

The forest picture is altered . . . . . . . . . . . . 107

The open land appears . . . . . . . . . . . . . . . . . . . 109

The soil deterioration increased . . . . . . . . . . 115

The historical perspective . . . . . . . . . . . . 119

List of English plant names and their Latin equivalents . . . . 121

List of English animal names and their Latin equivalents . . . 123

More important literature about the Late-Glacial and Post-

Glacial geology of Denmark . . . . . . . . . . . . 124 


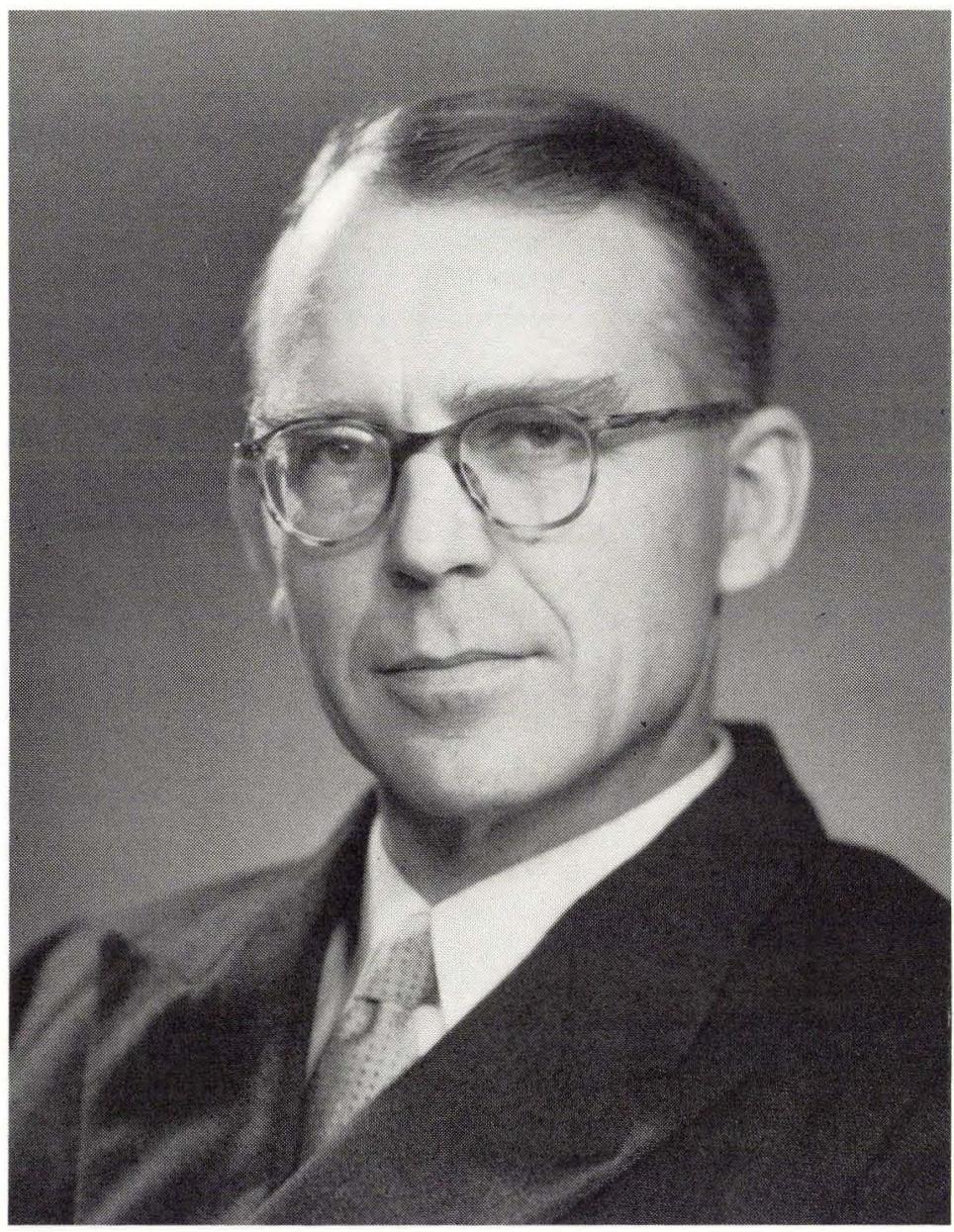




\section{Preface}

$\mathrm{T}$ he death of dr. Johannes Iversen, State Geologist at the Geological Survey of Denmark, on October 17th 1971, came at a time when he was still an eager and devoted scientist. It meant a deep loss not only to science but also to his personal friends and his colleagues in his home country and throughout the world. His scientific achievements ranged from botanical ecology to most aspects of the Quaternary vegetational history. His principal method was pollen analysis, which he in cooperation with others developed into a highly refined instrument; and the main subjects were Denmark's Late-Glacial vegetation and Post-Glacial foresthistory. Through his intimate botanical understanding and refined research techniques he mastered these fields; and as a result he created a picture, which was revolutionary in many ways and will stand unrivalled.

The scientific publications from Johs. Iversen's hand are innumerable and although in many cases of modest volume their scientific import is often the greater. Time did not permit him to produce a summary of his life-long experiences about Denmark's vegetational history in a scientific way; however we are so much more fortunate to have the essence of his opinions written for the general public in Danish. When Politikens Forlag was preparing its 12-volume work Danmarks Natur, Johs. Iversen was asked to contribute a section on the development of Denmark's nature since the last glacial. At that time he had finished his studies of the Late-Glacial and, particularly through his recent studies in Draved Forest, he had gained a mature and in many ways new comprehension of our PostGlacial forest history. $\mathrm{He}$ had for more than ten years been lecturing at the University of Copenhagen on the vegetational history of the Quaternary and had in this way found new inspiration. Obviously the proposal to write the contribution to Danmarks Natur came at a fortunate point of time, and it resulted in an inspired masterpiece written vividly and in plain words, the creation of which we welcomed with gratitude. We feel that his scientific institute can commemorate Johs. Iversen in no better way than by publishing The Development of Denmark's Nature since the Last Glacial in an international language. We gratefully acknowledge the warm-hearted collaboration of Politikens Forlag in making this edition possible.

The Development of Denmark's Nature since the Last Glacial is in a unique way based on its author's own research and experiences. The contributions of others were intimately known by him, however, and were eagerly drawn upon too. The following pages include a list of the more important of Johs. Iversen's own scientific contributions on the subject.

Names of plants and animals stated in Danish in the original text are given in English translation as far as possible. Lists of the English plant and animal names 
used and their Latin equivalents are added to the present edition. A list comprising the more important literature about the Late-Glacial and Post-Glacial geology of Denmark is also included.

The translation was skilfully done by Mr. M. Robson, B.A., at present of Copenhagen. Dr. Mrs. Winifred Pennington Tutin, of Leicester, kindly read the manuscript and suggested many valuable improvements. Mrs. B. Holm typed the manuscript and assisted in the editorial work.

The publication forms the third part of a Geology of Denmark. The two preceding parts are in preparation.

Svend Th. Andersen 


\section{Contributions by Johs. Iversen on the Vegetational History of Denmark}

(For a complete list of Johs. Iversen's scientific contributions, see e. g. Pollen et Spores, vol. 13, pp. 377-380).

Fund af Vildhest (Eqvus caballus) fra overgangen mellem sen- og postglacialtid i Danmark. - Danmarks geol. unders. IV, 2, 13. 16 pp. 1934.

Sekundäres Pollen als Fehlerquelle. Danmarks geol. unders. IV, 2, 15. 24 pp. 1936.

Unders $₫$ gelser over Litorinatransgressioner i Danmark. - Medd. dansk geol. for. 9: 223-232. 1937.

Pollenanalytiske tidsbestemmelser af midtjydske mesolitiske bopladser. In Mathiassen, Th.: Gudenaa-kulturen, Aarb. nord. oldk.hist. 1937: 182-186. 1937.

Planterester i Jelsfundet. - In: H. C. Broholm: Jelsfundet. Aarb. nord. oldk.hist. 1938: 5-6. 1938.

Planterester fremdragne i tre Høje i Haderslev Amt. - In: H. C. Broholm og Margrethe Hald: Skrydstrupfundet. Nordiske Fortidsminder 3: 1821. 1939.

Blütenbiologische Studien. I. Dimorphie und Monomorphie bei Armeria. - Kgl. dansk vidensk. selsk. Biol. medd. 15, 8. 39 pp. 1940.

Landnam i Danmarks stenalder (Land occupation in Denmark's Stone Age). - Danmarks geol. unders. II, 66, 68 pp. 1941.

En pollenanalytisk tidsfæstelse af ferskvandslagene ved Nørre Lyngby. - Medd. dansk geol. for. 10: 130 151. 1942.

Geological part. - In: Degerbøl, M. and J. Iversen: On a find of a sheatfish (Silurus glanis L.) from the Ancylus period in Denmark. - Vi- densk. medd. dansk naturh. for. 105: 443-446. 1942.

Et litorinaprofil ved Dybvad i Vendsyssel. - Medd. dansk geol. for. 10: 324-328. 1943.

Viscum, Hedera and Ilex as climate indicators. - Geol. för. Stockholm förh. 66: 463-483. 1944.

Helianthemum som fossil glacialplante i Danmark. - Geol. för. Stockholm förh. 66: 774-776. 1944.

III. The dating of the bison finds. IV. Conditions of life for the large herbivorous mammals in the Late-Glacial Period. - In: Degerbøl, M. and J. Iversen: The bison in Denmark. Danmarks geol. unders. II, 73: 3362. 1945.

Geologisk datering af en senglacial boplads ved Bromme. - Aarb. nord. oldk. hist. 1946: 197-231. 1946.

Centaurea cyanus-pollen in Danish Late-Glacial deposits. - Medd. dansk geol. for. 11: 197-200. 1947.

Plantevækst, dyreliv og klima i det senglaciale Danmark. - Geol. för. Stockholm förh. 69: 67-78. 1947.

The influence of prehistoric man on vegetation. - Danmarks geol. unders. IV, 3, 6. 25 pp. 1949.

Pollenmorfologiske definitioner og typer. Pollenmorphologische Definitionen und Typen. (With J. TroelsSmith). - Danmarks geol. unders. IV, 3, 8. 54 pp. 1950.

Steppeelementer i den senglaciale flora og fauna. - Medd. dansk geol. for. 12: 174-175. 1951. 
Radiocarbon dating of the Aller $\phi \mathrm{d}$ period. - Science 118: 9-11. 1953.

The Late-Glacial flora of Denmark and its relation to climate and soil. - Danmarks geol.unders. II, 80: 87119. 1954.

Forest clearance in the Stone Age. Scientific American 194: 36-41. 1956.

Pollenanalytischer Nachweis des $\mathrm{Re}$ liktencharakters eines jütischen Linden-Mischwaldes. - Veröff. geobot. Inst. Rübel Zürich 33: 137-144. 1958.

The bearing of glacial and interglacial epochs on the formation and extinction of plant taxa. - In: Hedberg, $\mathrm{O}$. (ed.): Systematics of today. Uppsala univ. årsskr. 6: 210-215. 1958.

Problems of the early Post-Glacial forest development in Denmark. Danmarks geol. unders. IV, 4,3. 32 pp. 1960.

Retrogressive vegetational succession in the Post-Glacial. - J. Ecol. 52 (Suppl.): 59-70. 1964.

Textbook of pollen analysis. (With Knut Fægri). - København (Munksgaard) 237 pp. Second revised edition. 1964.

Retrogressive development of a forest ecosystem demonstrated by pollen diagrams from fossil mor. - Oikos Suppl. 12: 35-49. 1969. 


\title{
The Development of Denmark's Nature since the Last Glacial
}

\author{
Researchers and methods
}

$\mathrm{T}$ The history of nature since the Ice Age has occupied Scandinavian researchers for more than a century: it is probably no exaggeration to say that Scandinavia during the whole of this period has been a centre for such research. The most important techniques were developed here, and the crucial ideas were formulated and made the subject of lively, even violent debate, all whilst a great number of observations was being accumulated. The peat bogs with their abundant remains, the plant growth of previous ages, animal life, and human activity, were an especially prized object of study. The ability of peat to preserve organic material makes peat bogs a valuable archive in which everything is stored in chronological order, the oldest at the bottom and the youngest at the top.

\section{The investigation of peat bogs is founded in Denmark}

This fruitful research began in Denmark. This is naturally not unrelated to the great importance of peat as a fuel in our rather treeless country. However, the fact that this practically orientated interest in peat bogs developed into a flourishing new branch of science is due to the work of three highly gifted men: Heinrich Dau, Japetus Steenstrup, and Christian Vaupell. Of these three, Dau was the real pioneer, the founder of bog investigations.

\section{H. Dau - an unappreciated pioneer}

Heinrich Dau (1790-1831) was born in Holstein, which at that time belonged to the Danish kingdom. Dau was induced to begin his studies on peat bogs by an award offered by the Agronomical Society, and gave in his contribution the first botanically valuable description and classification of peat bogs. He recognized three types, but to one of these, the raised bog, he attached special interest. With astonishing perception he recognized immediately that raised bogs differ from other bogs by one fact of "great chemicoatmospheric Curiousness"; they obtain all their nutrition from rain and from the atmosphere. But Dau was too far ahead of his time; his discovery was greeted only with criticism, and he was not awarded the prize. Nearly a century elapsed before the full correctness of Dau's observations was realized and inspired a new epoch in the study of the Post-Glacial climatic development (se page 105).

Dau continued his bog investigations under extremely difficult circumstances and published a book on the bogs of Zealand (1829). In this he substantiated and expanded his opinions, and also put forward another new idea. He explained the frequent occurrence in bogs of trunks of coniferous trees which no longer grow wild in this country, with a theory of forest history. Dau hoped to prove this after 


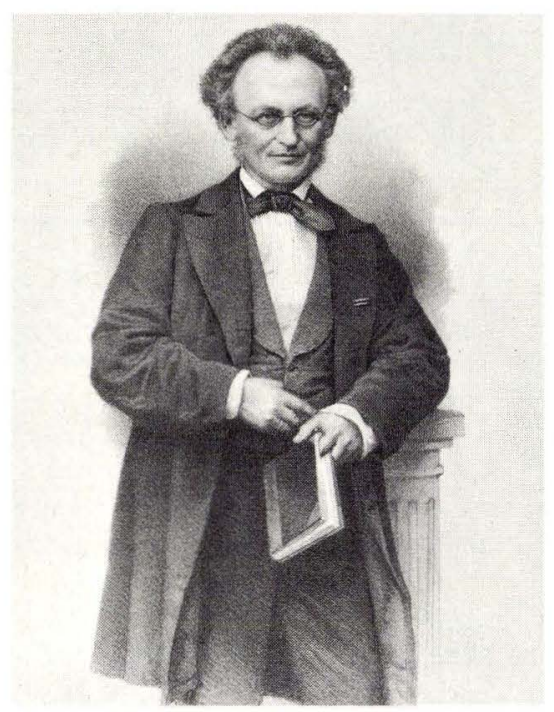

1. Japetus Steenstrup (1813-97), who was the first to decribe the layers of a bog and their plant remains.

more extensive investigations, but shortly afterwards he died while still quite young.

\section{Steenstrup's forest periods}

The young Japetus Steenstrup (181397) reaped what Dau had sown. The Danish Academy of Science offered an award for the solving of the problem which Dau had put forward in his last book. Steenstrup entered the contest, and won both the prize and all the honour and support which had been denied his predecessor. The honour was well-deserved: Steenstrup gave the first thorough description of the various layers in a bog and the plant remains found there. $\mathrm{He}$ established what Dau had suggested: that the forests of Denmark have undergone a succession.

In 1841 Steenstrup published his investigations and his famous division of forest history into four periods: the
Aspen, Pine, Oak, and Alder periods. This division, which aroused intense interest in the whole scientific world, was in fact not especially well based. However, it is to Steenstrup's credit that with his wide-ranging interests he recognized peat bogs as one of the best possible means for the investigation of the country's past. Plant and animal remains as well as traces of bygone cultures were all-important parts of this historical material. Steenstrup did not say much about the causes of the great changes in the forest composition: he connected them with the prevailing theories of a slow, continuous improvement in the climate.

\section{Vaupell discovers the competition by trees for light}

Christian Vaupell (1821-62) gave the first competent evaluation of the causes of the forest succession. Vaupell had himself carried out thorough investigations in peat stratigraphy using improved botanical-microscopical techniques, and on important points he revised Steenstrup's determinations and period divisions. But the decisive new factor was that forest history for Vaupell was not a diagram, but a living process. To understand it, one had to go out in the field and study the relationship of the various tree species with each other and with their surroundings. Vaupell pointed out and emphasized one factor of fundamental importance - the competition for light.

Everyone has probably heard of the competition of the beech with the oak, where the beech wins because it both casts and can tolerate more shade than the oak. It was Vaupell who first elucidated the light requirements of the various tree species; of this we shall hear more later. Vaupell expressed 


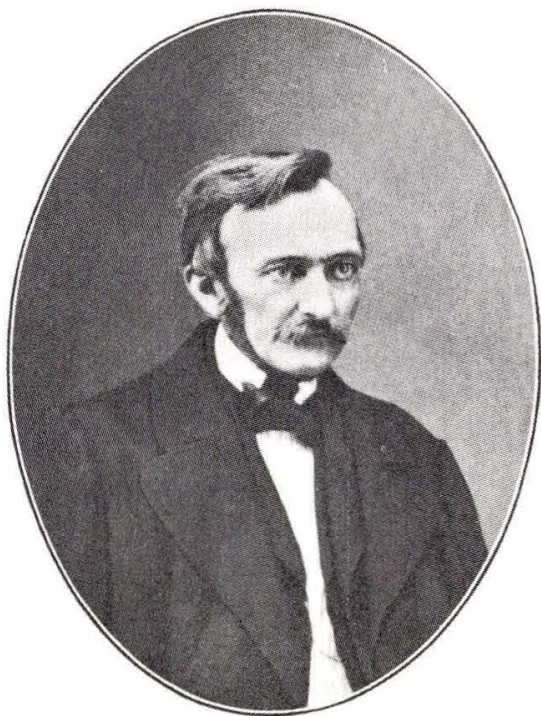

2. Chr. Vaupell (1821-62), who in his studies of forest history emphasized the decisive role of the competition among trees for light.

himself more cautiously concerning the influence of climate. The pine trunks in the Danish bogs could not have grown up in a raw, cold climate, as Steenstrup maintained, since their annual-rings are broad like the trees in the German pine forests, not narrow like those of trees growing in cold conditions. Only the presence of remains of north-Scandinavian species, such as dwarf birch, could definitely prove that the layer in question was formed in a climate colder than that of the present day. In this assumption Vaupell was correct, but neither he nor Steenstrup had examined the lowest clayey layers in the peat-bogs.

\section{The discovery of Ice Age plants}

Some years after Vaupell's early death, the Swedish botanist A. G. Nathorst was the first to find the remains of an arctic flora in the clay underlying the peat, first in Scania (1870), a year later in North Zealand, and later in many places in Europe. Nathorst's discovery formed a turning point in bog research: at one stroke the climate, and its influences, took the centre of the stage as an explanation of all changes in vegetation and animal life through the past. The final breakthrough of the Ice Age theory at the same time also contributed to this change of emphasis. The overall picture could now be seen - the immigration of plants and animals in the wake of the receding ice: first the undemanding, coldtolerating species such as Dryas (mountain avens), arctic willow, and reindeer, later as the climate improved trees and shrubs and a more warmthdemanding fauna.

For a long time a lively international debate followed regarding the course of the climatic development in the Post-Glacial period, with two Swedish botanists, Gunnar Andersson and Rutger Sernander as leading exponents. The question was mainly one of methods. Andersson continued in the spirit of Steenstrup, by preparing and determining the macrofossils (fruits, leaves, animal remains, etc.) of the peat layers. This led him to the conclusion that the Post-Glacial temperature curve had risen steadily to a culmination in the Oak period, and had then decreased somewhat, equally steadily.

\section{The Blytt-Sernander climatic periods}

The peat layers of a bog can also reveal changes in climate in a more direct way: the wetness of a bog, and thus its vegetation, is affected by the climate. If this changes greatly, for example from dry to humid, the peatforming vegetation wil reflect the change by paludification. The Norwegian botanist Axel Blytt (1876) unhesitatingly explained the occurrence of 


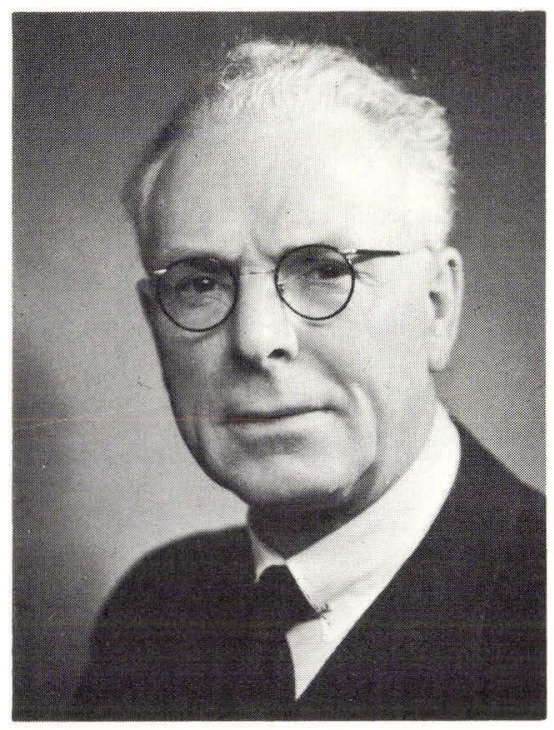

3. The botanist Prof. Knud Jessen, D.Sc., Ph.D. (1884-1971).

tree-stump layers as evidence for an alteration between dry and rainy periods.

Through Sernander's contributions this theory obtained a firmer foundation and won general acceptance. Sernander found four periods recorded in the bogs: the Boreal period (dry), the Atlantic (humid), the Sub-Boreal (dry and warm), and the Sub-Atlantic (humid and cool). The transition between the last two periods was considered by Sernander as an abrupt change, a climatic catastrophe - the Fimbulwinter of the Sagas.

The Blytt-Sernander theory of climatic changes was more dramatic than Andersson's more uniform climatic curve. We shall see later that both interpretations were too schematic and not sufficiently detailed. The conflict between the two schools did not end with a victory for either side: it died out when a new and more pow- erful method appeared, opening up completely new possibilities and perspectives.

\section{Pollen analysis}

The new method was pollen analysis, which was put forward in fully developed form by the Swedish geologist Lennart von Post at the 16th Scandinavian Nature Researchers Meeting at Kristiania in 1916 (See "Pollen analysis" in Danmarks Natur Vol. 1, p. 219).

\section{Relative and absolute chronology}

It quickly became evident that pollen analysis fulfilled all hopes: here at last was a clear expression of forest history and a method for dating (even with small peat samples) botanical, zoological, and archaeological material according to the new, relative chronology. The Danish botanist Knud Jessen, who earlier had used the previously described methods to create a foundation for further investigations of the Danish vegetational history, divided the Danish pollen diagrams into nine zones (I-IX). This division has also proved to be applicable in our neighbouring countries, and attempts are made to correlate the revised Steenstrup forest periods and the Blytt \& Sernander climatic phases with the pollen-analytical zones, so that the divisions by and large conform with each other.

The pollen analysis chronology is only relative, and the zone boundaries are not always contemporaneous over large areas. An absolute chronology is, however, made possible by the modern Carbon-14 dating method, and a satisfactory chronology, based on a combination of pollen analysis and the Carbon-14 method is now being developed.

The dates used in the following pages are chiefly based on datings 
made in the C-14 dating laboratory led by Henrik Tauber in Copenhagen. The dates must to a certain extent be regarded as provisional, since the exact half-life of C-14 has not yet finally been determined. A few laboratories use a half-life which produces ages increased by $3 \%$.

\section{Ecological pollen analysis}

The principal emphasis in pollen analysis today lies in a new area. The great drama of the development of vegetation after the Ice Age is known in its main features, and it is now important to single out the factors that have determined the whole drama and its various phases: the climatic variations, the development of the soil, and not least the manifold influences of mankind in prehistoric and historic times. To come to grips with these problems, all pollen types must be identified and counted as far as possible; the more pollen curves available, the more strings there are to play on. Many things are required of those who will master such an instrument: first and foremost, an intimate knowledge of the growth conditions of the various plant species in nature, and their competition with each other under various external conditions: in short, their ecology. We shall see later how a knowledge of plant ecology can help to explain characteristic and systematic episodes in the pollen diagrams, and to reveal events in nature which otherwise would go unnoticed.

Today work is carried on using all the methods mentioned above, and others which will be described later. Because of the close co-operation between the various branches of science further great advances can confidently be expected.

\section{Europe 20,000 years ago}

In order to understand the immigration of plants and animals into Denmark after the Ice Age, we must have a knowledge of the conditions in Europe during the coldest part of the Ice Age, before the climatic improvement had begun. Strangely enough, knowledge of the vegetation and climate during the coldest, high glacial phases of the Ice Age has long been uncertain.

Originally, most geologists considered the Ice Age to have been accompanied by a colossal and world-wide cooling, but there was in fact no evidence for this, and gradually various, mostly indirect, arguments for a more moderate change in climate were put forward. Among plant and animal geographers the opinion came to pre- vail that many rather warmth-requiring plants and animals of North Europe and North America had survived the Ice Age quite close to the edge of the ice cap. It was thought that such a theory could best explain their present distribution. The great vegetation zones as we know them from modern Europe, tundra, coniferous forest, deciduous forest, etc., were probably displaced a little to the south, but had not been very different apart from this. Geologists were not prepared to accept this theory, but it was hard to find any decisive disproving arguments.

In Europe north of the Alps, pollen analysis has not been able to provide a satisfactory picture of conditions during the high-glacial, since solifluc- 


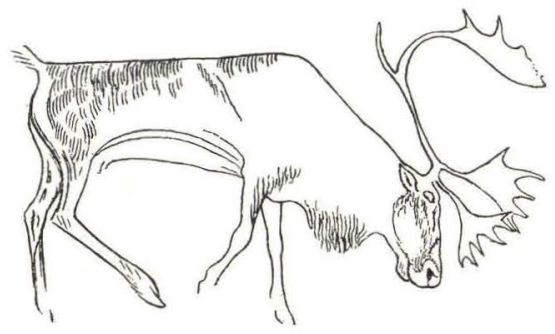

4. Grazing reindeer. Copied from an engraving on a reindeer antler found in a cave in Switzerland.

tion has destroyed all possibility of pollen analysis. In recent years new methods have helped to supply this missing information. Simultaneously, pollen diagrams have shed light on the nature of the glacial vegetation of France and Southern Europe, so that now for the first time it is possible to build up a well-based overall picture of the climate and the vegetation belts in Ice Age Europe.

\section{West Jutland}

We shall now attempt to go back mentally 20,000 years in time. The long Ice Age was near its end, and the temperature, which during the Ice Age had fluctuated somewhat, had now waned to its lowest point (see illustration facing p. 16).
Our picture is built up from information from many localities where it has been possible to date pollen analyses reliably and accurately within the critical period. Information on animal life comes primarily from investigations in the nearest caves containing bone remains which from archaeological and C-14 evidence could be dated to the same period.

If we begin from the north, we travel first over the massive north European ice-sheet. At Hald, near Viborg, the edge of the ice made a sharp angle. From here it extended westward towards England, and to the south lay West Jutland free of ice. Eastwards the ice edge extended down through mid-Jutland. At intervals there were enormous gaps in the ice, out of which poured torrents which carried enormous quantities of suspended sand and silt. These rivers flowed in ever shifting courses down over the great sandplains they had themselves built up. The plains were absolutely sterile, and even the mounded islands which projected above the river plains were largely barren. They resembled a desert with wind-worn stones, and only here and there had some sparse patches of green.

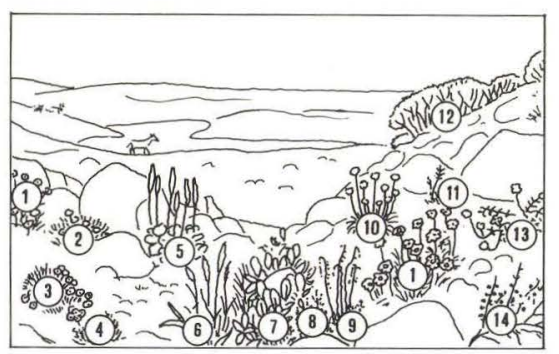

16
Upper: Europe 20,000 years ago.

Lower: Landscape and flora in the Older Dryas period. 1. Mountain avens, Dryas octopetala. 2. Purple saxifrage. 3. Moss campion. 4. Arctic willow. 5. Mountain sorrel. 6. Viviparous knotgrass. 7. Creeping willow species. 8. Club moss. 9. Alpine meadow rue. 10. Thrift. 11. Moonwort. 12. Sea buckthorn scrub. 13. Rock-rose, Helianthemum nummularium. 14. Dwarf birch. Reindeer, a wild horse, and a ptarmigan can also be seen. From a water-colour by Ingeborg Frederiksen, in the Museum of Natural History, Århus. 

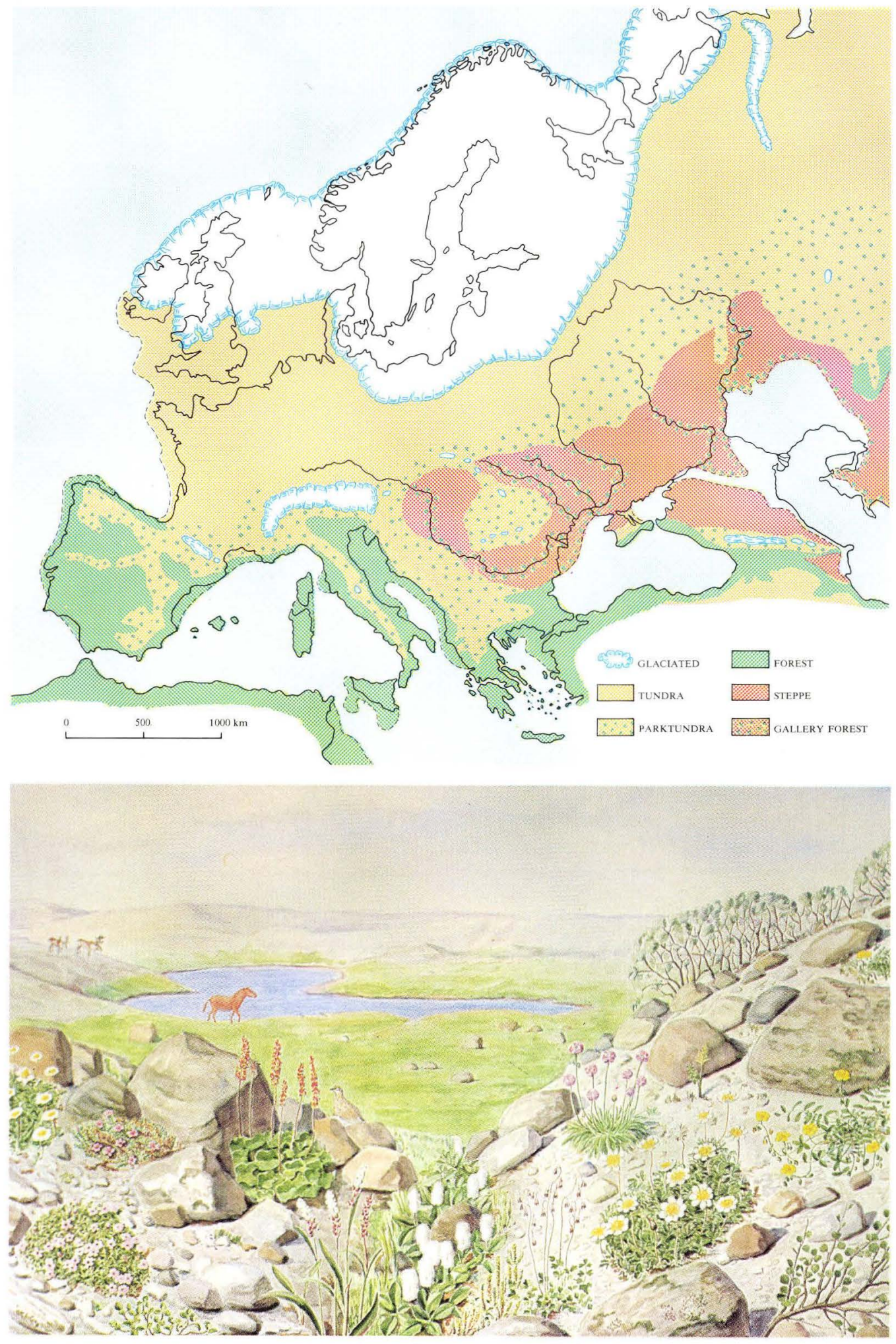


\section{France}

The barren landscape extended further to the south-west, and it was first brightened by green areas where reindeer could graze, in Holland. In France there was more vegetation and animals were more abundant. Wild horses and bison as well as reindeer ranged in small herds in these areas. Huge mammoths with shaggy dark brown hair and enormous tusks also lived here, along with musk-oxen and saiga antelopes; the musk-ox is an arctic animal and the saiga antelope a steppe animal, but during the Ice Age they overlapped with each other on the steppe-like tundra of middle and west Europe.

These areas must have been an eldorado for hunters, and it was in fact here that the men lived whose culture reached an artistic zenith in this period of the final culmination of the Ice Age. With pieces of ochre and black ferrimanganese they depicted the animal life of the time in their unrivalled wall paintings in the French cliff caves.

Further to the southwest the plains became more luxuriant and greener. Near the Spanish border, at the foot of the relatively low westerly outliers of the Pyrenees, one would have expected to find forest. The Atlantic Ocean was only a few miles to the west, and the warm Gulf Stream could run through the deep Bay of Biscay close in to the coast, but trees were lacking and shrubs were few. The summer temperatures were too low for even the most hardy tree species. Instead there was a luxuriant vegetation of grasses, enlivened by flowering plants of a cold-tolerating nature. On south-facing slopes the curious dwarf bush, Ephedra, resembling a horsetail, which preferably grows on steppe, was present. The arctic fox also lived here; this is a genuine arctic animal, but during the Ice Age it was completely at home even in southernmost France. The presence of frost fissures, traces of solifluction, and other geological phenomena, is evidence of a very cold tundra climate. The Pyrenees were covered by a large ice-cap, and in the area north of these mountains the vegetation changed in character going from west to east. The treeless tundra near the Atlantic Ocean was soon replaced by a "park tundra" where small pine groves alternated with tundra, and near to the Mediterranean the pine forest became continuous. To the east the Alps were covered by a large independent ice-sheet.

\section{Italy}

In North Italy around the river Arno the plains were covered by coniferous forest. Scots pine was most numerous, mixed with patches of mountain pine or common spruce. Silver fir occurred sparsely, but apart from a few birches there were no deciduous trees.

On the other side of the Appennines which were completely treeless, there grew open pine forest with a little common spruce. Silver fir was not present; it was replaced by larch, which unlike silver fir can tolerate a dry continental climate and has equally low warmth-requirements. Only the hardiest deciduous trees could exist there: some birch and aspen, but no beech and none of the more warmth-loving trees such as lime and oak.

\section{Greece}

During the Ice Age the Adriatic Sea was a forested plain, with only a bay of the sea at the southern end. In the mountains near the Aegean Sea, the vegetation was especially remarkable. The mountains were clad with open 
pine forest, whilst in the great valley plains not a tree was to be seen; usually the reverse is found. In the valleys it was warm and dry, and the vegetation consisted of xerophilous grasses and wormwood; plants of the Goose-foot family, Chenopodiaceae, were also abundant. Everything was characterized by dryness. It is obvious that here in the valleys it was not cold, but dryness, which excluded tree growth. This is the decisive difference between the cold tundra and the dry steppe, and we realize with some surprise that the rainfall in southeast Europe must have been extremely low during the Ice Age. A low precipitation is the only possible explanation as to why these valleys, which were wooded both before and after, were unforested during the Ice Age, in spite of the fact that the lower temperatures must have tended to increase the humidity by reducing the evaporation.

The mountain tree cover was characterized by the predominance of pine and the presence of a few deciduous trees. Beech trees occurred here and there, and, even though it has not definitely been established, we must assume that more warmth-requiring deciduous species such as oak and lime found refuges in warm and sufficiently moist places in the lower mountains during the Ice Age.

\section{From Rumania to Vienna}

A journey from the Rumanian lowlands towards the north-west would first have traversed wide continuous steppes where trees only occurred along the rivers. Enormous dustclouds of fine clay particles, "loess", blew from time to time over the plains. In the area where Vienna now stands, there was abundant sunshine, but little warmth. The ground was covered with grasses and herbs, but no trees were to be seen; the vegetation bore the mark of a cold and dry climate, and also of the peculiar, humus-free, clay soil, the loess.

In this area one could have met reindeer, blue hares, lemmings, and a few arctic foxes - all arctic animals, and it would also be possible to find arctic plants such as Dryas, mountain avens. But on the other hand, steppe plants also occurred, and wild horses ranged in the area. On this journey from Rumania to Vienna the boundary between steppe and tundra has been crossed, even though the transition to this "loess tundra" was very gradual.

A summary of this survey of Europe during the glacial maximum, would first and foremost be as follows:

The Ice Age climate has totally altered the landscape of the whole of Europe; the great vegetation belts are completely changed, and this is also true of the animal life, and even of the soil. But what can we conclude with any certainty concerning the climatic conditions in this particularly cold phase 20,000 years ago?

\section{A temperature depression of at least $10^{\circ} \mathrm{C}$}

Firstly it must be made clear that the fall in temperature was very great, and was just as pronounced in the Mediterranean area as in Europe north of the Alps. From the fact that the treelines in the Alps, Pyrenees, and Appennines were at least $1600-1700 \mathrm{~m}$ lower than today, and that the tundra and its fauna extended all the way to Vienna in the southeast and to the Bay of Biscay in the southwest, we can conclude that the summer temperature was at least $10^{\circ} \mathrm{C}$ lower than now. Important new investigations on the extent of permafrost during the 
Ice Age have given the same result. Permafrost, or the presence of permanently frozen subsoil at a certain depth, with only the uppermost layers of soil thawing in the summer, produces several easily recognizable disturbances in the upper soil layers which make it possible to demonstrate its occurrence during the Ice Age. In France, permafrost was absent only in the warm southeasterly provinces bordering the Mediterranean. Experts have calculated from this evidence that the temperature in central Europe during the coldest phase was about $12^{\circ} \mathrm{C}$ below that of the present day.

\section{Reduced precipitation}

The temperature depression during the Ice Age was previously thought to have been somewhat smaller $\left(5-8^{\circ} \mathrm{C}\right)$, according to calculations based on changes in the position of the snowline in the mountains of central and south Europe. The snowline marks the altitude above which the snow does not melt during the summer; its position during the last glaciation can be determined with the help of the easily- recognizable corries which occur where snow collects year after year, and which form the source of glaciers. Such corries can be found everywhere in the mountain chains, far below the present snowline, but yet not as far as one would expect from the downward displacement of the tree-line. There is, however, a satisfactory explanation for this discrepancy; the snowline is in fact not only determined by temperature but also by the amount of precipitation. If the climate was drier during the Ice Age, then there was obviously less snow to melt. This was exactly the case; it is demonstrated by the striking numbers of steppe animals and steppe plants which occurred all the way to the Atlantic, by the wide distribution of loess even in western Europe, as well as by the occurrence of genuine steppe in Greece during the Ice Age. Climatologists have also calculated theoretically that precipitation in Europe would be considerably reduced when the ice-sheet was so widespread and the Atlantic Ocean was cooler. On the other hand, there was a belt of high rainfall across the Sahara, which is now so dry.

\section{The final phase of the Ice Age, 13,000-8,300 B.C.}

The final phase of the Ice Age, the so-called "Late-Glacial" phase, was characterized by a decisive amelioration of the climate. The north European ice-sheet retreated in stages from Denmark, and around 10,000 B.C. its southern boundary was a little north of Scania (southern Sweden). If it were possible to take a look at the Danish landscape at that time, what impression would first strike us with particular force?

\section{The light earth}

The absence of trees would naturally be immediately obvious, but then we are used to see Denmark as an open country. The light colour of the landscape would probably be more surprising. The vegetation was still of a very open character, and even where herbs and small shrubs grew more closely and produced a predominance of green, the light and, in sunlit con- 
ditions, nearly white earth formed a universal background for the green. This light earth characterized the landscape, and this would strike us as unusual. The word "earth" usually suggests darkness, for example in poetic phrases such as "the dark earth".

It is the large content of humus which makes earth dark, but the deposits left by the ice were without humus; on the other hand they contained lime. This is the reason for their greyish-white colour. Humus did not yet exist - all soils were raw and unleached. Today we can only see such raw earth near the sea-shore; the outermost sand-dunes along the coast of West Jutland, the "white dunes" with lyme- and marram-grass, can give us some idea of the light landscape of 10,000 years ago.

In spite of the presence of considerable amounts of lime and a few other nutrients, the Late-Glacial raw earth, even when it contained clay, was poor to a marked degree. The surface layers of the clay-containing raw earth are only gradually converted into humus-rich, fertile soil after a slow "maturation", the result of many different and highly complex chemical and biological processes. The maturation of the Late-Glacial raw earth commenced almost as soon as the first plants had taken root in it, but the process was very lengthy, not least because the climate was still cool and the vegetation was for a long time rather sparse.

Humus formation is also retarded when the upper layers of soil are unstable, as they were during the LateGlacial period, especially in its earlier stages. As long as there was no dense and continuous protective plant cover, the uppermost layers of soil, especially on hills and slopes, were constantly exposed to erosion by wind and rain, whilst cloudbursts washed out deep gullies. Fresh raw soil was thus constantly brought to light.

\section{Plants}

\section{The Late-Glacial Dryas-flora}

See colour plate facing p. 16.

The barren but lime-rich raw soil which the plants were to invade as soon as Denmark became ice-free, was only suitable for particularly undemanding species. The climate also was still unfavourable, with short and cool summers. The first flora was recruited to a large extent from the hard core of glacial plants which had survived in West Jutland even during the last cold climax.

The most characteristic plant of the "cold" component of the Late-Glacial flora is Dryas octopetala, mountain avens, whose small leathery leaves are especially common and easily recognizable in the Late-Glacial clay layers. Thus we refer to "Dryas flora", "Dryas layer" (upper and lower) and "Dryas period" (Early and Late), when we discuss the "cold" Late-Glacial plants and the Late-Glacial layers or divisions of time (see p. 29). Dryas is often praised for its beauty: it has large ivory-white flowers on long stalks arising from woody creeping stems which form a dark green carpet.

The tiny leaves of two creeping willow species, less than $5 \mathrm{~cm}$. high, $S a$ lix herbacea, dwarf willow (called "the world's tiniest tree" by Linnaeus) and Salix polaris, arctic willow, are also common in Dryas deposits. The resemblance between them is so great that only experts can tell them apart. The third willow species, Salix reticulata, is easy to recognize, however, by the slightly larger leaves with their finely netted veins which have given the species its name. These three in- 


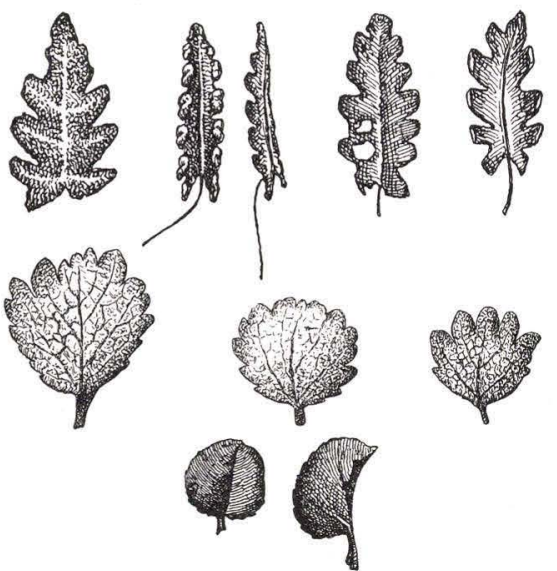

5. Leaves of arctic plants found in Dryas clay. Above, Dryas octopetala, centre, dwarf birch, and below, arctic willow (From N. Hartz).

conspicuous willow species are especially characteristic of the cold Dryas flora; their present habitats are limited to an even greater degree than Dryas itself to the high mountains and the tundra.

On the other hand the dwarf birch, Betula nana, whose small rounded leaves are so frequent in all Late-Glacial layers, also grows commonly at low altitudes and in bogs - for example, as close to Denmark as in Småland in southern Sweden. It is thus not a true member of the typical Dryas flora.

Although leaves and twigs of these dwarf shrubs are the most frequent remains in Late-Glacial deposits, a number of herbaceous plants should also be mentioned as being characteristic members of the Dryas flora, even though they occur more sparsely. Purple saxifrage, Saxifraga oppositifolia, a small plant with large violet flowers, is a typical mountain species and the most beautiful of the Late-
Glacial saxifrage species. Moss campion, Silence acaulis, is another joy to the eye at flowering time; its compact, slightly rounded tussocks can be completely pink with countless numbers of stalkless flowers. Saussurea alpina, Alpine saw-wort, is a small thistle without prickles and with purple flowers distinguished by their pleasant vanilla fragrance. Less eyecatching is mountain sorrel, Oxyria digyna, but its leaves with their high vitamin-C content were certainly as important in the diet of Late-Glacial man as they are in that of arctic people today.

\section{Thrift as an Ice Age plant}

It will surprise all who know this elegant plant from the Danish seashore, that thrift, Armeria maritima, must be included in the Dryas flora. It has also given geologists headaches to find that Armeria fruits are so characteristic of Ice Age deposits in middle and west Europe, and especially in deposits dating from the colder periods. This is one of the reasons why the Ice Age Armeria was considered to have been A. arctica, which is an arctic plant having no connection with the seashore. A definite species-determination has only become possible after an investigation of the pollen of the genus has revealed new and interesting details.

The European species of Armeria have all been found to consist of two types of plant, A and B, which are equally frequent and can only be distinguished by the fact that their pollen and styles are clearly different. This remarkable dimorphism is an expression of physiological differences which make self-pollination impossible: A-pollen can only germinate on B-styles and B-pollen only on A-styles. This situation, however, does not hold for the arctic species, which has only 
one type of plant and one type of pollen: it is monomorphic. Since the $A r$ meria species which was so widespread in Ice Age Europe is now known to have had two types of pollen, it could not have been the arctic one.

A mountain variety, A. maritima var. planifolia, occurs in the British Isles, the Færoes and Iceland, but not in the Scandinavian peninsula; this variety differs in several ways from the coastal type. The most striking difference is that this variety can form compact raised tussocks, unlike the coastal type and the monomorphic arctic species. Since this mountain variety is dimorphic, there can hardly be any doubt that it is a living relic of the cold-tolerant Armeria species which was so characteristic of the cold phases of the Late-Glacial period.
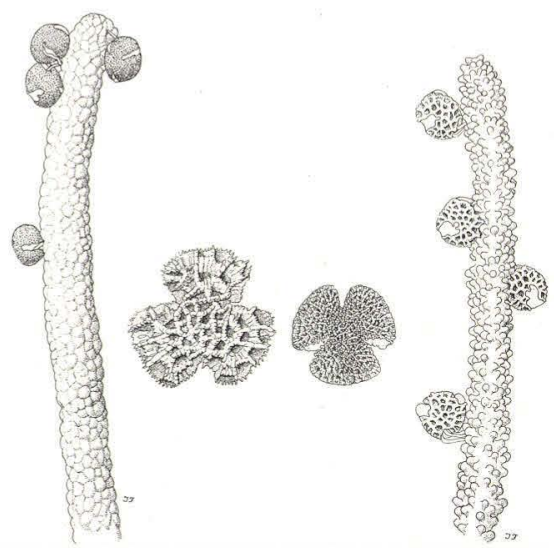

6. Thrift consists of two types of plant; the A-type has a smooth stigma and coarsely sculptured pollen, whilst the Btype has a warty stigma and finely sculptured pollen. A-pollen can only germinate on a B-stigma, and B-pollen can only germinate on an A-stigma. Both types of pollen are common in Late-Glacial deposits. (Drawing by Ingeborg Frederiksen from Johs. Iversen 1940).

\section{Common characteristics of the Dryas flora}

Low temperature requirements, short growing season, and hardiness are features common to all the species grouped here as the Dryas flora. Some of them, such as dwarf willow and mountain sorrel, can tolerate snow cover most of the year and still manage to flower and set seed in the brief growth period. Others, such as Dryas and Armeria, can survive the cold and the storms of winter, even in the most exposed places, without a protecting snow layer.

\section{Sea buckthorn and wormwood}

The Dryas flora seemed to correspond so well to the arctic vegetation, that the development of the Late-Glacial vegetation was for a long time interpreted by reference to the vegetation belts found in the north European polar zone. This opinion had to be revised when a closer study of the pollen of the Late-Glacial deposits produced astonishing results, which completely upset the picture.

The first discovery was of the pollen of sea buckthorn, Hippophaë rhamnoides. This thorny shrub is wellknown, because its branches with their attractive orange berries are frequently displayed in florists' shop-windows. The original home of sea buckthorn is probably the west Asiatic steppes, where it is most frequent; from here it spread westwards across Europe during the Ice Age. It came to LateGlacial Denmark as the first pioneer shrub on dry raw soil.

Later it was also discovered that the pollen of wormwood, Artemisia, appears in all Late-Glacial deposits, and in such quantities that one is forced to the conclusion that it must have been one of the most widespread plants, 


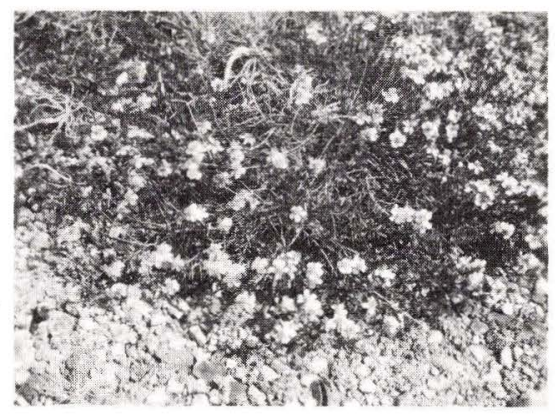

7. The öland rock-rose blooming on Great Alvar on Öland, the only place where this plant, so widely distributed in the Late-Glacial period, has survived (R. Sterner).

even in the first pioneer vegetation. This was completely unexpected. True enough, one extremely rare wormwood species grows in the mountains of Norway and Scotland, but its pollen differs from the other wormwood species, which in northern Europe are lowland plants with a pronounced easterly distribution. Unfortunately the pollen grains of these species are so alike that up to now it has not been possible to determine the species to which the Late-Glacial pollen belongs. However, it is probably not too rash to assume that our native field wormwood, A. campestris, and common wormwood, A. vulgaris, already grew in Denmark in Late-Glacial times.

\section{The öland Rock-rose}

The Öland rock-rose, Helianthemum oelandicum, was the next surprise. It was found that the pollen of this species occurs frequently in Danish LateGlacial deposits and, moreover, in the lower, older layers. The öland rockrose is famous in Scandinavia since the only place in the whole world where it is found is the Swedish island of Öland. Here, in compensation, it is so common on the "Greater Alvar" that in the flowering season it colours large areas of the massive limestone slabs yellow when the sun shines. If a cloud passes the sun, the öland rockrose immediately closes its flowers, and the Alvar is grey-green until the sun comes out again. We may thus conclude that this interesting little dwarf shrub has also at certain times coloured southfacing raw soil slopes in Denmark yellow during the Older Dryas period. In Denmark the species was soon displaced, but on öland it has managed to survive on the Alvar, and remains there as a living witness of the Late-Glacial rock-rose vegetation.

Three more rock-rose species also occur on Öland, and at least one of them, our native Helianthemum nummularium, was already found on southfacing slopes in Denmark in the Early Dryas period, although less frequently than the öland rock-rose. In contrast to the last mentioned species it has fewer but much larger flowers - see no. 13 on the plate facing p. 16 .

\section{Late-Glacial refuges and relics}

The Alvar on Öland harbours many other rare plant species with peculiar discontinuous or isolated distributions

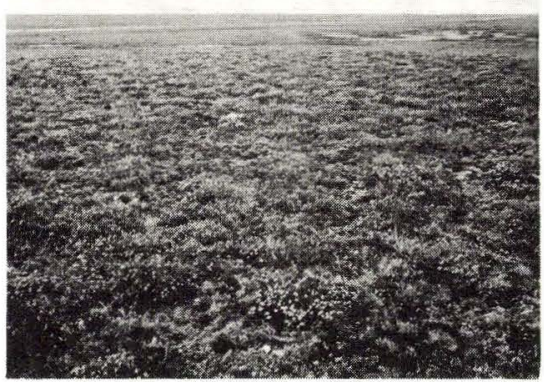

8. From Great Alvar, Öland's limestone plateau which is a refuge for many LateGlacial plants. (R. Sterner). 


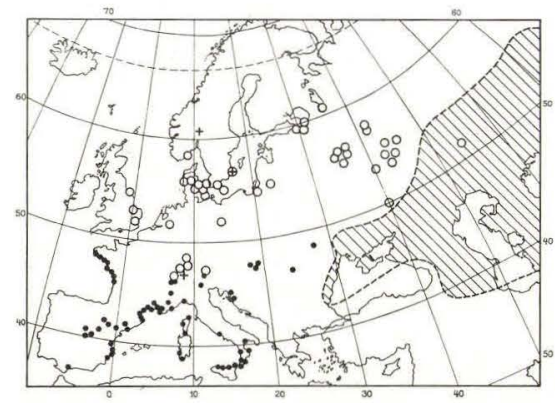

9. The present distribution of Ephedra distachya and the occurrence of fossil Ephedra pollen of the distachya-type. The species appears to have still been present on the Alvar of öland in the Atlantic period. (From Johs. Iversen, 1954; more recent pollen finds are not shown).

in west Europe. Areas such as the Alvar are regarded as being "refuges" for these species, since it is thought that they grow there as "relics" - remains from a time when they had a wider and more continuous distribution because the conditions at that time suited them better. Many of Öland's relics have an "easterly" character, in that they first become common far into eastern Europe.

It was believed that these species were relics from a drier, warmer time, in short the Sub-Boreal period, which according to the classical climatic scheme was especially warm and dry (see p. 14). But pollen records have now shown that some, at least, of these relics had already immigrated to Scandinavia in the Late-Glacial period. This is true of the elegant small Gypsophila fastigiata, a species related to the pink, pollen of which was found in layers from the Early Dryas period on Bornholm. This species has also survived on the Alvar but not in Denmark. However, a species which has survived here is the purple milkvetch, Astragalus danicus, a leguminous plant with pretty blue flower clus- ters, whose pollen is found in Danish Late-Glacial deposits. This, too, is an eastern species, with its centre of distribution in West Siberia at the boundary between forest and steppe. In Denmark it is a relic from the LateGlacial period.

\section{Sainfoin, a southern European chalk plant}

Sainfoin, Onobrychis viciifolia, is another illustration of the strange fact that in the Ice Age certain plants had a far more northerly distribution than today. Sainfoin is a south and central European leguminous plant, which grows at high altitudes on mountains in limestone areas and has disputed relic occurrences on chalk hills in central Germany and south-east England.

In Denmark this handsome plant with its pinnate leaves and long-stalked clusters of pink flowers is sometimes cultivated as a garden plant, or as fodder on poor fields, from which it may escape and grow wild on chalky soil. Its extremely characteristic pollen has been found on Funen in layers from the Older Dryas period, and it has been found in central Sweden together with Dryas pollen in clay which was deposited shortly after the ice there had melted. Since sainfoin is highly specialized for pollination by insects, the possibility of long-range transport of pollen by the wind can be excluded.

\section{Ephedra - a steppe plant}

The greatest sensation and discussion was aroused by the discovery of LateGlacial pollen of Ephedra, a most remarkable horsetail-resembling small shrub, grey-green, with reduced scalelike leaves and bright red fruits. Ephe$d r a$ is related to the conifers; all its species are found in deserts and on steppes, apart from the small dwarf 
shrub E. distachya, which has isolated occurrences in some bone dry alpine valleys and on sand-dunes in Brittany. The characteristic pollen of this or a closely related species has been found in Late-Glacial deposits in Denmark and in other places in northern Europe, although somewhat sparsely.

But did Ephedra really grow in the north, or did this pollen come flying from long distances? The dispersal of the pollen of Ephedra distachya cannot be particularly effective, since hardly any Ephedra pollen was found only a few paces from one of its bestknown habitats in the Alps (Valais), where it grows together with sea-buckthorn, wormwood, and other LateGlacial plants.

Taken in connection with other fossil finds of steppe animals and steppe plants, and the distribution of living relics, the appearance of Ephedra in southern Scandinavia in the Late-Glacial period is understandable enough. It demonstrates particularly clearly that the Late-Glacial vegetation must be regarded in the light of the conditions further south during the glacial maximum. The fauna and flora at that time had, as outlined in the previous section, a pronounced steppe-element as far west as in France. The present occurrence of Ephedra in Brittany is a typical example of a glacial relic.

\section{Cornflower and other weeds}

Cornflower, Centaurea cyanus, once coloured our rye-fields blue, and the sight awakened pleasure in the citydweller and annoyance in the farmer. Now this weed has been eliminated in most areas, and cornflower will probably soon be seen only as a decorative garden plant. Since cornflower has been widespread throughout Europe and W. Asia as a weed in winter corn, it has been difficult to decide its ori- gin. General opinion, however, has been that its native area was in the easterly Mediterranean countries, where it grows wild on the dry steppes. Once more, pollen analysis brought a surprise when the easily recognizable cornflower pollen was found on Funen in layers from the early Late-Glacial period. Other finds were soon made, and it is now clear that it has been a widespread Late-Glacial plant in northern Europe, until displaced by the advance of the forest.

This and other more recent discoveries of weed species in glacial deposits in Europe support a hypothesis put forward on theoretical grounds by an English research worker. He suggested that the original home of the weed flora was to be found in the moraine deposits which bordered the edge of the ice during the Ice Age. But one must also assume that the coastal vegetation has made its contribution to our weed flora.

Here in Denmark and in southern Sweden, great plantain, Plantago major, knawel, Scleranthus annuus, spurge, Euphorbia, hemp-nettle, Galeopsis, and other species as well as cornflower have been identified in Late-Glacial deposits. None of these are today so closely confined to cultivated land, however, as is cornflower.

\section{Common characteristics of the Late-Glacial pioneer flora}

It was thus a highly complex flora, with species from north and south, east and west, which met as colonizers on the newly created Danish land. To begin with the Dryas flora was still dominant, because it was still rather cold for the other colonizers, but as the climate became a little milder, the others quickly established themselves.

Common to all these species is first and foremost their requirement for 
abundant light and their preference for a limy soil. Poor soil or a chilly climate is less important, not because these species prefer to starve or to freeze, but because light and lime are the most essential factors. Where it is warm and the earth is rich in humus, other less hardy but larger and stronger species soon arrive and shade out the pioneers.

\section{The poorness of the raw soil}

On the new ground there were no competing neighbours, and there was plenty of light. But the poorness of the raw soil in nutrient substances, apart from lime, was naturally a problem for the Late-Glacial pioneer plants. This is shown by the fact that so many of them today are renowned for their low nutrient requirements. This is true not only of several already-mentioned species, e.g. Dryas and the öland rock-rose but also of lesser burnet, Sanguisorba minor, and hoary plantain, Plantago media, both of which can today be found wild on chalk slopes, undoubtedly as relics from the Late-Glacial period. Chalk and limestone are particularly poor in nutrient substances because they do not contain clay particles which in association with humus form the most important part of the nutrient capital of the mull.

One of the most important nutrient substances, and which is most frequently lacking in raw soil, is nitrogen. For the leguminous plants, however, this is no problem. They can utilize atmospheric nitrogen with the help of small bacteria-containing nodules on their roots, in which the bacteria act as nitrogen "fixers". The leguminous plants are also especially well represented in the Late-Glacial flora. This relationship was long overlooked since they are almost exclusively insect-pol- linated and spread their pollen very poorly; moreover, their leaves are not preserved in bogs. However, in the Danish Late-Glacial deposits a considerable number of species of milkvetch, Astragalus, have been found; especially common, even in the oldest layers, was Alpine milk-vetch, A. alpinus. As already mentioned, sainfoin immigrated very early, and so did kidney vetch, Anthyllis vulneraria, and bird's foot trefoil, Lotus corniculatus. All three species are capable of growing on pure chalk, and they are sometimes cultivated because of this tolerance; the latter two species, moreover, grow on the "white dunes" and in fact everywhere where raw earth comes to light, e.g. on cliff landslips. The leguminous plants with their nitrogenfixing ability have contributed to a high degree to open up the raw earth for other plants.

Among the Late-Glacial shrubs sea buckthorn is a typical example of a "raw earth" plant. It has small nodules on the roots resembling those of the leguminous plants, and it is known that they function in the same way as nitrogen fixers.

\section{No similar plant communities exist today}

The vegetation which developed on the young moraine deposits differs widely from that found today in areas with corresponding climatic conditions. This situation was not only due to the richness in lime and deficiency in soil humus; it was especially due to the fact that the competition between the plant species had only just begun and had not yet reached a point of equilibrium. Such equilibrium exists within the corresponding climatic belts in Europe today - if violent human attacks have not destroyed the natural vegetational balance. 


\section{Light plants and temperature}

Since, as already mentioned, light is the decisive factor for the Late-Glacial pioneer plants, their distribution is not so much determined by temperature as by the occurrence of nonwooded areas. They can only grow in places where dense forest is absent for some reason - on tundra, alpine mountain zones, steppes, the sea shore or on cultivated ground. During the Ice Age both temperature and precipitation were lower than today, and the southern forest border was probably pushed northwards by the dryness in easterly areas, whilst its northern limit was simultaneously displaced a long way south. Those steppe plants which could tolerate the cold thus grew in far cooler conditions than previously. In the park-like landscape between the tundra and the steppe, arctic and steppe plants met, and from here steppe plants and animals migrated westwards through the open park tundra.

The Ice Age was a time of prosperity for the light-demanding plants, but few conclusions concerning their temperature requirements can be reached from their present-day distribution in Europe.

\section{Earlier conflicting opinions on Late-Glacial temperatures}

Estimates of Late-Glacial temperatures were uncertain for a long time owing to the fact that comparisons between the Late-Glacial vegetation and the present-day vegetation zones are impossible. This is clearly reflected in the literature. When Nathorst had demonstrated the Dryas flora in Scania, he believed that it corresponded exactly with the high Arctic flora, familiar to him from Spitsbergen. On the other hand, Gunnar Andersson maintained that the temperature must have been milder since a flora of water-plants could always be found together with the Dryas flora even in the deepest layers. He suggested that the mean temperature for the month of July had increased from $6^{\circ} \mathrm{C}$. to $9^{\circ}$ in the Dryas layers.

The Danish zoologist A.C. Johansen went even further. On the basis of his studies on the well-preserved shells of molluscs in Danish Late-Glacial lake deposits, he concluded that the mean July temperature varied between $8^{\circ}$ and $14^{\circ} \mathrm{C}$; the latter high temperature was reached in a temporary mild interval in the middle of the Late-Glacial period, namely the Allerød oscillation (see p. 30).

\section{Aquatics as climatic indicators}

Johansen was strongly opposed by his zoological colleague, $C$. WesenbergLund, in a lively discussion in the Danish Geological Society (1906). The latter maintained that aquatic organisms were unsuitable as indicators of prevailing temperatures. This excellent expert on lakes pointed out that the low altitude of the sun in the polar regions results in a greater reflection of sunlight from a lake's surface and a reduced warming of the water as compared with lakes in lower latitudes. From this it must be expected that today's arctic lakes will be colder than the Late-Glacial Danish lakes, even though the air temperature may have been the same. This argument seemed convincing. Nevertheless, later investigations have clearly shown that the northern and the altitudinal limits of aquatics in Scandinavia and the Alps and also in Canada, are parallel with the forest limits, quite independently of the sun's altitude. This is possibly due to a compensation for the 
increased reflection by the longer summer day-length in higher latitudes.

In fact, aquatics have several ecological features which make them especially valuable for the geologist in his attempts to ascertain the Late-Glacial temperature curve with the help of plant fossils. Compared with trees, waterplants have a far higher dispersal rate, partly because they are spread particularly effectively over long distances by migrating waterbirds and produce seed already in the year of establishment, and partly because they do not require any maturing of the soil before they can thrive. Aquatics therefore react far more rapidly to a rise in temperature than do the tree species. It has thus been found that every improvement of climate during the Ice Age has been first registered by aquatics - the trees were often delayed in their reaction.

\section{The chronology of the Late-Glacial}

Once the trees had eventually appeared, however, the extent and denseness of the forests became the best expression of the changing climatic conditions. This is elegantly registered in the pollen diagrams, where the combined curve for birch, pine, and aspen follows a characteristic course which can be found in all Danish diagrams. Carbon-14 determinations have confirmed that the maxima and minima in this curve occur simultaneously everywhere, from the Alps to Denmark and from Ireland to Poland. These vegetational changes were presumably conditioned by world-wide climatic oscillations, even though the changes were naturally only registered clearly and in a similar way in pollen diagrams from those areas which in Late-
Glacial times were covered by the broad zone between thick forest and pure tundra. From no other period of such length as the Late-Glacial do we have such a detailed and reliable temperature curve. The chronology of the Late-Glacial based on pollen diagrams can thus be regarded as particularly reliable.

It should be pointed out, however, that one source of error caused some uncertainty until it was cleared up; the problem was that glacial deposits in Denmark and other countries contain well-preserved pollen grains of prequaternary or interglacial origin. Such "secondary pollen" is thus also found in Late-Glacial deposits, when these consist partially of clay washed down from the moraine. Many of the washed-out pollen grains can immediately be recognized as being secondary, i.e. pre-quaternary types, but not all of them can, and so a false picture of the Late-Glacial vegetation may be obtained.

It is however possible to subtract the secondary pollen from clay-containing Late-Glacial deposits, by means of a simple calculation based on pollen analyses from the moraine clay. The diagrams thus obtained are in good agreement with diagrams from purely organic lake sediment or "gyttja", which does not contain secondary pollen. Since the curve for secondary pollen is an indicator of the degree of clay admixture, it registers solifluction and similar processes to some degree, and always shows maxima in cold periods and minima in warm periods.

\section{The earliest tundra period}

The boundary between the Full-Glacial and the Late-Glacial periods is not always set at the same point. Here in Scandinavia it is often fixed at the start of the retreat of the ice-sheet 
from its outermost limit in mid-Jutland, and there is no doubt that this does indicate the beginning of an improvement in the climate. However, the boundary in pollen diagrams is set appreciably later, where a marked rise occurs in the pollen curve for wormwood, since this is regarded as being the first clear indication for a rise in temperature. But there are few pollen diagrams available from north of the Alps which reach so far back in time, and none at all extend appreciably further. This fact in itself indicates a pronounced rise in temperature at around 11,000 B.C., since before this time powerful solifluction processes prevented a normal sedimentation. The sea temperature in Vendsyssel also shows the first rise at this time.

The only Danish pollen diagram which goes so far back in time, comes from Lake Bølling between Silkeborg and Herning. The pollen analyses just below the increase in the wormwood curve give us an impression of the poor tundra vegetation at the boundary between the Full-Glacial and LateGlacial periods. Grasses dominated the higher, drier ground, sedges the wetter. Dryas, dwarf willow, species of saxifrage, club mosses, thrift, harebell, grass of Parnassus, sea plantain and others also occurred; all of them plants that tolerate an arctic climate, even though the latter species are common in Denmark this very day. Heaths of dwarf birch and willow were the highest form of vegetation. The ice had by that time retreated from North Jutland, and the ice-bridge to England had long been disrupted.

The transition to the Late-Glacial period was quite gradual. Pollen diagrams from Lake $\mathrm{B} \phi l l i n g$ show that sea buckthorn, the Öland rock-rose, hoary plantain, and water-plants immigrated shortly after the rise in the wormwood curve. The appearance of these species indicates a continued amelioration of the climate. Trees, however, were still absent, so the vegetation must still be classified as a tundra. But heaths and scrub of sea buckthorn, willow, and a little juniper, Juniperus communis, prepared the soil for the tree growth which was only lacking because the trees, on their advance northwards, had still not reached that area.

\section{The Bølling period:}

10,500-10,000 B.C.

When eventually birch, Betula pubescens, and rowan, Sorbus aucuparia, appeared, they quickly occupied the most favourable places and displaced the sea buckthorn. This first Late-Glacial warm phase is known as the $B \phi l$ ling period, after the locality where it first was demonstrated. It has only been demonstrated in Denmark in a few places in northern and western Jutland, apparently because the icesheet during its retreat from Denmark left behind a landscape with enormous quantities of dead ice. The more or less stable surface where higher plant growth could take root, and the basins in which sediments could settle, could only be formed after the gradual melting away of this dead ice.

In the B $\phi$ lling period pine advanced from the south-east up to Poland and mid-Germany, but not to Holland or to Denmark. The vegetation here was a "park tundra" with birch woods on the warm places and tundra on the cold north-facing or damp areas. Park tundra was perhaps the dominating type of vegetation in Late-Glacial Denmark, but it is probable that the distance between the pure tundra in the north and the continuous forest in the south was even greater at that time in Europe than it is today in North 


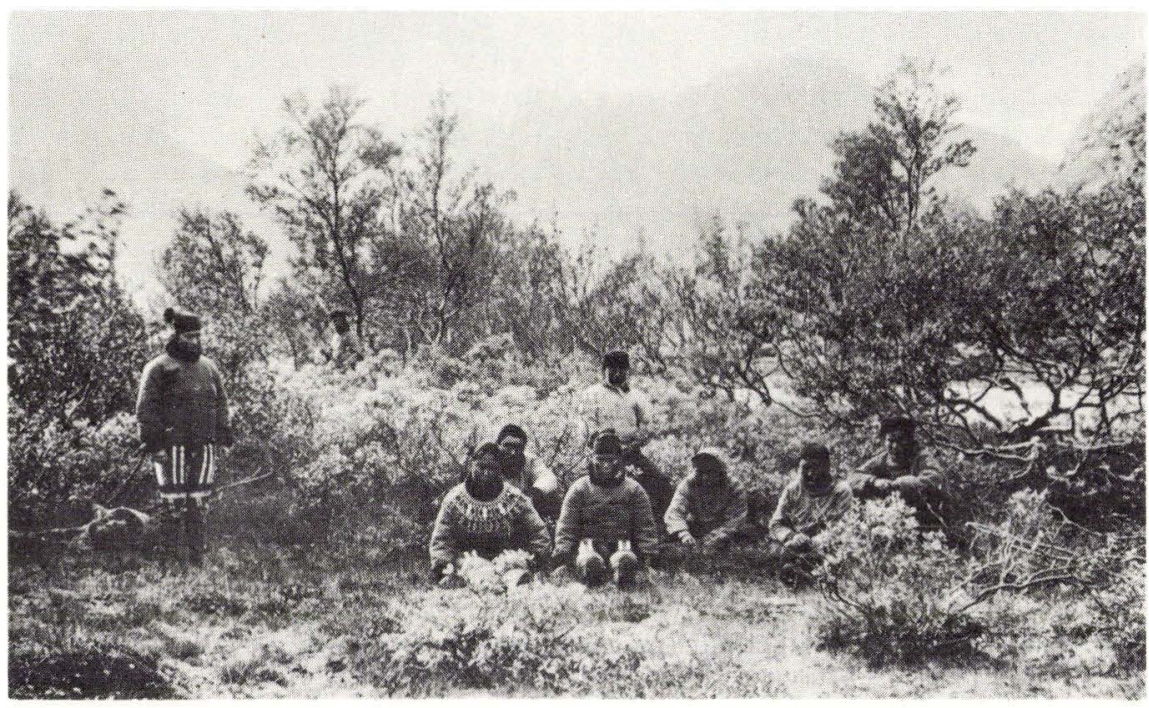

10. "Park tundra" in the southernmost part of Greenland. In Late-Glacial Denmark park tundra was very widespread, but its soil, flora and fauna were very different from the present-day type.

America and North Asia, where park tundra forms a broad zone.

\section{Older Dryas period: 10,000-9,700 B.C.}

The amelioration in climate was followed by a deterioration; the trees disappeared and tundra again became dominant for a time. This cold thrust lasted only a few centuries. When the temperature again began to rise, many lake basins were formed over the whole country, and sediments containing plant and animal remains were deposited in them. But, just as in the previous $B \phi l l i n g$ oscillation in West Jutland, this rise in temperature was also introduced by a treeless pioneer phase, which is considered as still belonging to the Older Dryas period; its interesting flora has already been depicted (see p. 20). The boundary between the Older Dryas period and the succeeding, well-known Allerød period is set at the point where the birch curve begins to rise. We must remember, however, that this boundary may not be simultaneous everywhere.

The Allerød period: $\mathbf{9 , 7 0 0 - 9 , 0 0 0}$ B.C.

A significant discovery was made in the year 1901 by the botanist N. Hartz and the geologist $V$. Milthers. In a brickworks pit near Allerød in North Zealand, they found proof of a distinct climatic change within the LateGlacial period - the "Aller $\phi d$ oscillation". The two researchers were puzzled when in the great exposures they observed running through the clay a broad band of clay-free gyttja, which divided the clay into a lower and an upper layer. Hartz demonstrated the presence of the characteristic Dryas, flora in both clay layers, whilst in the gyttja layer he found traces of tree birch, Betula pubescens, and aspen, together with the bones and shells of animals which today are found in the 
forest region. A similar profile is shown in fig 11.

From this it was clear that the gyttja layer in itself was evidence of a temporary climatic improvement. The upper and lower Dryas-layers were, to begin with, considered to be synchronous with the Younger and Older Dryas periods, but it soon became evident that these time divisions could not be established from the composition of the layers, since local conditions can be very important. The pollen diagrams give a more reliable record of the temperature curve and their evidence is at its clearest when there is no significant change in sediment-type, i.e. when gyttja (not clay) was deposited during the Older and Younger Dryas periods as well.

The Allerød oscillation is expressed clearly in all diagrams, but not in the same way in all parts of the country. Whitebeam, Sorbus aria, is at present only to be found on Bornholm, which it reached before any other tree in the Late-Glacial period. More important, pine reached Bornholm simultaneously with birch and dominated in the forests, while there is no absolute certainty that it grew in the rest of the country in the Late-Glacial. The frequency of the pine pollen here is so low that it could be explained as being due to wind-transport from the dense pine forests of Germany, but pine may still have occurred sparsely during the later part of the Allerød period. Birch, at any rate, was strongly dominant, aspen and rowan less common, and the tree-like goat willow, Salix caprea, was also present. Juniper and willow species were common shrubs, and bird cherry, Prunus padus, was found too.

\section{Summer temperatures}

There must have been a considerable fall in the summer temperature going

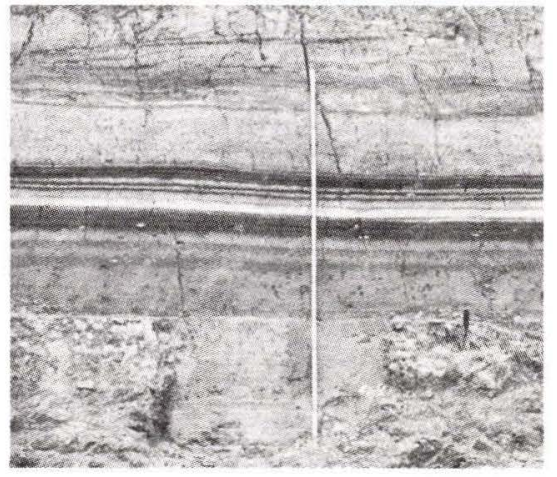

11. Brickworks pit at Ruds Vedby, with an Allerød layer appearing as two dark gyttja stripes with an intermediate layer of white, clayless lake marl.

from south-east to north-west. In the south-eastern part of the country the forest was continuous, although the unstable soil as yet led to clearings in the forest. Water and marsh plants such as fine-leaved water dropwort, Oenanthe aquatica, and reed-mace, Typha latifolia, and the shade-tolerating land plant bittersweet, Solanum dulcamara, as well as light-demanding plants such as sheep's bit, Jasione montana, and Seseli libanotis, show clearly that the climate in southern Denmark was temperate with an average July temperature of $13-14^{\circ} \mathrm{C}$. The relatively minor role played by pine, except on Bornholm, was probably due to the fact that, after its late immigration from the south-east, it had difficulty in invading a country which was already covered by birch forest.

A slight deterioration of climate occurred in the middle of the Allerød period, and caused a maximum of juniper at the expense of the trees, but afterwards the temperature rose again and reached a culmination for the Late-Glacial period. All the pollen curves for herbs were depressed with 


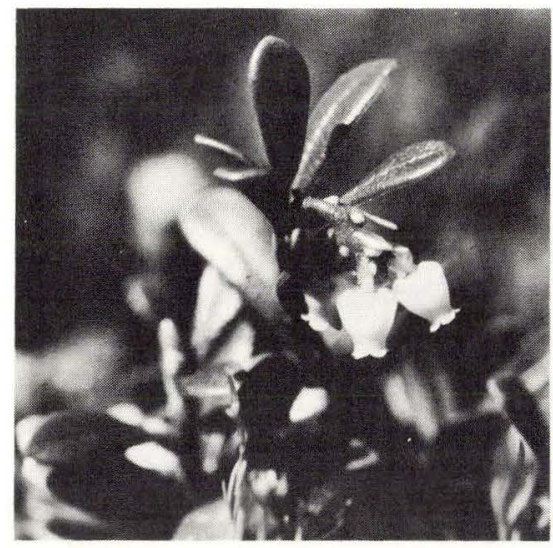

12. Bearberry, Arctostaphylos uva-ursi, which began to flourish when humus began to form on sandy soil in the Allerød period.

the exception of the cold-avoiding, shade-tolerating species meadowsweet, Filipendula ulmaria, and stinging nettle, Urtica dioeca. Humus formation began, and heath plants such as crowberry, Empetrum nigrum, bog whortleberry, Vaccinium uliginosum, and bearberry, Arctostaphylos uva-ursi, began little by little to appear in sandy areas.

\section{The Younger Dryas period: 9,000-8,300 B.C.}

The next temperature decrease occurred with a strange suddenness; it can be demonstrated over the whole of Europe north of the Alps and the Pyrenees, and characterizes the Younger Dryas period. The trees did not disappear entirely in south-east Denmark, but a very open park tundra replaced the forests. Tundra became universal in north-west Jutland, but it was not exactly similar to the tundra of the Older Dryas: crowberry had replaced the Öland rock-rose and other calcicolous pioneer plants. Dwarf shrub heaths now occurred throughout the country. In addition to dwarf birch and juniper, plants such as crowberry, black bearberry, Arctostaphylos alpi$n u s$, and even, although extremely rarely, common heather, Calluna vulgaris, were present. The vegetation corresponded much more closely to that of the present day northern forest limit. As to temperature, a total decrease of 3 to $4{ }^{\circ} \mathrm{C}$. from the last, warm part of the Allerød period can be demonstrated. The retreat of the ice-sheet ceased, and massive moraines were formed at this time in southern Norway (the Ra stage), mid-Sweden, and southern Finland (Salpaussälkä).

\section{The Late-Glacial winter temperatures}

The Late-Glacial chronology is based upon changes in vegetation which reflect changes in the temperature conditions during the growing season, or in other words, in summer warmth. Not much is known of temperature conditions during the winter.

Only a few plant species depend on a low winter temperature in their distribution. One exception, apparently, is the umbelliferous Pleurospermum austriacum, a chiefly Asiatic plant species which now in Scandinavia is only found in a few mid-Swedish "ravines", steep-sided valleys originally caused by cloudbursts, and known for their especially low minimum temperatures.

The western limit for Pleurospermum falls almost exactly along a line dividing an eastern area where the average January temperature is $-2^{\circ} \mathrm{C}$. from a western area where the average is higher. It appears that Pleurospermum seeds, which remain on the umbels throughout the winter, require especially low winter temperatures in order to be able to germinate. The occurrence of Pleurospermum on Bornholm in the Allerød period would seem 
to show that the winters must have been at least $2^{\circ} \mathrm{C}$. colder than today, whilst the summers as already mentioned could at most have been $3{ }^{\circ} \mathrm{C}$. colder. However, the presence of thrift, Armeria maritima, in the FullGlacial period and in the coldest phases of the Late-Glacial suggests that the winters were not extremely cold. In contrast to its arctic relatives, this species today avoids areas with very cold winters, i.e. with January mean temperatures below $-8^{\circ} \mathrm{C}$.

\section{Precipitation}

As previously mentioned, p. 19, the precipitation was considerably reduced throughout Europe during the FullGlacial period, and perhaps most of all during its latest phase. There is scarcely any doubt that the precipitation in the Late-Glacial also was less than today, even though it undoubtedly increased somewhat as the ice receded and the sea temperature rose. The occurrence of Ephedra and other "steppe plants" supports this opinion. On the other hand, one must bear in mind that the lower temperature reduced evaporation, and thus gave rise to greater moisture. Only the warmer parts of the Late-Glacial period can be assumed to have been rather dry, especially of course when they are compared with the cold phases.

The situation was presumably very similar with regard to snowfall. The pollen frequency of pronounced snowbed plants such as mountain sorrel and common sorrel, Rumex acetosa, which are both wind-pollinated, is low compared with the numerous pollen grains of e.g. rock-rose, whose species do not tolerate prolonged snow-cover. It must therefore be assumed that the snowfall in the Late-Glacial period was only moderate, at any rate during the milder phases.

\section{Animal life and hunters}

\section{Reindeer and other tundra animals}

The reindeer is the characteristic animal of the tundra. Reindeer could be found in Denmark throughout the whole of the Late-Glacial period, in the cold phases perhaps especially during the summer, and maybe a few in the winter. There are altogether more than 200 Danish finds of reindeer, mostly shed antlers of course, but also various pieces of the skeleton. A reindeer skeleton excavated in 1938 near Villestofte on Funen, fig. 13, is unique; it is the most beautiful of the extremely few complete reindeer skeletons that have been found in European deposits. The skeleton has been dated by pollen analysis to an early phase in the Older Dryas period, and is thus one of the oldest Danish reindeer finds. We may be confident, however,

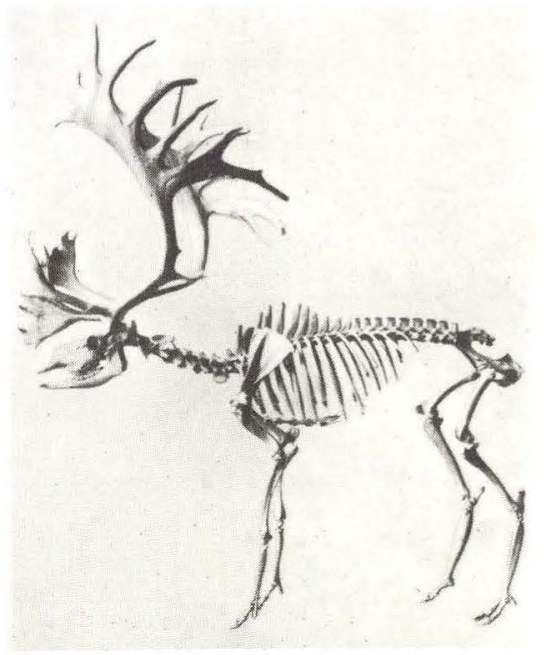

13. The unique reindeer skeleton from Villestofte on Funen, where it was excavated in 1938. It is the most beautiful of the very few complete reindeer skeletons found in European deposits. It has been dated to the Older Dryas period. (U. Møhl). 


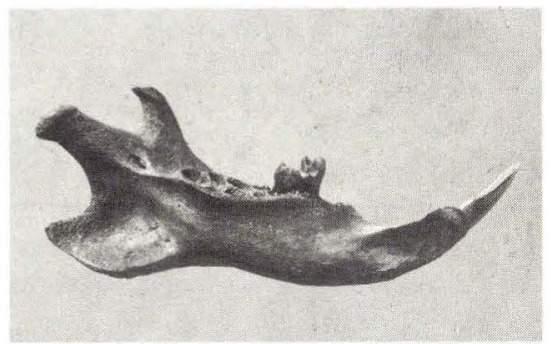

14. The lower jaw of a suslik, found by Steenstrup in 1877 in Late-Glacial deposits in the cliff at Nørre Lyngby in Vendsyssel. (D.G.U.).

that reindeer immigrated even earlier, at any rate to Jutland, which became icefree long before Funen.

Together with the reindeer came its worst enemies, the wolf and the wolverine.

The lower jaw of a wolf is known from the Dryas clay in Denmark, and a find of wolverine is known from the Aller $\phi$ d period. The wolverine was already present in Holstein in the early tundra period, as was the lemming. Lemmings must also have lived in Denmark during the Late-Glacial period, even though traces of them have not yet been found. The blue hare, another member of today's poor arctic tundra fauna, is known from a single find from the Younger Dryas period.

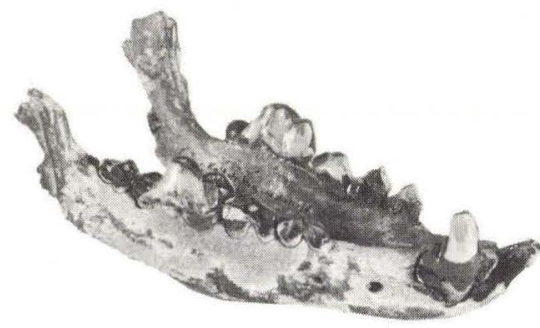

15. A wolf lower jaw found in Allerød brickworks pit, deep in the Dryas layer. The jaw probably comes from the Older Dryas period. (U. Møhl).
Tundra birds are only represented by two finds: the skeleton of a whooper swan in south-west Scania, in clay from the Older Dryas period, and the bone of a ptarmigan from the Younger Dryas. The whooper swan only appears in present-day Denmark when on migration, and the ptarmigan does not occur at all.

The sparseness of finds of tundra animals is partly owing to the fact that it still has not been possible to find human settlements with well-preserved bone remains from the Late-Glacial period. A find of the large salmonid whitefish, Coregonus lavaretus, in icelake clay near Tistrup, south-west of Århus, is notable for its great age; it can not be younger than the Bølling period and is probably older. Whitefish is to some extent a cold-water fish and appears to have been common throughout the Late-Glacial period. It has held its own in Denmark to the present day, however, and now has a peculiar distribution, see Danmarks $\mathrm{Na}$ tur, vol. 2. Perch and pike have also been found in Late-Glacial deposits.

\section{Late-Glacial steppe animals}

In 1877, Japetus Steenstrup found the lower jaw of a European suslik, Spermophilus rufescens, in a profile in the coastal dunes near Nørre Lyngby, see fig. 14. The suslik is a small, reddishyellow rodent, which today occurs only on the steppes, where it lives socially in holes in the ground. The nearest place of occurrence is in south-east Russia. Like many other steppe animals it had a wide distribution during the Ice Age, extending right to northwest France. Steenstrup's discovery gave rise to theories of a steppe period between the tundra period and the forest period, but when after many years no traces of steppe plants and no new fossils of steppe animals had 


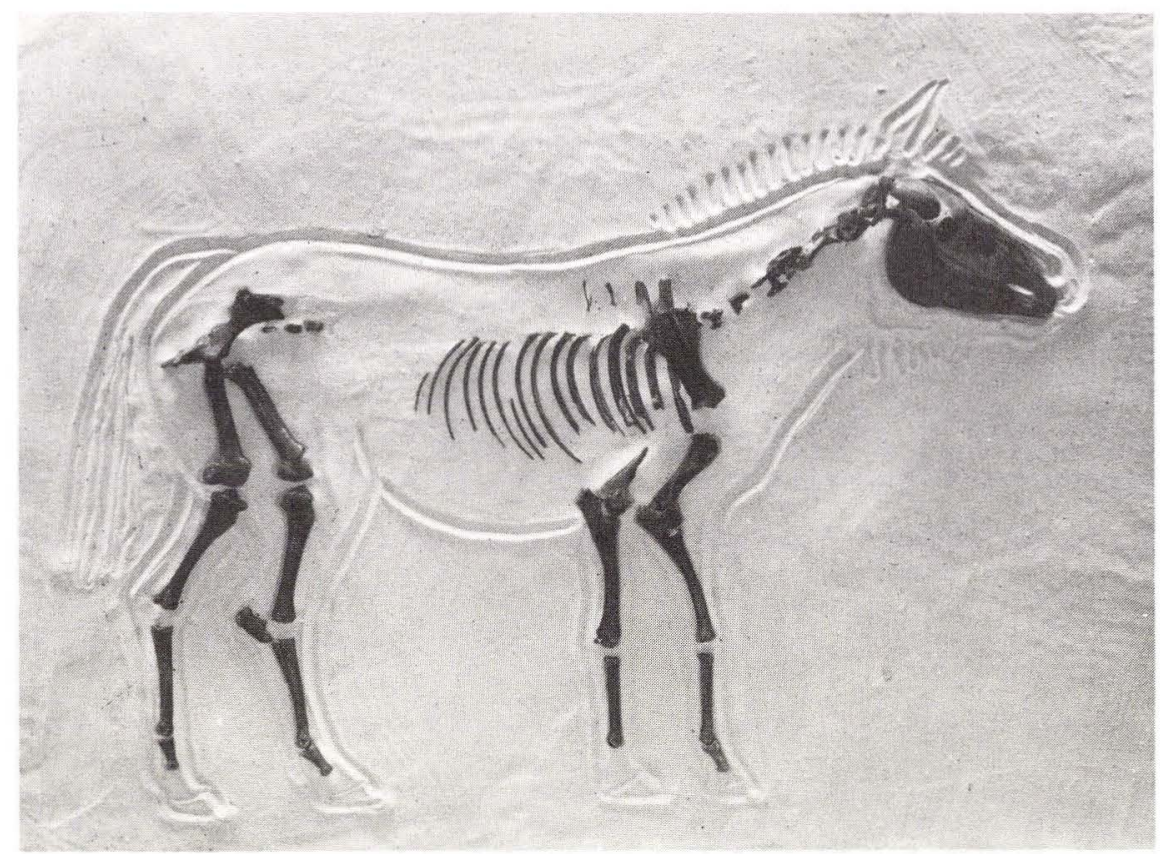

16. The wild horse from Vedelshave on Funen. It is shown here modelled on a sand wall with the original bones set in the sand. Designed and photographed by Uirik Møhl. Se page 35.

been found, this theory of a steppe period was again abandoned.

The next discovery of a steppe animal was not made until 1933, when two horse bones, which could be dated by pollen analysis to the end of the Younger Dryas period, were found near Fjerritslev in Hanherred. The bones must have belonged to wild horse. Some bones found later at the bottom of a bog further east in Hanherred are probably also from about the same time. Finally, parts of a wild horse skeleton were found underneath a spring chalk deposit, near Vedelshave on Funen, fig. 16. Although only one pollen analysis from the inner part of the skull is available, there is scarcely any doubt that it must be dated to the Older Dryas period. It may sound surprising that wild horses appeared so early in Scandinavia, but the evidence is strengthened by an even older find from Holstein: a bone found in a dwelling site layer from the earliest tundra period. The wild horse thus lived alongside the reindeer throughout the Late-Glacial period.

Bison were also present in the Danish park tundra. Three old bison finds are known, but these were undated. It was originally assumed that the Danish bison was a forest animal like the aurochs and the present-day, nearly extinct, European bison. When new bison finds appeared, all the material was subjected to pollen analysis, and it was shown that four finds, two from Funen and two from North Jutland, could be dated to the Younger Dryas period, but only one to the succeeding Birch-Pine period of open forest. This 


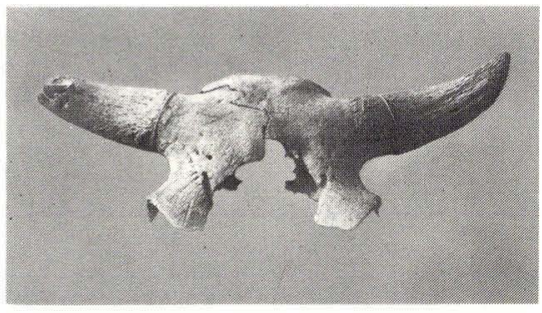

17. The forehead of a bison found on Funen. The find is from the Younger Dryas period, and the animal was associated with open park tundra, in contrast to the present-day European bison, which is a forest animal.

bison was therefore not a forest animal like the present-day race. Moreover, this race is smaller than the fossil Danish bison, which has been determined by the zoologist, M. Deger$\mathrm{b} \phi \mathrm{l}$, to be a special variety, Bison bonasus arbusto-tundrarum.

The suslik, wild horse, and bison in
Denmark were descendants of the Ice Age steppe fauna which had lived further south, and they fit naturally into the picture which now, based on pollen analysis, has been revealed of the Late-Glacial conditions of northern Europe. They are just as little evidence of a real steppe climate in Denmark as is the steppe plant Ephedra, see p. 25 , but they emphasize the special character of the Late-Glacial fauna and flora.

\section{The first reindeer hunters}

In the last part of the Ice Age there were several human cultures in $\mathrm{Eu}$ rope, which had specialized among other things in the game which they hunted. The culture of the reindeer hunters is the best known in North Europe.

A knife of reindeer horn, found in a layer of clay at the bottom of the

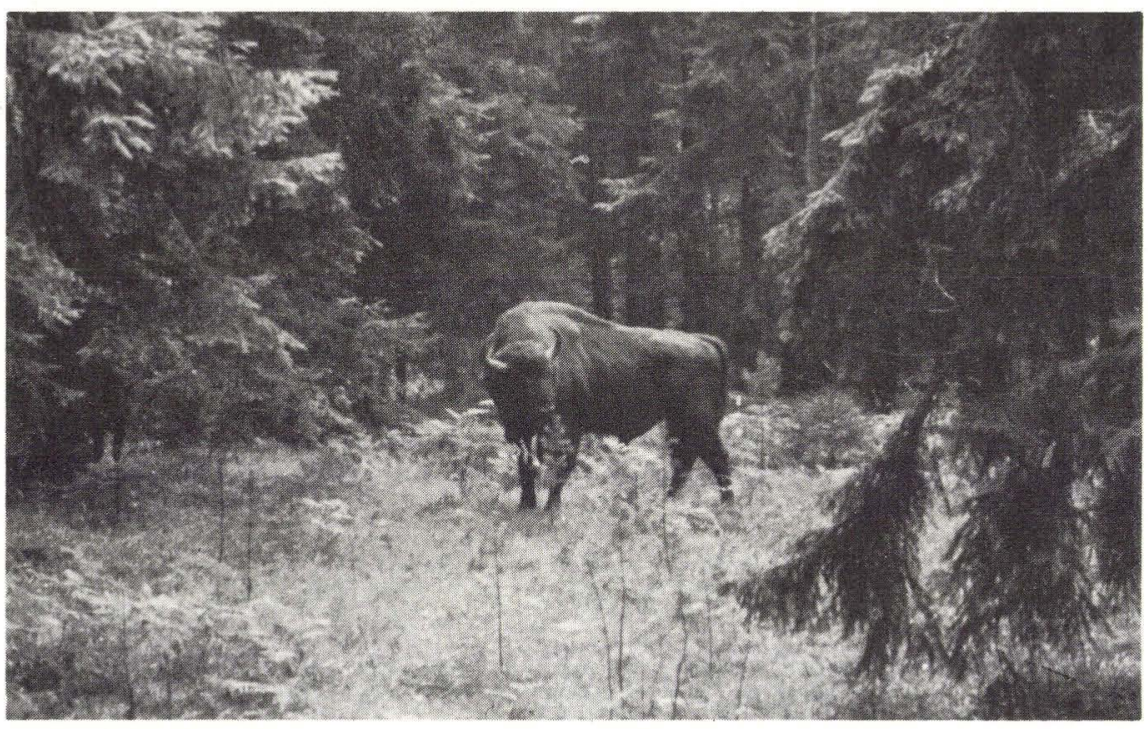

18. A picture from the great Bialowieza primeval forest in Poland, where the European bison still lives wild. European bison can also be seen today in many zoos, including our own Zoological Gardens. The animal has been preserved from extinction by these stocks and by the now quite large wild population in Poland. Photo by J. Fabijanowski. 
$\emptyset$ resund, seems to come from the Older Dryas period, judging from a pollen analysis, and it is thus the oldest trace of reindeer hunters yet found in Denmark. It has some similarities with finds from the famous Hamburg culture, which is however even older, belonging to the close of the earliest tundra period. These hunters apparently lived in tents - ballast stones for skin tents have been found - close to small lakes, and fortunately they had a habit of throwing refuse and pieces of game animals into the water, and a rich bone collection was preserved. The discovery of bones of cranes, geese and swans, as well as other evidence, shows that these sites were summer habitations. Reindeer bones were the most abundant by far, and most of them had been split to gain access to the delicious marrow. A few complete reindeer skeletons with stones in the ribcage must be interpreted as sacrifices. Marks on a number of bones are evidence of the hunters' use of bows and arrows. The whole culture was apparently based on reindeer.

\section{Reindeer hunters from the Younger Dryas period}

The shaped reindeer-antler axes, fig. 20 , found in several places in Denmark are completely unknown in the Hamburg culture. The same is true of an arrowhead found in the important coast profile near Nørre Lyngby between Lønstrup and Løkken in Vendsyssel, in which Steenstrup made his discovery of the suslik. Since one of the antler axes was found on the beach very near the site where the arrowhead was found, the two discoveries were linked and referred to the "Lyngby culture" which for a long time was the oldest known in Scandinavia. The flint arrowhead and other objects were

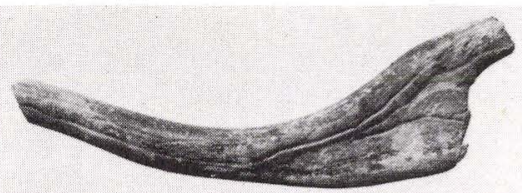

19. Reindeer horn knife collected from clay deposits at the bottom of the Øresund. (Nat. Mus.).

found in a saucer-shaped basin filled by freshwater deposits, through which the sea has constantly cut new sections. The arrowhead came from a sand-layer which later could be dated by pollen analysis to the Younger Dryas period.

Since several reindeer bones were found in this layer as well as remains of whitefish and the previously mentioned bones of blue hare and ptarmigan, it could be anticipated that there was a reindeer-hunter dwelling site from the Younger Dryas period in the neighbourhood. But as yet it has not been possible to find such a site in Denmark; we must once again turn to Holstein to find dwelling sites from that time. They are situated in the same valley as the dwelling sites of the

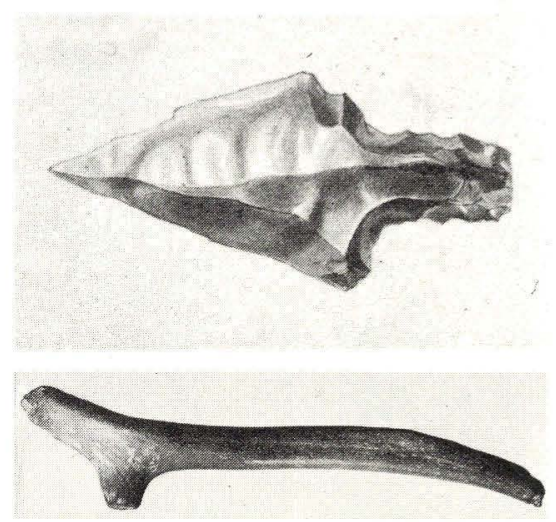

20. Arrowhead (ca. 1/1) and reindeer antler axe (1/9) from Nørre Lyngby, Vendsyssel. 
Hamburg culture, and are similarly found beside small lakes where the refuse layers can be studied. The tools of this culture, the Ahrensburg culture, are very different from those of the Hamburg culture; among other things arrowheads and reindeer-horn axes have been found which resemble those of the "Lyngby culture", although the arrowheads of the Ahrensburg culture are much smaller than the Danish ones. The reindeer-horn axes are thought to have been used chiefly for smashing bones; they are quite unsuitable for chopping wood. No less than 20,000 bones chiefly of reindeer were found near the largest dwelling site. Among other animal species, two must be noted which have not yet been demonstrated in Denmark, namely the lemming and the desman, Desmana. The first mentioned is also a tundra animal today; the latter is associated with streams and rivers in steppes.

\section{The fauna of the Allerod period}

Just as the flora of the Allerød period and the immediately preceding transi-

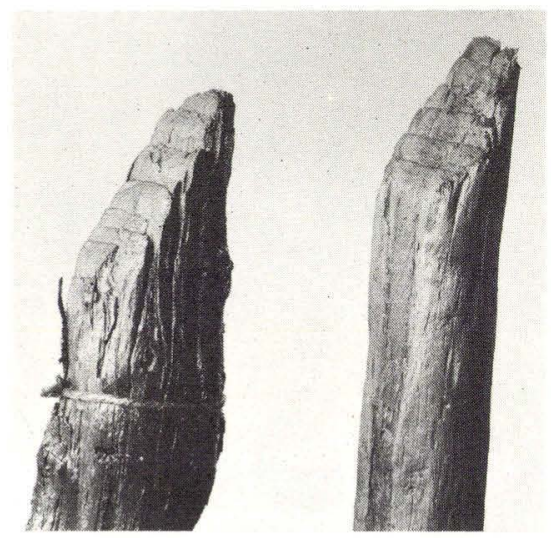

21. Willow branch gnawed through by beavers, from the Allerød period (left); for comparison a beaver-gnawed branch from a zoo. (From V. Nordmann 1924). tion period was very varied, the fauna too was of a strangely mixed composition, especially with regard to mammals. The tundra and steppe animals of the glacial period could not move further north and still found favourable conditions in the as yet light birch forests, whilst simultaneously forest animals had followed the forests into the country.

\section{The extinct Irish Elk}

The Irish elk, Megaloceros giganteus, and the common elk were the characteristic animals of the time. They somewhat resembled each other, but the Irish elk was by far the larger. Only two of the five Danish finds of Irish elk have been dated by pollen analysis; both are from the Allerød period. One is a shed antler found near Vævlinge on Funen; the other is from Holsteinsborg on Zealand and consists of bones from three animals, an adult and two young. A third find presumably also belongs to the Allerød period, to judge from the conditions of sedimentation. There have been remarkably few finds of Irish elk from the last glacial period in Europe; only in Ireland have many skeletons been found, by far the most from the Aller $\phi$ d period.

It appears that the Irish elk had a final flowering at this time in northwest Europe, before completely dying out. The youngest find is from the transition between the Younger Dryas period and the Birch-Pine period. The original homeland of the Irish elk was presumably like that of the wild horse and the bison, the open steppe country in the south-east. From here it spread westwards in company with them during the Ice Age. Strangely enough not one single bone of an Irish elk has been found in the rich bone material of the Hamburg and Ahrensburg cul- 


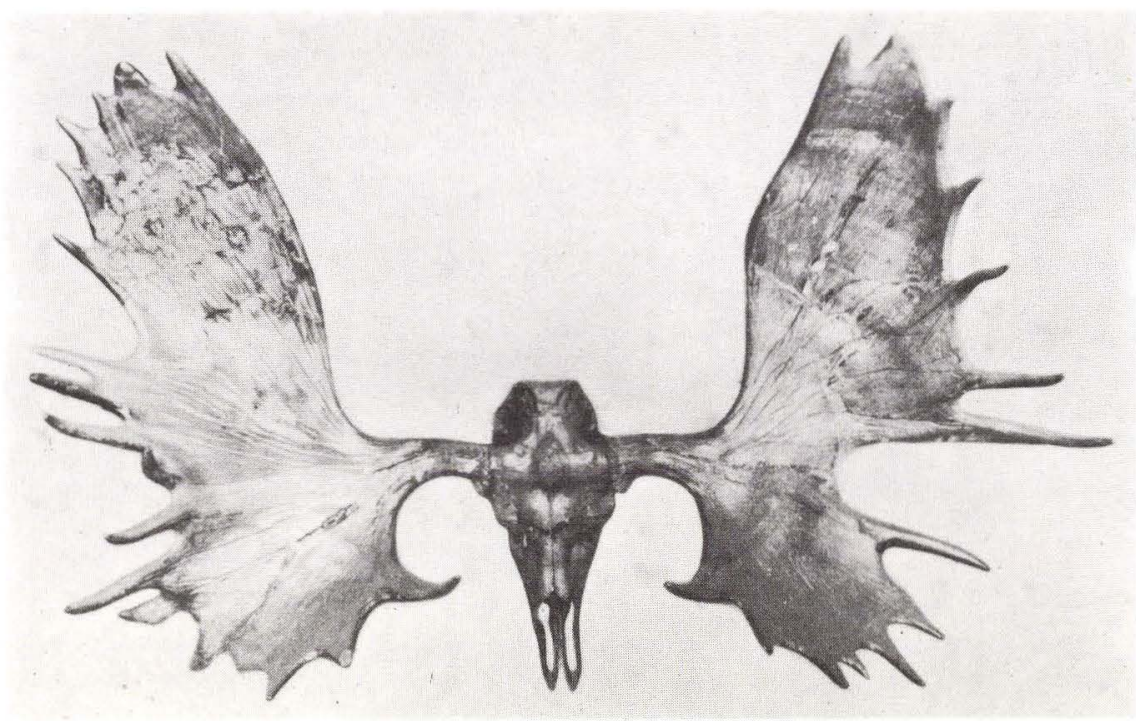

22. The beautiful elk skull found in Allerød layers in Gentofte. The splendid antlers have a span of 1.65 meters. (U. Møhl).

tures, even though a skeleton has been found in Holstein in layers from the earliest tundra period.

\section{Elk and other game}

A number of elk antlers are known which according to descriptions of the sites, must be assumed to be Late-Glacial. Two skeletons have been dated with certainty to the Allerød period; one was unearthed at Gentofte and belonged to an unusually powerful animal with mighty antlers, almost $1.65 \mathrm{~m}$ across from tip to tip, fig. 22 .

The beaver had also spread across the whole of Denmark; it is a typical forest animal, and reveals its presence by marks of its gnawing on branches and trunks. Thus numerous willow branches bitten through by beavers were found in the previously mentioned profile near Nørre Lyngby in Vendsyssel, fig. 21. The convex surfaces left by the concave rear side of the beaver's powerful front teeth are highly characteristic. The beaverworked branches lay in the clay layer of the profile which dates from the Allerød period.

The wild horse was still present here just as the reindeer, and the same is undoubtedly true of the bison, even though finds are still lacking.

of carnivores, only brown bear which is a typical forest animal, and wolverine have been demonstrated as yet; but the wolf, already present in the Older Dryas period, must also have taken its share of the abundant game, together with the lynx which is known from the somewhat younger Ahrensburg culture.

\section{An elk-hunter dwelling site from the Allerød period}

Whilst new reindeer-hunter dwelling sites from the oldest and the youngest phases of the Late-Glacial period were being found in Holstein, archaeologist Erik Westerby succeeded in 1944 in 


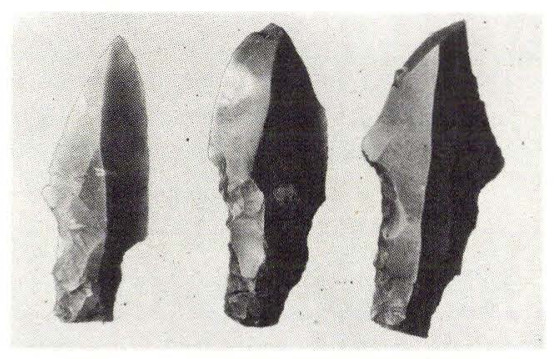

23. Arrowheads from Bromme dwelling site. The dwelling was found in 1944 and is the oldest Danish dwelling site known; it is dated to the Allerød period. (Nat. Mus.).

finding the first Danish Late-Glacial dwelling site. Geological investigations have dated it with certainty to the Aller $\varnothing \mathrm{d}$ period.

The archaeological material is of an ancient type - flint axes are not present, for example - and it differs distinctly from both the older Hamburg culture and the younger Ahrensburg culture. It contains many arrowheads of the same type as the Lyngby arrowhead, which is much coarser than those of the Ahrensburg culture. The larger ones can possibly have been used on throwing-spears. Since the dwelling site thus can not be related to any known culture, it has given its name to a new culture, the Bromme culture, from the finding place Bromme, north-west of Sor $\emptyset$.

The site lies on a low elevation, which was covered by light birch forest with the elegant little fern, Dryopteris linnaeana, in the undergrowth. The bone material was sparse and strongly decomposed. It differs distinctly from that of the Holstein dwelling sites: elk, not reindeer, was the chief game animal of the Bromme hunters. As well as the many elk bones and the not infrequent bones of beavers, two reindeer antler fragments and the remains of a wolverine skull were found; some horse bones are also thought to belong to the culturelayer, and the same is probably true of the bone of a red deer. Such a combination of dominating forest animals and of remnants of the tundra and steppe animals of the open landscape, is exactly what one would expect in a dwelling site from the Aller $\phi$ d period. Bones of swan and pike also occurred.

\section{Smaller Late-Glacial animals}

Lower animals, especially molluscs and insects, have also contributed to an understanding of the natural conditions in the Late-Glacial period. The use of fresh-water molluscs to illustrate the course of the temperature curve has already been mentioned, see p. 27; new finds of species which only live in temperate areas, for example Bithynia leachi, confirm the mildness of the Allerød period. The discovery of land snails such as Vallonia pulchella and Buliminus obscurus in the culture layer of the Bromme site is additional confirmation. A small land snail, Vertigo genesi, which today has a peculiar distribution, was also found here. It occurs in the Alps in the uppermost forest zone and the alpine zone; otherwise it is only known from some scattered localities in England and southern Scandinavia, where it is apparently a relic from the Late-Glacial period. In dry-land deposits such as loess, the snail fauna is often the only, and in any case the most important, means of estimation of the contemporaneous climatic conditions, and it has been of great significance for the investigation of the glacial climate in loess areas.

Flying insects spread just as rapidly as waterplants, and are thus among the first to indicate climatic temperature variations. The Danish Quaternary 
insect fauna is relatively well known through the researches of the zoologist Kai L. Henriksen, and some interesting beetle finds will be mentioned here. Amara alpina and Bembidion glaciale are characteristic "cold" species from Dryas layers. Amara alpina to-day is only found in the mountains and tundra of the arctic region, while Bembidion glaciale occurs exclusively in the mountains of middle and south Europe, not in the arctic. The Allerød period, on the other hand, is characterized by insect species which today are only known from the temperate zone. Among these species was Chlaenius illigeri, which today has an easterly but by no means northerly distribution; it occurs from North Germany to Siberia, but neither in Denmark nor in Sweden.

\section{The Late-Glacial sea}

The increase in sea-level and the rising of the land after the melting of the inland ice

The water-level of the oceans was lower than to-day during the Quaternary glaciations, because enormous quantities of water were stored in the great ice-masses of North Europe and especially of North America. As the ice gradually melted, the sea-level increased, and the Late-Glacial shorelines are now usually deeply submerged.

The relationship between land and sea in areas that were ice-covered during the Ice Age is more complicated. Here, the enormous ice-mass had pressed the land down just as a heavily-laden ship is pressed down by its cargo. The depression was greatest in the central part of the ice-shield where the load was greatest, and it was least in the peripheral areas. Gradually, as the land was released from the pressure of the ice, it raised itself again.

The uplift has been greatest in those areas around northern Sweden where the original depression was largest. In Denmark the uplift is most pronounced in the north-eastern part of the country, especially in the northern part of Vendsyssel, where the LateGlacial beach-lines to-day are raised high above sea-level. Near Frederikshavn such beach-lines occur up to 60 meters above sea-level; they decline towards the south-west and near $\mathrm{Ma}$ riager Fjord they are at most 6 meters above s.l. Beyond this point they sink below the far younger Post-Glacial shorelines and therefore can not be followed further.

Two factors thus have affected the positions of the shoreline in Denmark simultaneously: firstly the rise in the oceans since the Ice Age, the "eustatic" factor, and secondly the uneven lifting of the land, the "isostatic" factor. These two factors work against each other, and the domination of one factor or the other has caused the sea either to rise ("transgression") or to recede ("regression"). The mechanism was further complicated by the fact that the uplift of the land was delayed in relation to the melting of the ice; it was a slow process which continued with decreasing speed through many thousands of years - in fact it is still not finished even today.

The Late-Glacial ice-sea (Yoldia Sea), ca. 13,000-ca. 11,000 B.C.

Whilst the ice melted away from North Jutland in the transition between the Full-Glacial and the Late-Glacial periods, the country still lay deeply depressed. Vendsyssel was broken up into one large and a series of smaller islands, surrounded by the ice-cold 


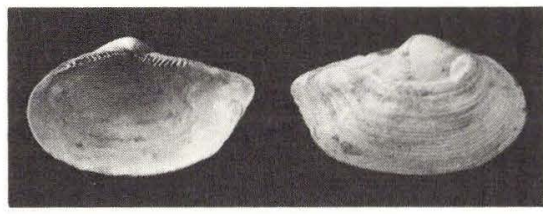

24. The high Arctic bivalve Portlandia (earlier called Yoldia) arctica, which has given its name to the Late-Glacial icesea, the Yoldia Sea. (D.G.U.).

Yoldia Sea, named after the higharctic bivalve Portlandia (previously called Yoldia) arctica. This ice-sea extended further across the Kattegat and Læs $\varnothing$ down to near Zealand's north coast, and an arm of the Yoldia Sea continued down the $\emptyset$ resund valley as this was gradually uncovered by the melting of the ice. The Baltic Sea was still covered by ice. The deposits of the Yoldia Sea are known as the younger Yoldia clay, to distinguish them from the older Yoldia clay of interglacial age, Danmarks Natur, vol. 1, p. 248. They contain a typical arctic snail and bivalve fauna consisting of many species. Three of these are today only found in the Polar Sea around North Greenland, Svalbard, and other places, where the water has a temperature of around $0^{\circ} \mathrm{C}$.

The Yoldia clay cannot be investigated by pollen analysis since it contains only redeposited pollen, but it has been possible to date its bivalve shells by the carbon-14 method, which shows that the clay was deposited over a period from about 12,700 B.C. to about 11,000 B.C. In spite of the higharctic mollusc fauna this period must have been one of climatic improvement, as demonstrated by the rapid melting of the glaciers of which the Yoldia clay is itself evidence.

The uplift of the land was faster than the rising of the oceans, however, and the sea receded - we do not know

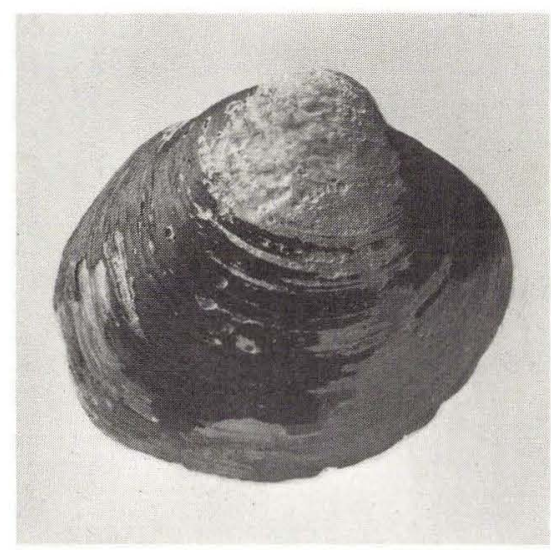

25. The clam Cyprina islandica. (D.G.U.).

how far. The Yoldia clay is usually covered by a layer of sand containing shells of the bivalve Saxicava arctica.

\section{The Zirphaea Sea of the Bølling period}

The climatic improvement in the $\mathrm{B} \phi \mathrm{l}$ ling period brought with it a new rise in the sea-level in Vendsyssel, however. The land continued its uplift uninterruptedly, but now the oceans rose more rapidly than did the land. This can be observed for example in profiles near Skeenmølle Bæk near Uggerby. The Yoldia clay is found at the bottom of the profile, and is overlain with a sharp contact by a layer of gravel, which is much younger than the clay. It was presumably deposited

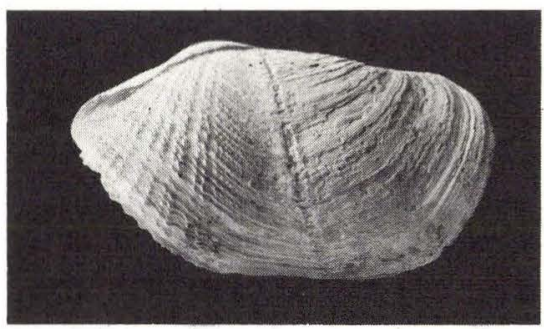

26. The oval piddock, Zirphaea crispata. (D.G.U.). 
when the sea rose above the Yoldia clay which for a time had been left dry. Above the gravel layer follow 3-5 meters of stratified sand with clayey layers - the water-depth had increased! Gravel is sometimes found again at the top. A pollen diagram has been worked out from the clayey sand and shows that birch forest had temporarily advanced up to Vendsyssel, to be succeeded by pure tundra. Carbon-14 datings of bivalve shells in the clayey sand layers lie between 10,400 and 10,200 B.C. and thus place the birch maximum in the Bølling period. The beginning of the rise in sea-level has been determined as ca. 10,600 B.C. at this locality. The uppermost shells in the Yoldia clay have been dated to 11,660 B.C.; there is thus an interval of 1,000 years between the Yoldia clay and the gravel layer.

The rise in sea-level during the $\mathrm{B} \phi \mathrm{l}$ ling period was characterized by a new mollusc fauna. The arctic molluscs were replaced by a more temperate fauna including such species as the common mussel, Mytilus edulis, and the bivalve Cyprina islandica, and the oval piddock, Zirphaea crispata. The last-named species is the most warmthrequiring; the Yoldia sea has become the "Zirphaea Sea". It is estimated from the present distribution of these species in northern waters, that the average temperature in the North Jutland Zirphaea Sea was ca. 4 to $6^{\circ} \mathrm{C}$.

The sea-level fell rapidly around Vendsyssel during the Younger Dryas time, and we have no finds of marine deposits.

\section{Whales, seals, and other marine animals}

The Late-Glacial ice-sea was unfavourable for animals and plants. In the winter the sea was frozen over,

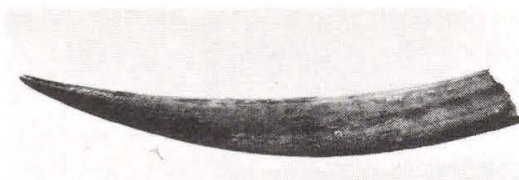

27. The tusk of a walrus, which was found washed out on the beach near Rudbjerg Knude, south of Lønstrup. (U. Møhl).

and in the summer there was abundant drift-ice. The great melt-water rivers were cold and milky with suspended clay, and they affected the surface water far out to sea. But whales and seals did occur. Finds of the Greenland whale, Balaena mysticetus, killer whale, Orcinus orca, and a whole skeleton of a ringed seal, Pusa hispida, which today lives chiefly around the coasts of the Arctic ocean, have been made in the Yoldia clay in Vendsyssel. Half of the lower jaw of a polar bear, found north of Hjørring, in all probability also comes from the same period. Furthermore, walrus tusks of both adult animals and young have been found on the shore near Lønstrup; these must also have been washed out from the Late-Glacial Yoldia clay.

The arm of the sea which extended down into the $\emptyset$ resund has left clearly visible traces on the Swedish side, in the form of shore-lines. In clay layers near Lomma, north of Malmö, which were deposited whilst the ice was still in the immediate vicinity, a considerable number of the high-arctic cod species Gadus saida has been found, and in certain layers a rich flora of brackish-water diatoms has been demonstrated. On the Danish side of the Øresund we have only indistinct traces of the Yoldia sea. The best indicator is a well-preserved bone of a ringed seal found in a clay layer, near 
Nivå, which must however be considerably older since there is evidence that the ice during a short period of advance returned over the clay layer. The possibility that the bone was carried by the ice to this spot from an interglacial marine deposit on the island of Ven cannot be completely excluded, either.

Unlike the Yoldia Sea, the Zirphaea Sea was not characterized by cold melt-water rivers and large amounts of drift-ice. The animal life became richer but occurrences of Zirphaea layers are few and the material is thus scarce. Of the great baleen whales, rorqual. Balaenoptera physalus, and the blue whale, Sibbaldus musculus, the greatest of all living animals, now occurred as well as the Greenland whale. Long-tailed duck, Pagonetta glacialis, is the only known representative of the Late-Glacial sea birds in Denmark.

\section{The Birch-Pine period, 8,300-7,000 B.C.}

\section{A change in climate}

At the transition point between LateGlacial and Post-Glacial, a very sudden and steep rise in temperature occurred which in a short time transformed the open landscape of the Younger Dryas period into continuous forest. The recession of the ice, which had come to a halt in mid-Sweden, was accelerated again; the ground-water level sank as a result of the increased evaporation, and many shallow lakes became overgrown. A purely organic sediment was now deposited in all Danish lakes - the washing-down of clay had ceased everywhere. There can be no doubt that a new period had begun.

\section{The forest conquers the land}

\section{Juniper, crowberry, and meadow sweet}

A strikingly steep and short-lasting maximum for juniper marks very sharply the boundary between the Late-Glacial and Post-Glacial periods in Danish pollen diagrams and indicates the sudden rise in temperature.
Juniper scrub must have been the dominating type of vegetation in large parts of the country at that time. Juniper had been there in advance, but in a rather subdued form, since only the snow-covered parts could survive through the winters. The climatic improvement made it possible for juniper to grow tall and form a richlyflowering scrub before its most dangerous competitors, the trees, arrived.

The juniper maximum seems to have been more weakly developed in the heath areas of north-west Jutland; instead, the climatic improvement is here registered as a large maximum of crowberry. As previously mentioned, crowberry heaths were already present at the close of the Aller $\phi$ d period and they continued, though in somewhat weakened form, throughout the Younger Dryas period, but they first achieved their greatest extent immediately before the Birch-Pine period. Crowberry heath is found on poor, humus-containing, sandy soil, and this is undoubtedly the most important reason why it only achieved such a wide distribution in the poor sand areas of Jutland. This is also the explanation why crowberry did not make 
its presence felt before the close of the Allerød period; it was then that washing-out and humus formation first created the right soil conditions. Heather, which is a more pronounced humus- and acid-soil plant than crowberry, only became of significance at a later point in time, even though it already occurred extremely sparsely in the Allerød period.

Meadow sweet, Filipendula ulmaria, is the third plant that clearly registers the transition to the Post-Glacial. It also occurred rather frequently in the Aller $\emptyset$ d period, disappeared again in the subsequent cold period, and then simultaneously with juniper achieved a far greater abundance than ever before. Since meadow sweet can tolerate some shade and can also grow on quite wet ground, it was not immediately displaced by the birch-forests, but remained a characteristic component of the vegetation in the first part of the Birch-Pine period. In the flowering season meadow sweet formed a yellowy-white belt around the lakes and attracted insects with its characteristic, sweet honey smell.

\section{Water and marsh plants}

Naturally, all the water and marsh plants of the Aller $\phi$ d amelioration which had been driven out by the subsequent cold phase, now returned, and brought new ones with them, such as hornwort, Ceratophyllum demersum, species of bladderwort, Utricularia, and whorled water milfoil, Myriophyllum verticillatum. Most striking is the finding of fen sedge, Cladium mariscus, which to judge from its present range is more warmth-requiring than elm and hazel.

\section{The forest succession}

The temperature apparently rose so quickly that the trees could not keep

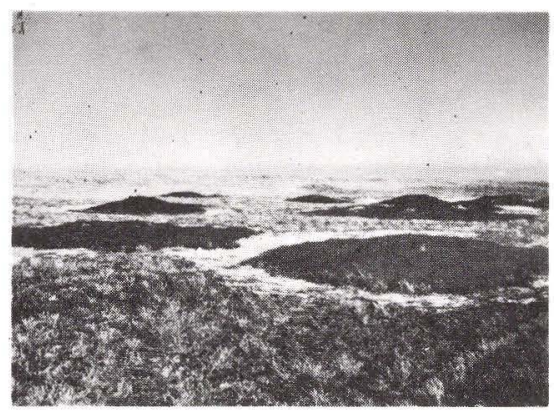

28. Present-day crowberry heath on sanddunes. The crowberry heath reached its greatest distribution just before the Birch-Pine period. (S. Sandermann Olsen).

pace. The tree succession found as yet only records the local spreading of the tree species and their competition for light. Aspen and birch had held out since the Aller $\phi \mathrm{d}$ period and through the subsequent cold period in especially favourable places. The tree-shaped aspens were killed by frost but their root shoots could survive without difficulty as low, sterile shrubs protected by the snow in winter. Apparently birch was in many cases able to form suckers after being killed by frost. When the temperature rose again, birch and aspen immediately grew up into full sized trees, and spread rapidly from their refuges in all directions. They overgrew the juniper scrub, first preventing it from flowering and then gradually stifling it by their shadow. Together with birch, Betula pubescens, the more warmth-requiring silver birch, B. pendula, which does better than $B$. pubescens on dry ground, now occurred too.

Pine immigrated from the southeast, and slowly began to force the birch back. The difference in light requirement of these two trees is not great, but the greater life-span of pine was decisive. 


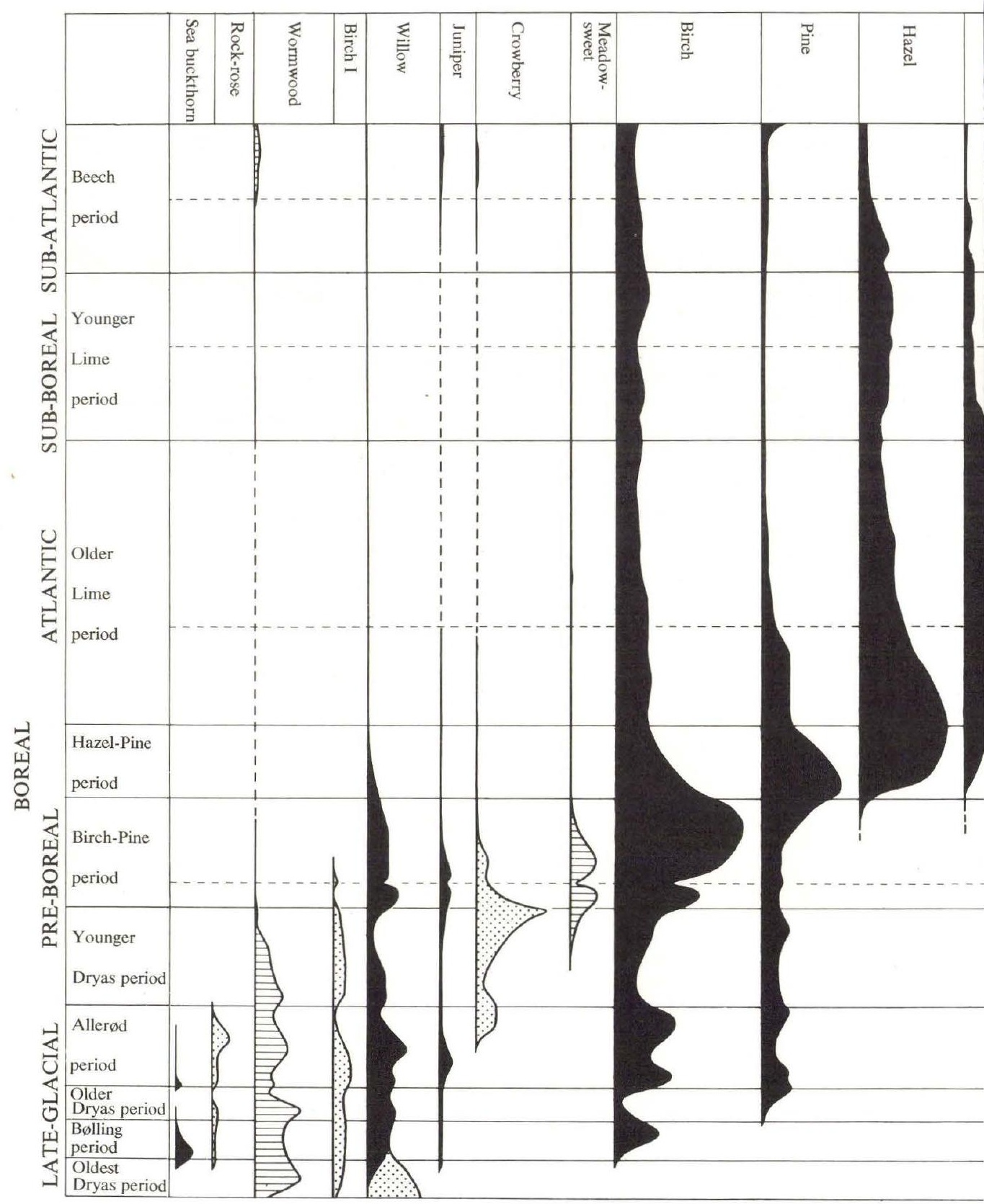

29. Pollen diagram from Lake Bølling in West Jutland. Silhouettes of trees and shrubs are black, 46 


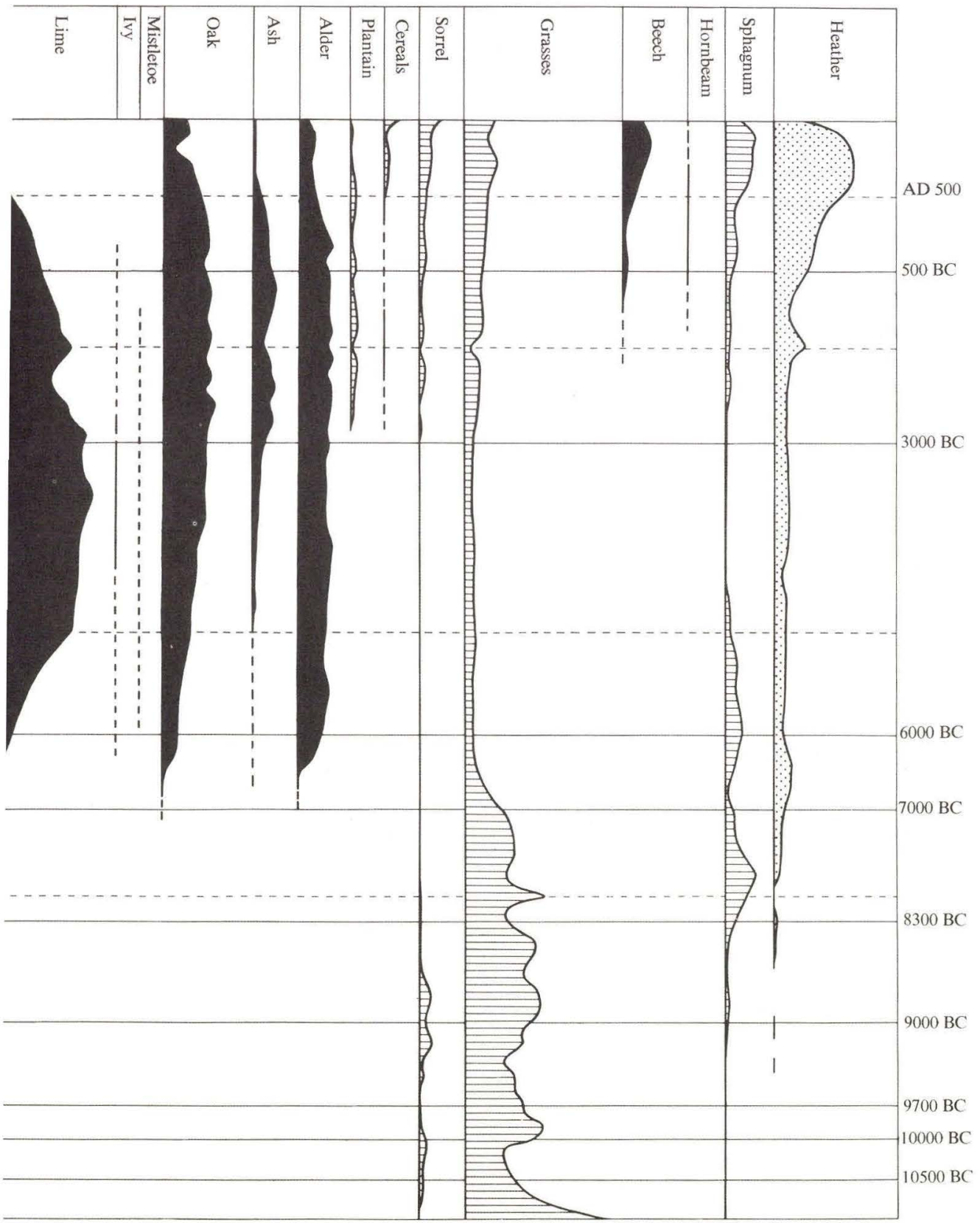

dwarf shrubs are dotted and herbs and Sphagnum are lined. "Birch I" is predominantly dwarf birch 


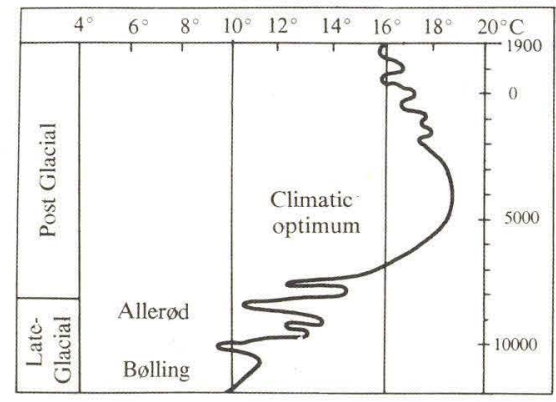

30. The Late-Glacial and Post-Glacial temperature curve for July. The PostGlacial section undoubtedly shows several oscillations similar to those of the Late-Glacial period, but their size is completely unknown.

The Birch-Pine period thus had a flying start, but after that the succession apparently came to a halt. Shadetrees - spruce, beech, elm, hazel, etc. remained absent; the forest remained a pioneer forest. As an explanation one can suggest a delayed immigration. This is undoubtedly true of a slowly-migrating tree species such as spruce, which does not require much warmth and which immediately occupied a place in the forests in the Balkans near its Ice Age refuges. But one would have expected elm, for example, which can spread effectively and rapidly, to arrive earlier.

An additional explanation can be put forward, however, which may join the former one. After the rapid increase in temperature a new recession may have occurred, which did not inhibit birch appreciably, but halted the advance of the more warmth-requiring tree species and may even have pushed them back temporarily.

\section{A short climatic recession}

Pollen diagrams with closely-spaced samples from Lake $\mathrm{B} \phi 1$ ling and East Friesland have simultaneously (1966) shown that this was in fact the case. In the diagram from Lake Bølling (see fig. 29) the beginning of the PreBoreal period is characterized, as usual, by the rapid rise in the birch curve, whilst the curve for herbaceous plants and crowberry falls. A sharp but shortlived fall in the birch curve then occurs, however, whilst the pollen frequencies of grasses and sedges temporarily increases greatly. Meadow sweet reacts in the same way as birch.

It is quite clearly a climatic recession which is recorded in this manner. A similar change is moreover also shown in the microflora, which like aquatics reacts very strongly to changes in temperature once a threshold value has been crossed. In the diagram from East Friesland, near the Dutch border, not ony the birch but also the pine curve shows a steep rise at the transition to the Post-Glacial period, and both, but especially the pine curve, shortly afterwards undergo a sharp but temporary decline, whilst crowberry and herbaceous plants again have a transitory maximum. There can not be the least doubt that this "Friesland oscillation" (K.-E. Behre) was caused by a short-lived fall in temperature. The conclusions which can be drawn from this are substantial. The steep rise in temperature at the transition from the Late- to the Post-Glacial period was a pronounced peak on the oscillating but on the whole rising temperature curve.

\section{The Post-Glacial temperature curve}

Corresponding temperature oscillations have undoubtedly also occurred during the ensuing Post-Glacial period. It is thus a well-known fact that we today are at a warm peak in an otherwise slowly waning temperature curve. However, these minor PostGlacial climatic oscillations are for 
various reasons difficult to demonstrate by pollen analysis. The duration of the waves on the temperature curve varies; the Friesland oscillation was one of the short-lived ones, as was the Older Dryas period and the depression in the middle of the Aller $\emptyset \mathrm{d}$ period; the order of size here is at most a few hundred years. The twopeaked mild Aller $\varnothing$ period in its entirety lasted 7-800 years, like the cool Younger Dryas period, but these, too, are only minor waves in the great climatic cycles of the Quaternary Epoch.

\section{The light pioneer forest}

It is not certain whether the short-lived Friesland oscillation discussed above caused visible changes in pollen diagrams from the warmer, south-eastern part of the country. New diagrams with closely spaced samples will decide this. The climate of the BirchPine period as a whole must be described as still moderately temperate. Judging from the common occurrence of pollen grains of hop, Humulus lupulus, and the rare finds of fen sedge, Cladium mariscus, one must assume that the average temperature for July was around $15^{\circ} \mathrm{C}$., that is to say, a little cooler than today.

Delayed immigration must be the explanation why, even after the shortlived cold wave had passed, no other tree species were found apart from the two birch species, pine, aspen, and two or three species of rowan. Guelder rose, Viburnum opulus, was a new shrub species, and there was also much willow with some bird cherry and juniper, as in the Aller $\phi$ d forests. Sea buckthorn had a short flourishing during the juniper-rich transition stage but then, together with the other lightrequiring pioneer plants, it was forced back to refuges near the coasts and other places where new soil was still

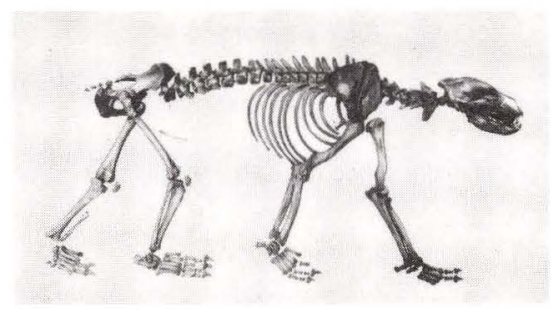

31. An extremely well-preserved bear skeleton from the Hazel-Pine period, found on Røsnæs. (U. Møhl).

being formed. The Dryas flora too certainly first and foremost disappeared because of the forest's shade, but some species probably held out for a time in special habitats.

\section{The animal life of} the birch-pine forest

A thorough-going change in the mammal fauna occurred at the transition between the Late-Glacial and the PostGlacial period. The reindeer disappeared; whilst no less than 32 finds are known from the Younger Dryas time, not a single one is known from the Post-Glacial period. One would expect that reindeer could have adjusted to the conditions in the light birch-pine forests, but perhaps the suddenness with which the warm period set in drove it out, since reindeer are thought to be sensitive to warmth. The wild horse occurred in the transition zone between the Late-Glacial and Post-Glacial periods, and since a horse has been found in layers from the Pine-Hazel period it seems certain that the horse was present right through the Birch-Pine period, even though it may have been rare. Only one find of bison is available from this period and this species is completely absent in the rich bone material of later times. It was replaced by the aurochs, which together with the elk made up the big game of the 
Birch-Pine period. As in the Allerød period, the brown bear was the largest carnivore.

These are the documented finds of Danish mammals from the Birch-Pine period; but the animal life was richer than they would seem to suggest. Red deer was the most important prey in a Holstein and in an English hunter dwelling site from that period, and the deer must naturally also have lived here, but the Danish red deer material found in bogs has not yet been examined geologically. The sparseness of finds is also due to the fact that no bones exist in the few known Danish Pre-Boreal dwelling sites, since these lay beside lakes with lime-free deposits in which bones are not preserved.

\section{The hunters of the Birch-Pine period}

The change from the open, ice-age

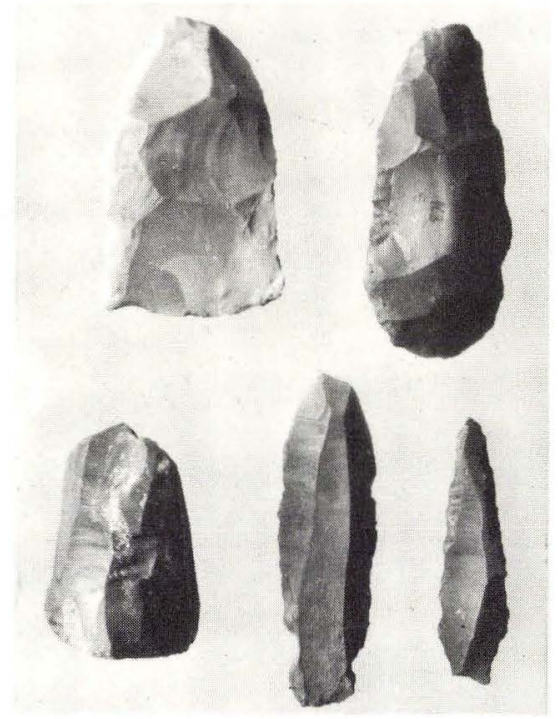

32. Flint tools from the Klosterlund culture. Above are a flake axe and (to the right) a core axe. These are the first axes known from Scandinavia which are suitable for tree-felling. Below are various types of scrapers. (Nat. Mus.). landscape to the continuous, closed forest was so decisive that it must have affected the hunters' way of life deeply. Whilst earlier it had been possible to roam around the open country and follow the wanderings of the game, the forest now was a hindrance. As did the game, the hunters became more localized, and they had to learn to adapt to the new living conditions. The forest was the great challenge; it demanded inventiveness. The first result was a new tool: the flint axe. With this one could chop down trees to create openings in the forest, or branches to make a platform on the damp lake margin, as can be seen in the Star Carr dwelling site, see below.

The oldest flint axes in Scandinavia are associated with the Klosterlund culture demonstrated by archaeologist Therkel Mathiassen, and named from a dwelling site at Klosterlund near Lake Bølling; the culture is dated to the close of the Birch-Pine period. The older dwelling sites beside the former Lake Draved south of Løgumkloster are of the same age and also have axes of an extremely primitive type.

Information on the game animals can only be obtained from one corresponding English dwelling site with the good Danish name of Star Carr (Starkær). Reindeer bones are absent; after red deer, aurochs was the most important game, with elk, roe deer and wild boar next in succession. Beaver, wolf, badger, fox, marten, hare and hedgehog have also been identified. Among birds, crane, white stork, grebe, merganser, and plover are worthy of mention. The most interesting fact, however, is that at this dwelling site we find the $\mathrm{dog}$, the oldest domesticated animal in Northern Europe, for the first time. The hunters of the Ice Age did not have dogs.

We do possess one find in Denmark, 


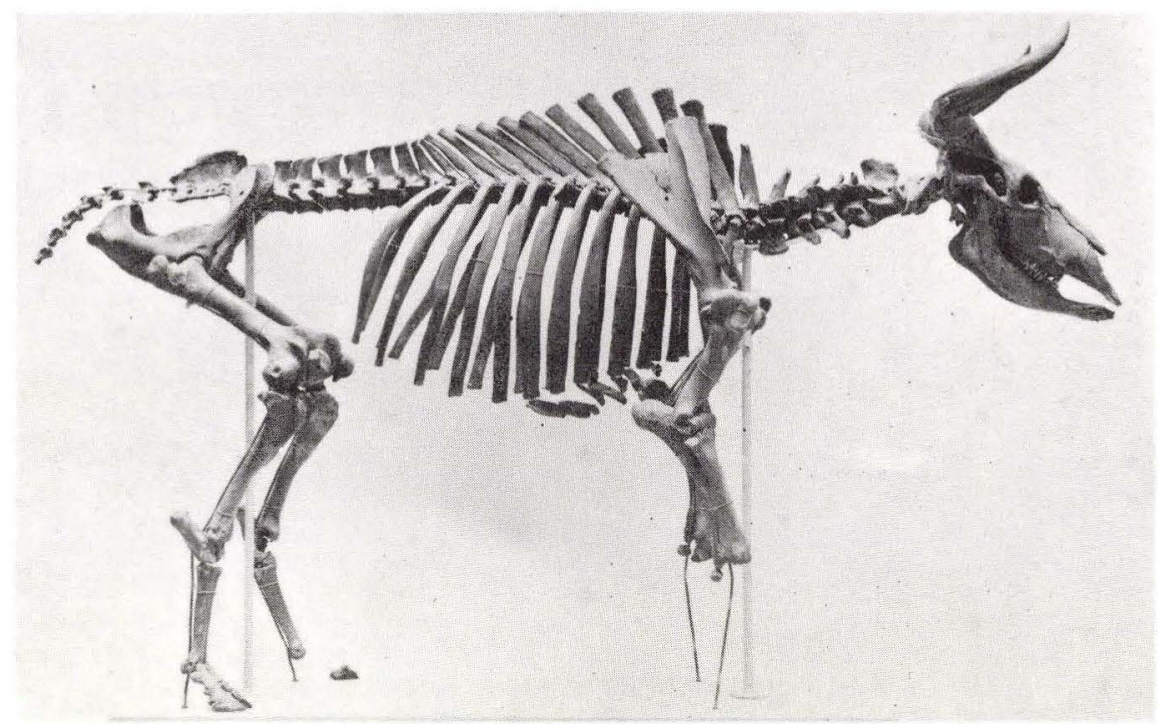

33. The magnificent Pre-Boreal aurochs skeleton found in Vig Bog in Odsherred. Two flint arrowheads of the Klosterlund variety lay in the chest cavity; moreover, two flint arrowtips were found in the ribbones and one of them was overgrown with bone. The wound had healed. (U. Møhl).

however, which as if in a glimpse lights up a hunting scene from the Pre-Boreal period. In Vig Bog in Odsherred a complete aurochs skeleton, fig. 33, was found, with two flint arrowheads of the Klosterlund type in the chest cavity. Moreover, flint tips had penetrated into two of the ribs, one of them grown over with bone material - the wound had healed itself. The animal had thus twice been exposed to the attacks of hunters.

\section{The earliest history of the Baltic Sea}

When the ice withdrew from the southern Baltic Sea basin, an enormous lake was formed, dammed up above sea-level, with an outlet either to the White Sea or else through the $\emptyset$ resund. Bornholm formed a bridge- head, connected to Germany, in this "Baltic Ice-lake" - see fig. 37. In the Younger Dryas period the Alvar of Öland emerged from the lake as a vast, flat limestone rock, washed clean by the waves. At this time the ice-lake was only separated from the sea to the west by the narrow mountain Billingen, and when the ice withdrew from Billingen's northern tip an enormous catastrophic draining occurred as a result of the ice-lake's higher waterlevel. This catastrophe can be recognized in the varved clay layers as a characteristic drainage varve. This varve has been dated by the Swedish varve chronology to 8,300 B.C., and marks the transition from the LateGlacial to the Post-Glacial period; it is in agreement with the C-14 datings of this transition.

The Baltic Sea thus became connected to the ocean, but because of 
the enormous quantities of meltwater it was nearly fresh for a few centuries more. This Baltic Ice-sea endured from $8,300-$ ca. 7,000 B.C. and is often somewhat misleadingly called the (Baltic) Yoldia sea - Portlandia (Yoldia) arctica only lived in the Stock- holm region during a very short interval (about 100 years), nearly 3,000 years after it had disappeared from the Northern Jutland coastal waters. The short appearance of this bivalve in mid-Sweden indicates how strongly the ice could cool the local seawater.

\section{The Hazel-Pine period, 7,000-6,000 B.C.}

During the long Birch-Pine period, not one tree species appeared which had not already grown in Denmark in the Allerød period. Later an eventful phase began, the so-called Boreal period, the Hazel-Pine period, in which all the tree species of the warm period immigrated and the forest succession began. The tree species arrived in a strange sequence, which did not correspond to their warmth-requirements as one would have expected, neither did it correspond to the order in which they immigrated during the last Interglacial for example. The sequence must be assumed to have been determined by the position of the trees' iceage refuges and by their rate of dispersal.

\section{The northward migration of the warmth-requiring tree species}

The ice-age refuges of the warmth-requiring tree species, as already mentioned, were situated as far south as in southern Spain, southern Italy, and the Balkan peninsula. In the Late-Glacial period these species migrated northwards from there and reached the great mountain chains from the Pyrenees to the Carpathians, which formed an effective barrier. Broadly speaking there were two routes of immigration to the north European lowlands, one south-westerly and one south-easterly.
The south-westerly immigration went chiefly through the narrow corridor from Spain to France between the Pyrenees and the Mediterranean Sea. The south-east French lowlands near the Mediterranean were so mild that the warmth-requiring trees could use them as a resting stage in the LateGlacial period from which to spread northwards in the Pre-Boreal. Pollen diagrams show that oak was the first to enter the warm Rhône valley in the Late-Glacial, followed shortly afterwards by elm and hazel; however, these trees were not common until the Pre-Boreal period. Lime and especially alder immigrated much later in the Post-Glacial, and beech and hornbeam came even later.

The south-easterly immigration from the Balkan refuges was probably the most important. Pollen diagrams from Jugoslavia show that oak, elm, lime and hazel arrived here simultaneously; spruce came earlier whilst beech and especially hornbeam arrived a little later. From here the way was open to south-west Poland through the passage between the Sudety-mountains and the Carpathians, and to southern Germany through the Danube valley. In both places the warmthrequiring tree species arrived nearly simultaneously, apart from beech and hornbeam, but elm had a slight lead in Poland. 
The diagrams from warm southern Switzerland at the foot of the Alps are very interesting; here oak, elm and lime immigrated simultaneously. Hazel arrived later than the other warmthrequiring trees and there was no $\mathrm{Ha}$ zel-Pine period. Spruce, silver fir, and beech were even more delayed, but upon their arrival caused a total alteration of the mountain forest belts.

\section{The immigration and dispersal of hazel}

As we have mentioned, elm, hazel, oak and lime reached southern Poland and South Germany at the beginning of the Post-Glacial period, and the same tree species, with the exception of lime, had arrived in southern France at a still earlier point of time. On their way northwards hazel outpaced the other tree species in northwest Europe and thus became the first shade-tree to arrive in Denmark and Scania; similarly it was first to reach the British Isles by the western route, whilst lime lagged behind. Since lime, like alder, came from the south-east, the delay was not so great in southeast Denmark, but it was far greater in Mid-Sweden, Norway, and England. Spruce, beech, and hornbeam could not keep pace at all with the others; they were absent in the north for purely immigration-historical reasons, but soil conditions may have slowed down the dispersal rate of spruce in particular.

As the first arrival, hazel spread so rapidly that it soon characterized the forest scene. The climate must have been especially favourable to hazel, likewise the soil in most places; mull must have developed nearly everywhere. But the great expansion of hazel was first and foremost due to the fact that at first it had no serious competitors. Being a shade-tree, hazel thrives excellently in the moderate shade of a forest of such pronounced light-trees as birch, pine, and aspen. The pollen production of hazel is poor, however, when it forms an underwood. The "tail" of low pollen percentages which one usually finds before the steep rise in the hazel curve probably signifies that hazel was already common, but was shaded by the other trees. The steep rise in the curve is a sure sign that the shading high forest had disappeared.

\section{The competition of hazel with birch and pine}

Birch and pine cannot rejuvenate under a thick underwood of hazel. Birch has a shorter lifespan than pine, not much more than 100 years, and one can understand very well the fact that birch was the first tree to succumb; pine was then also forced to give way on good soil - see fig. 34. In poor sandy areas and on bed-rock, pine was able to hold its ground - in fact, pollen diagrams show that the pine forests achieved their greatest extent in the first half of this period. Hazel does not thrive so well on poor sandy ground, and does not grow so densely as to prevent the regeneration of pine.

Nor was pine threatened by hazel on peaty soil or even on very moist ground, for example along flat lake shores, but on the common good mull pine had as little chance as birch of holding out for any length of time against hazel under the existing climatic conditions.

\section{Elm, oak, ash, and lime immigrate}

Hazel had no difficulty in establishing itself, because other shade-trees were lacking. When these at length arrived, the space was already filled by another shade-tree, and even though they could eventually grow up over the ha- 


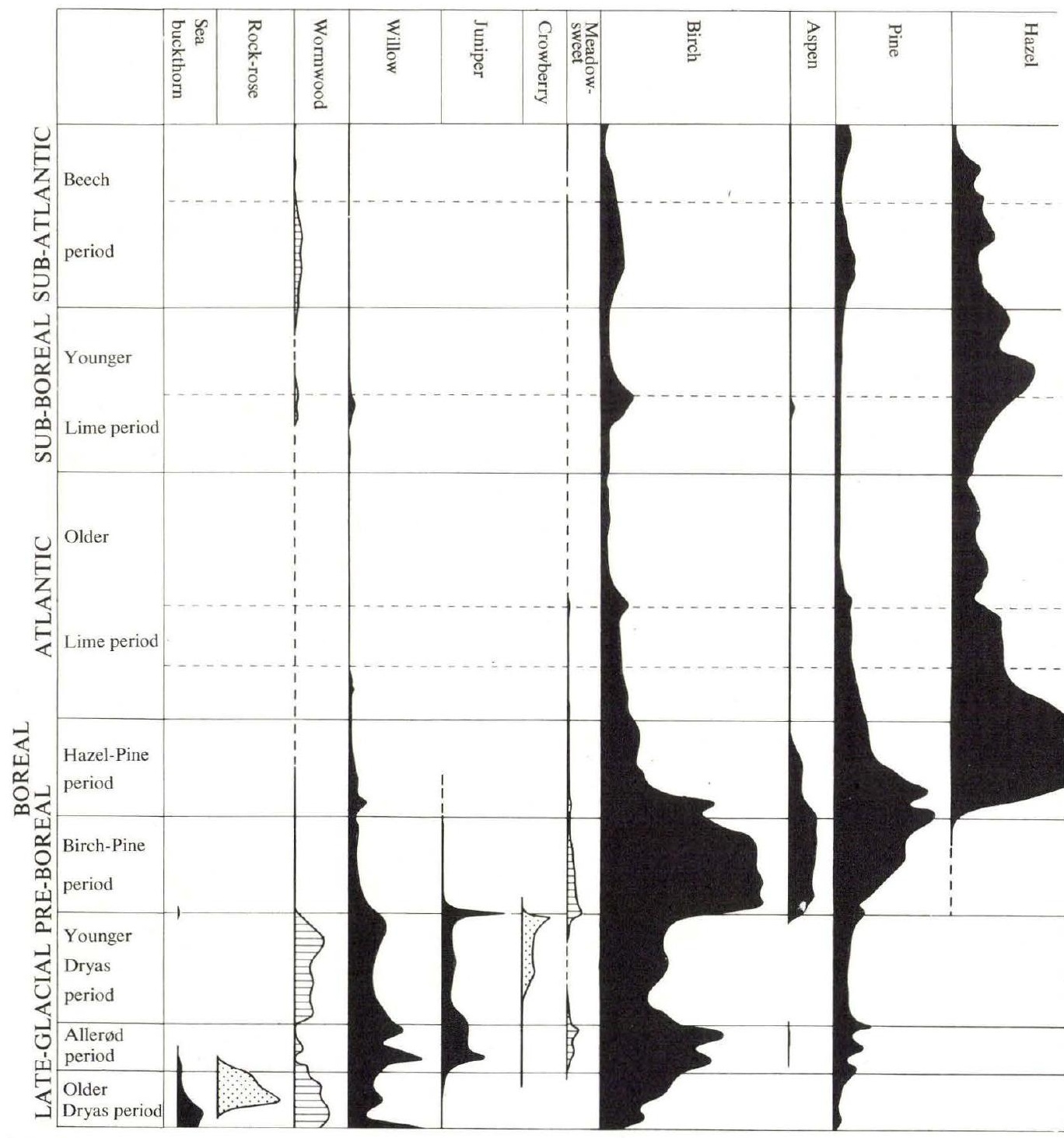

34. Pollen diagram from eastern Denmark, composed from diagrams of Svend Jørgensen, H. Krog, V. Mikkelsen, and others. Silhouettes of trees and shrubs are black, dwarf shrubs dotted and herbaceous plants lined. Certain considerations of the pollen pro- 


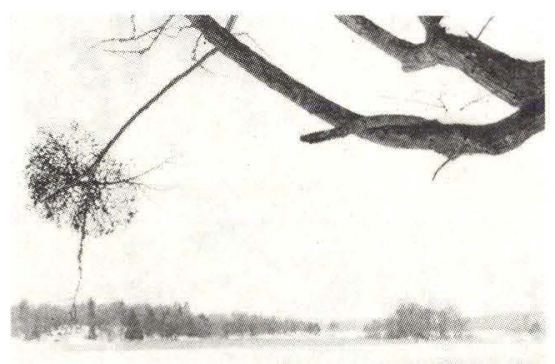

35. Picture of mistletoe growing on a lime tree on one of the warm Mälar islands in Sweden. (From B. Walldén).

zel and then strangle it, this took time. Elm arrived quite soon after hazel and perhaps still had a possibility of finding unoccupied spaces. It was more difficult for oak, which is moreover more light-requiring than hazel. Alder came late but had easier conditions; in its special habitat on wet ground it is superior to all other species. Lime immigrated at about the same time as alder, yet a little later in North Jutland.

Special interest is attached to the immigration of ivy and mistletoe, which came before the arrival of alder and lime; it gives information as to the temperature conditions in the middle of the Boreal period. First, however, we must explain how the distributions of the tree species depend upon temperature.

\section{The significance of the temperature conditions}

Temperature influences tree distribution in many different ways; only direct observations in the field on the influence of favourable, and especially of unfavourable, temperature conditions on the performance of every single tree species can give a deeper understanding of their significance. In general, however, one can say that three factors in combination are deci- sive for the tree species' temperature limit to the north and east: the warmth of the summer, the length of the growth period, and extremely low winter temperatures.

The influence of the summer warmth and the length of the growth period are closely related, since a lower summer temperature can be offset by a longer growth period, and vice versa. This can be seen in the fact that the northern limits of trees in northern Europe lie along a slowly increasing summer temperature (for example July average temperature) from west (the British Isles) to east; thus the decreasing length of the growth season must be compensated by warmer summers.

There is no compensation for the third factor. One single winter night of extremely low temperature can destroy the vital cambium between a tree's bark and the wood, but the position of this critical minimum temperature, which can have such devastating results, is very different for the individual tree species. The temperature conditions throughout the year are thus of significance and the simplest expression for these is given by the mean temperature for the warmest and the coldest month respectively.

\section{The Post-Glacial warm period begins}

The immigration and flowering of ivy in the middle of the Hazel-Pine period shows that the winter temperature was about the same as today (January mean temperature not lower than about $-1{ }^{\circ} \mathrm{C}$ ). It is informative that mistletoe pollen is found before the immigration of elm and lime, both in south-western and in eastern Denmark. Mistletoe only produces a little pollen; moreover it disperses very poorly and always occurs extremely sparsely in sediments. The finds of 
mistletoe pollen therefore show that the species has established itself locally. The summers, even before the immigration of alder and lime, must accordingly have been warmer than today, for nowadays mistletoe only occurs wild in a few spots in the warmest south-eastern part of the country. This shows that alder and lime, which are less warmth-requiring than mistletoe, were only absent because of delayed immigration.

This fact is even more obvious in the Oslo area. The explanation is that ivy and mistletoe berries are eaten by certain birds during the spring migration; they do a good job of spreading the seeds, whereas lime, on the other hand, has a far less effective wind dispersal mechanism. Mistletoe and ivy are thus especially well-suited for delimiting the "Post-Glacial warm period".

The occurrence of the European pond tortoise, Emys orbicularis, is also a striking testimony to warmer climatic conditions. The oldest Danish finds dated by pollen analysis go back, like those of mistletoe, to the later half of the Boreal period, and show that the July temperature at that time was already at least $2^{\circ}$ higher than now. Warm summers are essential for the hatching of tortoise eggs, which are laid in small pits in dry, loose earth.

The winter temperature has no great importance since the pond tortoise lies buried in hibernation during this time. The present breeding range of the pond tortoise is in southern and eastern Europe; it occurs in northern France and West Germany only as an occasional visitor, never breeding there.

\section{A dry climate}

The Ice Age was, as already mentioned, characterised by a dry climate,

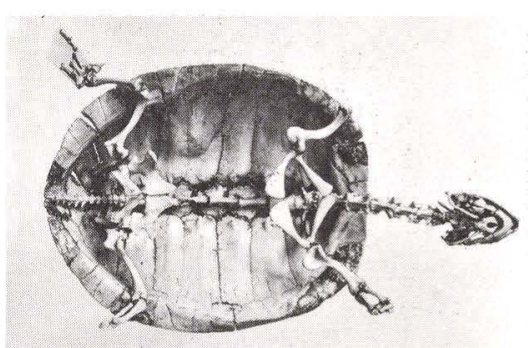

36. Pond tortoise found in a bog on Røsnæs. (D.G.U.).

and it is clear that already in the LateGlacial period there was a change towards increased humidity. In Denmark, however, the climate was still influenced by the fact that the country was continuous with southern Sweden and southern England, so that it was climatically somewhat more continental than it is today. A low waterlevel can be found in lakes both in England, Denmark, and further eastwards, exactly in the Late Boreal period. This in fact corresponds excellently with Blytt and Sernander's dry Boreal period (see p. 14) and was probably especially due to the temperature increase. It is possible, however, that other factors played a part; this complicated problem has not yet been solved.

\section{The channel between England and the continent}

The water-level of the oceans rose rapidly throughout the Pre-Boreal and Boreal periods, but North Jutland was now, like the rest of Denmark, raised above the sea, and the shoreline of that time lies everywhere below the present sea-level. The North Sea advanced from the north-west, however, across the broad land bridge between England and Jutland, whilst south of England an arm of the sea stretched increasingly further eastwards until it became united with the North Sea. 

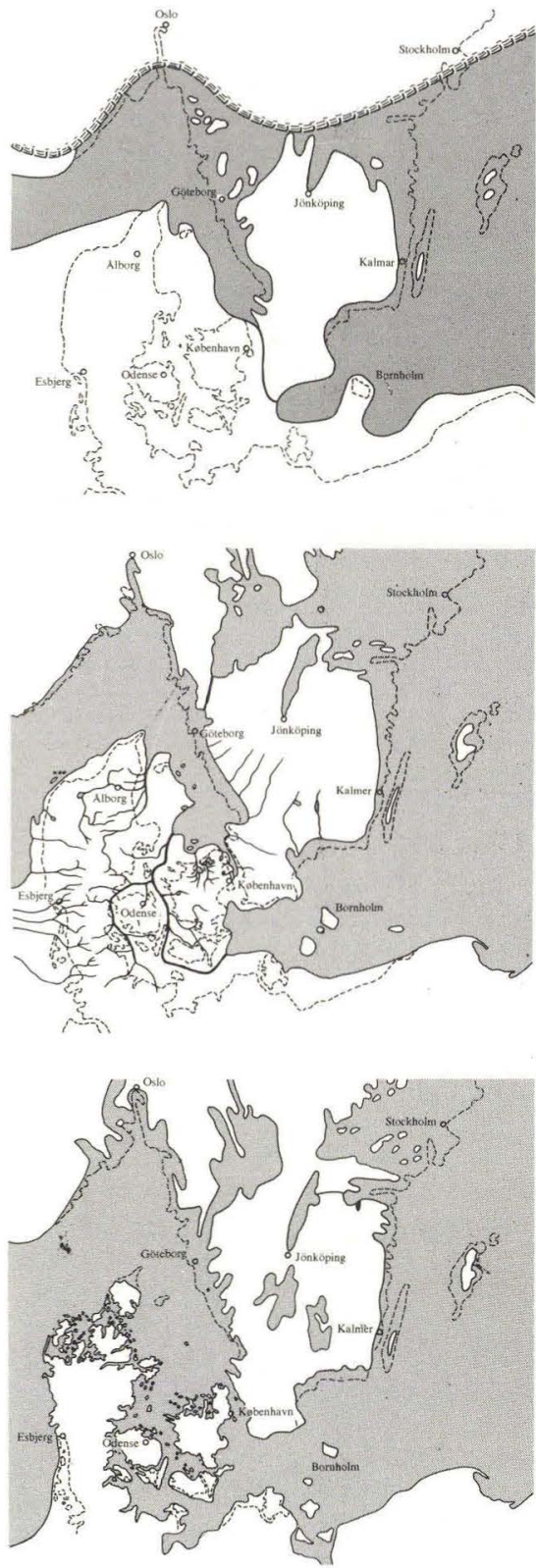

37. The history of the Baltic. Top: the final stage of the Baltic ice-lake, 8,300 B.C.. Middle: the Ancylus lake, 6,500 B.C.. Bottom: the Litorina sea, 4,500 B.C. (From Erik Fromm and V. Nordmann).
The Channel was formed and broke the connection between England and the continent.

\section{The Baltic Sea becomes fresh again}

Central Sweden rose rapidly, and at the transition between the Pre-Boreal and the Boreal period (ca. 7,000 B.C.) the threshold in the sound between the Skagerrak and the Baltic Ice-sea rose above sea-level. The Baltic once more became an inland lake, called the Ancylus Lake after the little snail Ancylus fluviatilis which could now be found in its sediments. To begin with, the Ancylus Lake drained across the mid-Swedish threshold, "Svea Elv", but the uneven upheaval of the land soon caused the water to rise over the Darser threshold south of Gedser, and the entire Baltic Sea then had its outflow through the "Dana Elv", which flowed as Europe's greatest river through the deep channel in the Great Belt. At the close of the Boreal period, or perhaps a little later, the rising of the sea resulted in the penetration of brackish water in through the Great Belt channel, but the outwards flow of freshwater was so strong and the channel so narrow that several centuries went by before the influx of salt water could really be noticed in the Baltic Sea.

\section{The animal life of the pine-hazel forest}

In comparison with the extremely sparse bone finds from the definitely game-rich Birch-Pine period, the bone material from the Pine-Hazel period may seem overwhelmingly rich, thanks to the dwelling sites of the Maglemose culture. Through the thorough investigations of the zoologists Herluf Winge and Magnus Degerb $\phi l$ an intimate knowledge of the higher animal life of that time has been obtained. 
The animals of the open landscape had almost totally disappeared; one solitary bone of a horse and of a hare are the only traces from the dwelling sites. The great meat-animals, aurochs and elk, were still frequent but they were soon to become rarities. The typical forest animals, red deer, roe deer, and wild boar were common the latter two are found for the first time in Denmark in this period. Among beasts of prey, bears and wolves are old acquaintances, whilst badger, fox, wild cat, pine marten, and polecat are new arrivals; to these can also be added lynx, of which finds have been made at the transition to the next period.

Among smaller animals there are, as one might expect, almost no finds in the dwelling site deposits; they were not regarded as game, and only hedgehog and squirrel have been found. One can probably assume that squirrels had golden days among the nutgroves, even though the pine martens certainly did their best to hold the population down to a reasonable size. For the sake of completeness we can also mention shrew and vole.

The bird life was no less rich. Capercaillie and black woodpecker must be mentioned first: stately characteristic birds of the pine forest which had its greatest extent in this period and then succumbed. The jay occurred just as commonly in the deciduous forest, especially when there were nuts and acorns to be found, and it must have contributed to a high degree to the dispersal of hazel and oak. Cranes and black storks frequented open swampy areas in the forest.

Birds of prey were not lacking: white-tailed eagle, osprey, and kite have been found at the dwelling sites. But of small birds we know nothing; the hunters left them in peace.

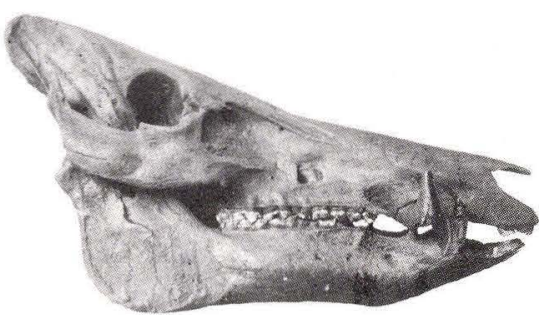

38. Skull of a wild boar, one of the typical forest animals of the Hazel-Pine period. The skull was found in Grønsø Bog, south-east of Slagelse. (D.G.U.).

\section{The animal life of the lakes}

A rich life was also found in the lakes; beaver built lodges and otter swam about after fish. Cormorants, too, took their share of the fish population, and likewise herons which stood post-like by the shore, watching for prey. The bittern hid itself during the day in the reeds and at night the booming of the male broke the stillness.

There was a multitude of ducks. Most stately were the mute swan and the grey lag goose, whilst a whole series of duck species has been demonstrated: mallard, pintail, tufted, longtailed, goosander, and others. Besides these, black-throated diver, great crested grebe, and moorhen also occurred, and the black-headed gull frequented the lakes too.

Finds of fish remains are surprisingly scarce in the dwelling site layers only the large fish seem to have interested the hunters. Pike is known from many dwelling sites and perch has been found. There is special interest attached to the catfish, Silurus glanis, partly because of its size - it can today grow up to 4-5 meters long and partly because it is a warmth-loving species which to-day has its main area of distribution in south-eastern Europe. A pollen-analysed find from 
Funen dates it to a late phase of the Pine-Hazel period. It had undoubtedly immigrated through the still fresh Baltic (the Ancylus Lake) perhaps together with the pond tortoise, mentioned previously. Bones of catfish have also been found in connection with dwelling sites from a late phase of the Maglemose culture. The remarkable occurrence of catfish in Sor $\varnothing$ Lake right up until 1799 must presumably be regarded as a relic from the warm period.

The nearness of the Ancylus Lake can be traced in dwelling site finds by the occurrence of grey seal and great black-backed gull. We know that grey seal lived in this enormous inland sea from Swedish finds, which among other things also include the fishes whitefish, Coregonus lavaretus, burbot, Lota vulgaris, and some roach species; these consequently must also have lived near the Danish Ancylus Lake coast, which around Bornholm and Møns Klint lay near to the present coast-line - see fig. 37 .

\section{The discovery of the Maglemose culture}

As we have seen, only flint tools are known from the Late-Glacial and PreBoreal dwelling sites in Denmark; none of the associated fine tools of bone and horn which appeal so greatly to our imagination and aesthetic sense have been found. They occur only as isolated finds unconnected with their surroundings, but ancient dwelling sites with bones and bone tools must undoubtedly lie preserved in the bog deposits of chalky districts, awaiting a lucky discoverer. Up to now, however, the Maglemose culture is the earliest culture stage to stand clearly illuminated in all its facets by Danish finds. This culture, which was widespread over northern Europe, is named after
Maglemose near Mullerup in West Zealand, where the first dwelling site of this type was discovered.

It began like an adventure; two small girls one day found some "crochet-hooks" of bone. They showed them to the schoolteacher in Mullerup, M. J. Mathiassen, who was no ordinary man, and who immediately perceived the nature and significance of the discovery. Helped by his pupils he carried out the first excavation; bone and flint tools as well as bones of all sorts of animals came to the light of day. Matthiassen immediately informed the National Museum of the discovery, and a few years later the dwelling site became internationally renowned through the work of the archaeologist and botanist Georg $\mathrm{Sa}$ rauw: "A Stone-Age Dwelling Site in Maglemose near Mullerup" (1903).

\section{The Maglemose people as hunters}

It is clear from the finds that the dwelling sites at Maglemose and the other Zealand bogs where similar finds have been made, (Sværdborg, Holmegård, Store Åmose, and others) were inhabited by hunters. The children's "crochet-hooks" were used as fishing spears, probably to spear pike; hooks and nets were also used. Finds of paddles presuppose the use of boats. Hunting, however, was more important, and here the chief weapon was the bow and arrow. We even have one find of a bow $1 \frac{1}{2}$ meters long, fashioned of elm-wood, which after yew is the most suitable wood for a bow; arrows have also been found. Numerous deer-antler axes have come to light, some with a recess for an edge of flint, etc. The game which these people hunted has already been discussed. The great variety is characteristic; they did not specialize in a single type of animal as did the reindeer 
hunters. Dogs were the only domesticated animals.

Discoveries in Åmose have shown how the summer dwelling sites were constructed. Large pieces of pine or birch bark were laid on floating peat islands to form a floor layer for a tent or hut of ground area 4-5 meters by 6-7 meters. It was a truly well concealed and protected site for the hunters.

\section{The significance of the hazel forest for the Maglemose culture}

It can, however, be questioned whether hunting and fishing were the chief occupations of the Maglemose people. The numerous bone tools and animal remains must not cause us to overlook the tremendous importance of nuts as source of supply. We must remember that these people lived in a time of endless nut groves, a Garden of Eden where one could reap without having sown. Even those hunting sites, which were only occupied in summertime and where nutshells often form complete layers, are evidence of the significance of nuts as a source of nourishment. Since the hazel forest enjoyed the full sunlight, it bore a rich crop, so there must have been unlimited quantities of nuts - for once we can say that there was food in abundance for the whole population! Hazel nuts are not only delicious but are at the same time extremely nutritious, rich as they are in fatty oils. Obviously these people would collect great quantities of hazelnuts; they would not need to learn that from the squirrels and jays. Naturally, they could also have collected other types of vegetable food: berries and other fruits, seeds (in one of the dwelling sites a great mass of the nutritious seeds of the yellow water-lily was found), roots, and so on - but these were only of

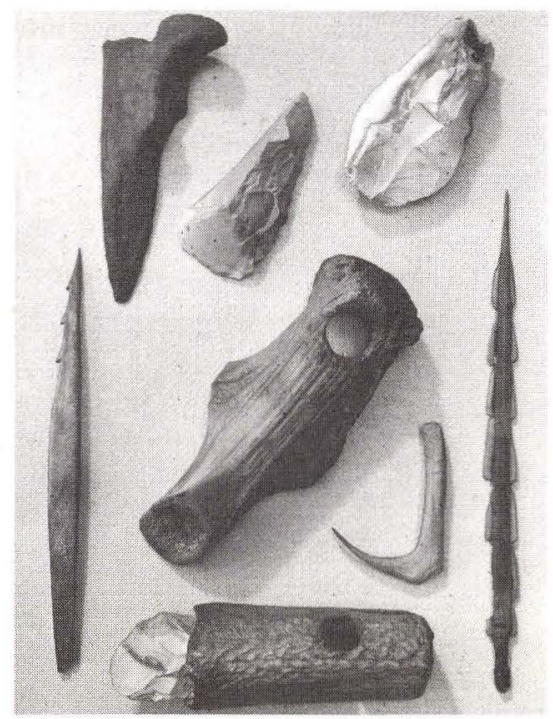

39. Implements from the Maglemose culture. Extreme left a fishing lure, on the right a flint-tipped spear, both of bone. Also shown are 2 deer-antler axes, a fishhook of bone, a bone dagger and two flint axes (Nat. Mus.).

importance as a change in diet and as a vitamin source.

Apart from the already mentioned rich dwelling sites of Zealand, dated to the Boreal period by pollen analysis, we know of many others, including the "Gudenå dwelling sites" in Jutland. However, only a few of these have been dated by pollen analysis, (for example the aberrant "Kongemose culture" in Åmose and a couple of Gudenå dwelling sites in Jutland), and no bone tools or animal bones are preserved from the Jutland sites. Even so, everything seems to indicate that the immigration of hazel to Denmark brought about a cultural blossoming, even though the quantity of game cannot have been increased - more probably the opposite. We must assume that the great hazel forests formed the ecological foundation for 
the great blossoming of the Maglemose culture. It is a well-known biological rule that an increase in food supply always leads to an increase in the number of consumers - the reverse being equally true. This rule holds for primitive man just as well as for animals.

\section{The possible immigration of hazel with man}

It would also be a reasonable guess that the rapid immigration of hazel, compared with the late immigration in the interglacial periods (see Danmarks Natur, vol. 1, Glacialer og interglacialer), was due to dispersal by man. Thus the two oldest Jutland dwelling sites dated by pollen analysis characteristically coincide with (Klosterlund) or begin with (Draved) the first faint occurrences of hazel in the diagrams. According to C-14 dating it appears that the immigration of hazel to the Great Belt area occurred a few

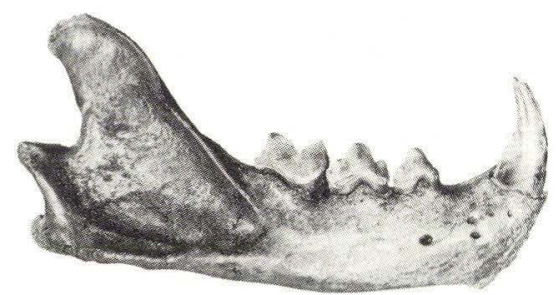

40. Lower jaw of a lynx from a bog near Lejre. The animal derives from the Hazel-Pine period. (U. Møhl).

centuries earlier than in south-west Jutland. Perhaps hazel came to eastern Denmark from the south together with man via the rivers Oder and Weichsel and further through Dana Elv. We have evidence of the use of boats right from the first beginning of the Maglemose culture.

This is only a hypothesis for the time being, however; there are too few certain C-14 datings to build on.

\section{The Older Lime period, 6,000-3,000 B.C.}

When Steenstrup proposed the Oak and Alder periods, the two important shade-trees, lime and beech, had not yet been discovered in our bogs. Beech was first found as a fossil in the year 1873 by the botanist Emil Chr. Hansen, later renowned as a fermentation physiologist; he also demonstrated the common occurrence of fossil remains of lime. The unfortunate name "Alder period" was altered to Beech period, whilst the Oak period retained its name for the time being. When it later became clear from pollen analysis that elm and ash, as well as oak and lime, had played a part during the Post-Glacial warm period, it came to be referred to as the Mixed Oak Forest period. This name is clumsy and presupposes that the four mentioned tree species grew together, with oak as the dominating tree. This was in fact not the case, and there are good reasons to abandon this lengthy term and to replace it by Lime period. As we shall see, lime was the most characteristic tree of this period, and it was also the dominant tree species of the primeval forest on the common mull soil.

The Lime period lasted for several thousand years, and it can be divided into two well-defined sections: the Older Lime period (Atlantic period), where natural factors prevailed, and 
the Younger Lime period (Sub-Boreal period), where the farmers of first the Stone age and later the Bronze age altered the forest scene to an increasing degree by clearance and cattlegrazing.

\section{The stable primeval forest arises}

All the tree species of the warm period had arrived one by one during the Boreal period, but the natural balance between them had not yet been established. The first phase of the Lime period was characterized by great competition between the tree species.

\section{The competition between}

\section{the tree species}

What does this word competition signify? We hear not infrequently of the struggle between the tree species, with the struggle of beech against oak as a classic example, and now and then this is even cited as an example of the cruelty of nature. In order to avoid such misunderstandings it will perhaps be appropriate to recall that the word struggle implies a conscious, active process, which one cannot ascribe to plants. The competition of trees for Inght is based purely and simply on the fact that their shoots develop in light and are repressed in shade. It makes no difference whether the shade is due to more vigorous branches of the same individual at a higher level, or is caused by the passive development of other individuals or species. The competition between shoots, branches, individuals, and species is one of the many factors that create and maintain the highly complex but perfectly functioning "ecosystem" of a forest. Ecosystems together with competition and its significance are fully described in Danmarks Natur volume 2.

In Denmark only a few tree species took part in the competition that determined the course of the PostGlacial forest development - a development which had as great a significance for the other terrestrial plants and animals as for mankind. Information about the requirements of these tree species with regard to the environment is necessary for an understanding of the role they played in the drama of forest history, both before and after man intervened as a new and decisive factor.

\section{Pioneer trees and climax trees}

The various tree species are variously equipped for the competition, depending upon which place they occupy in the building up and the maintenance of the ecosystem. In this way we can distinguish between two types of tree species: pioneer trees and climax trees, which are naturally connected by transition types.

Pioneer trees have a rapid turnover. They are usually distinguished by their rapid growth during youth; they set fruit at an early age, and they also have an efficient seed dispersal, even over longer distances. On the other hand, they are light-requiring and do not normally achieve a very great age. They are often very modest in their demands as to climate and soil.

Climax trees are slow but strong and tough. Their growth-rate is relatively low during youth; when they grow up together with pioneer trees the latter quickly outgrow them. But they tolerate shade and are not strangled in the light pioneer forest. When the pioneer trees die of age, the equally old climax trees are scarcely yet fullgrown; those which have been repressed by the shade quickly shoot up, 
whilst those which had already reached the crown canopy spread out to the sides.

Climax trees begin to set fruit at a late stage; the seeds are large enough to contain a rich food reserve which enables the seedlings to form leaves and proper roots even in shade. Their seed dispersal on the other hand is usually very inefficient and their speed of migration is low. Climax trees are demanding in their soil requirements, especially with regard to humus content.

\section{The fate of the pioneer trees in the Lime period}

The Pre-Boreal forest was characterized by pioneer trees with high lightrequirements: birch, silver birch, aspen, species of rowan and willow, together with pine. None of them could hold their ground in the long run against the advancing climax trees. Even the low shade-tree, hazel, was able, as we have seen, to suppress the light-trees in most of the habitats.

Pine and birch were still dominant as mentioned on the very damp ground, but when alder immigrated it forced them back everywhere where the ground was not too poor. On poor and dry sandy ground in Jutland the pine forest seems to have persisted until it was suppressed in the competition with oak, probably sessile oak, and lime.

There were now only the forest margins along the lakes and fjords left for the most light-demanding trees. Although they were here crowded between oak and other trees above and hazel below, there was still abundant light from the water side. Birch and pine could still survive on the poor boggy ground where alder did not thrive, but the bog pines were low and stunted and did not flower.
One cannot say that the pioneer trees are more poorly equipped in the struggle for existence than the climax trees - they did best, in fact, to begin with, thanks to those qualities that make them pioneer trees. They are significant in Nature's housekeeping because they improve the environment, particularly the soil conditions, for the succeeding, more demanding, forest generations. Where climate and soil conditions are unfavourable, pioneer trees form stable communities; this is especially true of Scots pine, which, apart from its high light-requirement, has many qualities in common with the typical climax trees, and is thus a transitional type.

\section{Hazel is forced back}

The shade of a thick hazel scrub can help it to withstand the attack of other trees for a long time. Under natural conditions in a forest, hazel does not form many-stemmed bushes but usually one- or two-stemmed trees (10$12 \mathrm{~m}$. high). The life-span of the individual stems is only short, and their fall gives the competitors a chance to force their way in. Since hazel, however, has the ability to form quicklygrowing regenerative shoots from the base of the trunk, any growth of light trees will normally be stifled. The growth of shade-trees will probably be checked, but some will survive and then, at the next opportunity, shoot up above the hazels and gradually strangle them completely in their shade.

Since lime and hazel have the same demands as to soil fertility and moistness, it was chiefly lime which took over the hazel areas. It is clearly shown in the diagrams that the great fall in hazel coincides with the increase in lime.

Hazel continued to play a signifi- 
cant role in the forest margins along lakes and fjords, however, and also as a pioneer tree when gaps appeared in the primeval forest after the fall of old trees or tree-groups.

\section{The tree species of the primeval forest}

\section{Lime - the primeval forest's commonest tree}

The dominance of lime in the PostGlacial warm period has only lately been realized. Examinations of peatbogs can easily give an exaggerated impression of the significance of oak, since the natural habitat of common oak includes exactly this low, peaty ground on the borders of bogs and lakes. Lime, on the other hand, belongs like beech to the normal high ground, where plant remains are rapidly broken down. In lake deposits from the warm period the fruits and leaves, etc. of lime are more common than the fossils of any other highground forest tree. At the same time, lime pollen occurs regularly in significant percentages, despite the fact that lime flowers are pollinated by insects and thus do not disperse the pollen so effectively as the other common forest trees, which have flowers specialized for wind-pollination. In addition, new investigations by Svend Th. Andersen have shown that lime in dense forests has a low pollen production whilst the pollen production by oak is very high. In other words, lime was much more frequent and oak was much more scarce than the pollen diagrams would appear to suggest. From this we may draw the conclusion that lime was the dominating tree in the primeval forest of the Atlantic period.

The lime forest consisted of smallleaved lime, Tilia cordata, but there

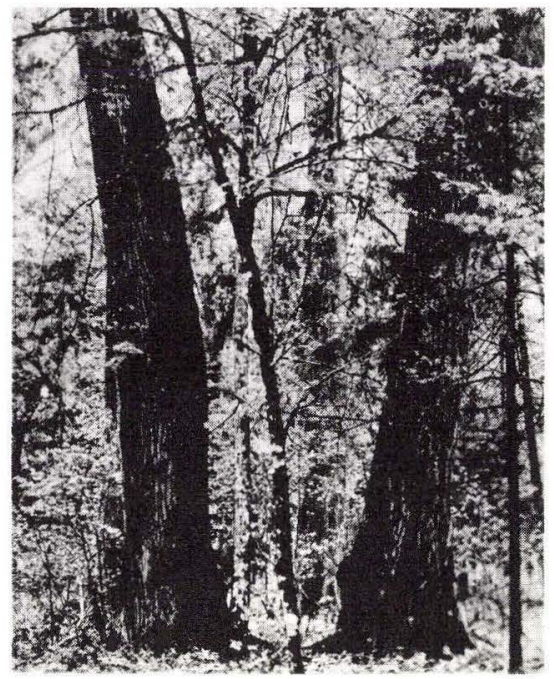

41. Primeval lime forest in the Bialowieza forest in East Poland. A young shaded lime can be seen between the two old limes. (Photo by J. J. Karpinski).

cannot be any doubt that broad-leaved lime, Tilia platyphylla, also grew in Denmark during the Atlantic period, even though we only have interglacial finds at present. This species has an even poorer pollen dispersal than its relative, but the presence of its pollen in small amounts has recently been demonstrated in English and south Swedish deposits from the Atlantic period.

\section{Lime as an example of a shade tree}

The wide distribution of small-leaved lime in the Post-Glacial warm period is explicable ecologically. Since its worst competitor, beech, was lacking, and both the climate and the soil at that time were favourable for lime, it was superior in ability to compete with the other forest trees on the normal ground. The light-trees, oak and ash, could not succeed against such a pronounced shade-tree as lime. If one 


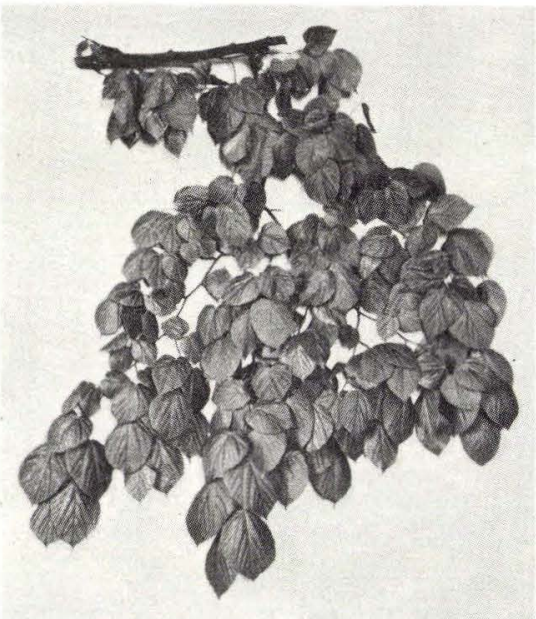

42. The leaf mosaic of the lime. Here, as with other shade-trees, all the leaves on the branch are arranged in one plane. (From P. Jaccard).

watches lime, oak and ash grow up together in a forest the difference is striking. The leaves in lime form a perfect mosaic, so that they do not shade each other, and the buds are in two rows; this results in flat branchsystems with all the leaves arranged in one plane, which is orientated with reference to the light. The young tree's vertical stem is elegantly curved at the tip so that the top shoot, so decisive for growth in height, has the most favourable light conditions in the shade of the forest. The next year the old top shoot straightens itself and the new top shoot gets the favoured position. The leaves are dark green, particularly suited to function in shade. But as soon as the lime reaches the full light in the tree-canopy, it forms another type of leaf - small, firm, blue-green "light leaves", adapted to the unfiltered sunlight.

All the typical deciduous shadetrees have a similar architecture with branches in flat plates and leaves in a mosaic, but in none of them is the structure so highly perfected as in the lime. These adaptations to life in the shade are almost totally lacking in the common oak. The leaves of a young ash growing up in a forest can tolerate shade well enough, but the whole architecture resembles that of a lighttree - the leaves shade each other. The result is that in the forest shade oak and ash thrive worse and worse the larger they grow, and finally they die. In lime and other shade-trees suppressed specimens become umbrellashaped when the light becomes too weak for continued growth in height; they are adapted to the shade and can vegetate for a long time. If the light is improved by the fall of a tree, new branches as straight as candles shoot upwards from the flat-topped suppressed individuals.

\section{The toughness of lime}

In the summer-warm parts of the country, lime is our toughest tree species. Like oak, it can reach a very great age because even ancient hollow limes are not attacked by deadly fungi or other diseases, as is the case with most tree species, such as beech for example. Lime can thus also survive all types of mechanical damage, caused for example by falling trees. And if it should happen that the lime itself is felled in a storm, it will often send up suckers from the roots, if these do not already occur around the base of the trunk; the suckers, aided by an efficient root system, can quickly grow up. Once a lime forest has established itself it is difficult for other tree species to displace it.

\section{Soil and climatic requirements of lime}

Small-leaved lime is more tolerant with respect to soil requirements than elm and ash. On the other hand lime 
is more demanding than oak and beech, and on very poor and dry sandy soil oak becomes its equal; if the sandy soil degenerates lime must give way completely, but it hardly came to this point during the Atlantic period. Lime can tolerate a slightly higher water-table than beech, but loses its fullness of leaf. The leaves become smaller and lighter, and common oak becomes first an equal and later, with increasing moistness, a superior competitor. Lime is also a climatically demanding tree species which only thrives if the summers are sufficiently warm. From the point of view of both climate and soil conditions, the Atlantic period was the best possible for the prosperity of lime.

\section{Elm characterizes the Atlantic period}

The pollen frequency of elm in contemporaneous deposits indicates that it too was a common forest tree during the Older Lime period. This wide distribution, followed by an abrupt decline on the boundary between the Atlantic and the Sub-Boreal periods, poses important and controversial problems. In order to illuminate these problems from all sides it is necessary to discuss in greater detail the three elm species, wych elm, Ulmus glabra, smooth elm, $U$. carpinifolia, and $U$. laevis, which certainly all grew here at that time. Unfortunately the fossil material does not give any information as to the relative frequencies, since no elm finds from the warm period have been determined to species with certainty.

\section{Wych elm}

One would be inclined at first sight to regard wych elm, Ulmus glabra, as the most important, because it is the only elm species which plays a part in our forests today. However, there is no connection between the elm population of the Atlantic period and that of the present forests. In the intervening thousands of years the elm has been almost totally eliminated by cattle and swine in the forests. When the forests became protected by law, wych elm was the only elm species that could spread successfully in the forest, partly from the few original remnants and partly from parks, etc. The climate had in the meantime become unfavourable for smooth elm and U.laevis, but not for wych elm, which is less warmth-demanding than the other tree species of the mixed oak forest, and which even in Germany grows chiefly in the mountains.

Pollen analysis cannot show whether wych elm was also the most important elm species in the forest of the Atlantic period, since wych elm pollen grains are intermediate between those of the other two elm species in shape and structure, and thus cannot be determined as to species. But the fact that carefully examined finds of charcoal and wood most resemble wych elm seems to strengthen the case, even though full certainty has not yet been attained in this difficult species determination.

Wych elm makes great demands as to soil, and grew on the best, slightly damp, mull. Here it had a keen competitor in the lime, which thrives on the same soil and was favoured by the warm climate. Wych elm, however, is the most pronounced shade-tree of the three elm species, and it probably had the advantage of being established in its habitat before the immigration of the lime.

Ulmus laevis and smooth elm, U. carpinifolia

In contrast to lime and wych elm, $U l$ mus glabra, Ulmus laevis and smooth 


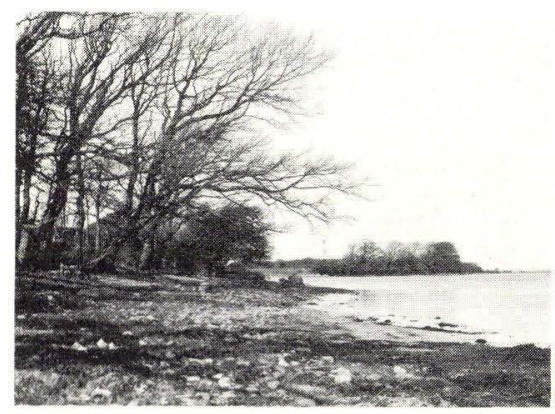

43. Smooth elms at Viksø (Guldborgsund). These are probably relics from the warm period. (D.G.U.).

elm, U. carpinifolia, can grow on wet soil: in fact unlike oak they can even tolerate a temporary flooding of the ground, since they possess a shallow root system which still functions during flooding as long as the water does not stagnate.

Ulmus laevis makes fewer demands as to soil fertility than do the other elm species, and can therefore grow in forest bogs. Its northern natural distribution limit today lies just south of the border to Germany, and it also grows wild, for example, in the border zone of a bog on Lolland.

Smooth elm, too, has undoubtedly made its contribution to the high pollen percentages of elm in the Atlantic period. The climate suited this warmth-requiring species and it is found, probably as a relic, in warm places in shore-scrub and on small islands. Its survival of the persecution from cattle and swine is probably due to its ability, unlike the other elm species, to form suckers which constantly renew the individual. It occurs as a forest-forming species in central and southern Europe along rivers and streams, but these flood plains are now rapidly disappearing throughout Europe as a result of cultural interfer- ence. In Denmark they were cleared long ago for meadow cultivation.

\section{The oaks}

Oak presents the same problem as elm: there are two closely related, but ecologically completely different oak species, the common stalked ("pedunculate") oak, Quercus robur, and the rare sessile oak, Quercus petraea. Unfortunately they can scarcely be distinguished from each other by the pollen. Steenstrup referred his bog finds to sessile oak, but Vaupell demonstrated the incorrectness of this species determination. In the Scandinavian countries only common oak has been found as fossil till now. This does not say very much, in fact, since species-determined oak remains are exeedingly few. Moreover, sessile oak does not grow in bogs. We have therefore no direct evidence concerning the distribution of the two species in the Post-Glacial period.

\section{Common or pedunculate oak}

The pedunculate oak is the common, well-known oak. Since it is a light-tree, it does not survive competition from the shade-trees where these find favourable conditions. Nevertheless, it is a climax tree which often dominates on moist but not completely wet ground. Only ash and alder thrive equally well in such places, and ash only on rich soil. The longer lifespan of oak, however, gives it an advantage in the long run, and this was especially the case in the Lime period, when its competitive powers were greater on account of the warmer climate. On the other hand we must remember that at that time Ulmus laevis and smooth elm were serious competitors in alluvial forests and in shore forests near lakes. 


\section{Sessile oak}

Sessile oak thrives on the drier sandy soil and on acid rocky terrain, but today it only grows in Jutland and on Bornholm. Its beautiful leaves are not randomly placed as in the common oak, but arranged in a mosaic. Sessile oak is thus somewhat better equipped for the competition for light. It can be assumed that it immigrated at the beginning of the Post-Glacial warm period, by the western route to Jutland and by the eastern route to Bornholm. Up to now, however, there have only been indirect indications of this in pollen diagrams. The climate must have been favourable for sessile oak in the Atlantic period, since the species has a westerly distribution.

Before man came and disturbed everything, it is unlikely that sessile oak and common oak grew together. Common oak belonged to the moist ground and found its best conditions on low clayey soil. Sessile oak, on the contrary, grew on the high, poor, sandy ground.

\section{The ash}

Ash played a completely subsidiary role in the first part of the Older Lime period, and became of great significance towards its end. It was presumably unable to find the right growing places when it arrived, or else they were occupied by elm and oak. Ash is quite a demanding tree species, but on fertile soil it grows up with such luxuriance that other tree species have difficulty in keeping up. As we have mentioned, ash is a light tree, especially in old age, and since it does not achieve a particularly great age it cannot compete with lime and wych elm in the long run. Ash can tolerate more dampness than these, however, and on wet but rich mineral soil along streams

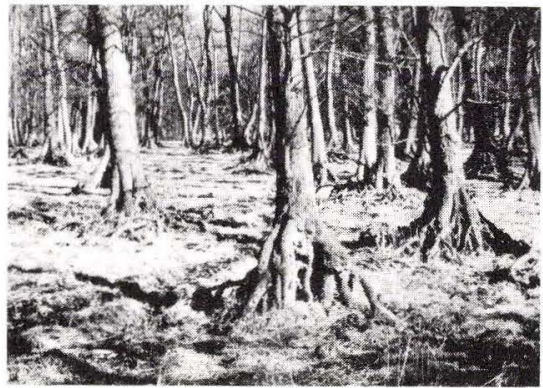

44. Alder-swamp forest. This type of forest was very important in prehistoric times. The contraction of the peat reveals the characteristic deeply penetrating root system of the alder in the foreground. (S. Sandermann Olsen).

and beside shallow lakes it cannot be displaced by another tree. The frequency of ash increases during the course of the Older Lime period, and we shall return to this later.

\section{The important role of alder in the past}

Alder, Alnus glutinosa, was in the past the most important tree beside our streams and lakes. Its pollen curve is essential to the understanding of climatically caused oscillations in the water-level of the lakes. Alder is our only tree species which can grow in places where all its roots are covered by water all the year round. Alder also has a greater need for moisture than any other Danish tree. It has deep penetrating roots which on lowlying soil can reach down below the ground water-table. These waterseekers make the alder independent of oscillations in the level of the watertable. Such oscillations are dangerous for the other tree species, because on low, occasionally wet ground they have all their roots in the uppermost soil layers, which can dry out completely in years of drought. Alder is 
a species with fairly high nutritional requirements; it does not thrive in acid bogs with thick deposits of peat.

\section{The stable primeval forest}

The competition between the tree species which immigrated during the Boreal period led during the first part of the Atlantic period to the establishment of climax forest, the stable primeval forest. The great succession came to an end, and whilst the lesser successions, occasioned by the fall of old tree groups, overgrowing at lake margins, etc., continued, the overall picture was not changed.

In the following section an outline is given of the Atlantic climax forest as a kind of synthesis of the previous sections, although in the full appreciation that this can only be a preliminary and tentative sketch. It is based on the presently available pollen-analytical and ecological data, and also to a considerable extent on the existing investigations and descriptions of the last widespread European primeval forests, which were still found at the beginning of this century in mountain areas in the Balkan peninsula. If special emphasis is placed on these forests it is due to the fact that only here can one be sure that such characteristics of tree species as exceptional longevity and tolerance for shade have had opportunity to exert their influence to the full. The special nature of the soil in the primeval forest and the scarcity of game are similarly of great importance since these have created ideal conditions for the renewal of the forests.

\section{The tree communities of the primeval forest}

The primeval forest covered the whole land with the exception of the many lakes and the somewhat scarcer bogs. It must be assumed that lime predominated on the general high ground, mingled with wych elm in richer places and with sessile oak on Jutland's poorer sandy hills. During regeneration of the forest hazel appeared as the pioneer. The forest was much more varied on moist mull with a relatively high groundwater-table: here it could be described as a mixedoak forest. Where it was even more damp, lime, wych elm, and hazel would be absent whilst common oak would still be present; alder would have appeared, and in rich soils as well as ash two further species of elm, $U l$ mus laevis and smooth elm, U. carpinifolia, were probably common. In the permanently wet fens with circulating water alder would be universal, and in poor deep peat bogs birch would have appeared as the only tree species.

This is just an outline of the types of forest; but what did the primeval forest look like, and what were conditions for the living of men and animals?

\section{The margin of the primeval forest}

If in the summer of the year 4,000 B.C. we made a visit to Denmark and approached the land from the sea, we would see the forest standing like a wall along the coast in varying shades of green according to the species of trees. Long before we reach the coast a fragrance greets us - a welcome from the blossoming lime forest.

In the thick forest margins there is a multitude of different trees and shrubs: towering dark green oak and elm beside lime which is closely covered with leaves right to the ground, and yellow with countless inflorescences bearing fragrant waxlike flowers. Norway maple stands more sparsely with its fresh green pointed leaves: 
there is also crab apple, holly, and presumably field maple, rather low trees all three, although taller than the hazel and hawthorn. Right at the foot of the forest edge, dogwood, buckthorn, spindle-tree and guelder rose also take their share of the life-giving sunlight.

\section{Ivy, honeysuckle and mistletoe}

Dark-leaved and tough ivy sets its mark on the forest margin in many places where it strangles its host's branches with its evergreen foliage and climbs to the top of even high trees. Like giant snakes the ivy trunks hang down from the trees, see fig. 45 . Honeysuckle, fragile and open-leaved, but no less dangerous, twists up small trees and shrubs and deforms their stems. Out in the light it decorates the forest margin with an abundance of strongly fragrant yellow and red trumpet-shaped tropical flowers which do justice to this, our only genuine liana - a term for a woody climbing plant. Mistletoe is also a northern representative of a tropical life-form, an evergreen parasite which completely avoids the competition for light: the sticky seeds, carried by birds, take root in the tree tops. Mistletoe is common on lime and other of its preferred host trees.

Elated by the rich pattern of trees, shrubs, and flowering plants on the shore's edge, by the humming of the insects in the tops of the lime trees, and by the fragrant air, we now leave the shore to get an impression of the interior of the primeval forest.

\section{The interior of the primeval forest}

When after some difficulty we have penetrated the thick undergrowth of the forest edge, the interior strikes us as a contrast: a world of naked trunks, thicker than those we are accustomed

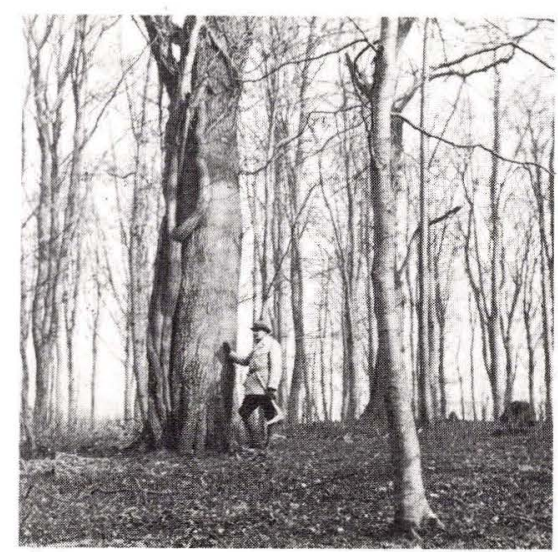

45. Oak tree with a large ivy stem which was killed in the winters of 1939-42. The picture was taken in a shore forest in South Zealand, where ivy is favoured by the mild climate. (D.G.U.).

to see today. There is no undergrowth. Young trees stand here and there in tight clusters, some of them dead or dying, others on the way up towards the opening in the tree canopy. Under such clusters of young trees it is even darker than usual. Some suppressed shade-trees also occur sparsely: their tops are flat and the height marks the moment at which a small hole in the canopy was closed by neighbouring trees. Now they vegetate through the decades, doggedly awaiting a new opportunity.

As we walk in the gloom of the primeval forest we feel as though we are cut off from life. It is because of the dead and dying young trees and the fallen, rotting old trunks among which we walk, whilst high up in the tree canopy life unfolds in its inaccessibility. The uniformity is tiring.

The vegetation of the forest floor is strikingly sparse. Wood sorrel and polypody grow on the old mouldering stems; dog's mercury and other low plants adapted to shade appear, but 
there are no flowers at this time of year to bring a little variety and colour.

\section{Renewal of the primeval forest}

The ground is soft to the tread, because of the decaying wood. This is a splendid rooting soil for renewal, but the deep shade and root competition from the trees exclude all rejuvenation. Only where a group of trees is declining due to age, is the shade a little reduced and root competition less severe. New trees begin to appear here, but soon the old trees are felled by a storm, and immediately there is enough light and nourishment: the undergrowth springs upwards. Smaller or larger green oases arise in this way, but they are of short duration and far apart. The young trees climb rapidly in height and become old.

There has been much discussion over the process of renewal in the primeval forest. Pollen analysis shows that the Danish Atlantic forest must have renewed itself in the same manner as that described by experts from the last South-East European primeval forests. It was not a process of cata- strophic renewal with a change in tree species, as is known to occur in coniferous regions and in cultivated forests.

The forest was stable, and new growth of the same tree species appeared upon the fall of old trees: pioneer tree species no longer appeared.

Hazel appears to have been an exception: it is a dogged shade-tree which could well have held the larger trees' reproduction in check for some time, but by virtue of its shade it only assisted in keeping light-loving trees out of the dark primeval forest.

\section{The animals and men of the primeval forest}

As indicated in the above sketch, there was not much food for mammals in the primeval forest. They had to wander around between the tree trunks and could not reach up to the greenery. It is also wellknown from the present day that primeval forests of shade trees are very poor in game. The rule does not hold, however, in the case of the wild boar, since these animals find most of their food by rooting in the forest floor for mast and acorns, roots, mice, and other ed-

Top: a picture of the little island Ormø in South Zealand. The island is overgrown by lime forest, and this spring picture can give an impression of what the primeval forest would have looked like, seen from the shore of a sheltered fjord. The lime forest is in bud, and in the forest margin on the left the gnarled and still bare branches of an oak can be seen sprawling out over the shore meadow. Near the shore, maple, crabbapple, ivy, hawthorn (completely green) and sloe (still brownish) extend in among the limes, which are covered with branches right to the feet of the trees.

Bottom left: Pine forest in the primeval Bialowieza forest in Poland. The forest grows on very poor ground. In the foreground two silver birches can be seen. (Photo by S. Th. Andersen).

Bottom right: Spring picture from Draved forest in southern Jutland. In the foreground mor with undecomposed beech and oak leaves is visible. Two strong beeches and a two-stemmed lime grow on the boundary with the moist mull with its fresh green growth of spring plants. Lime, oak, alder, and beech grow together here in a mixture, alder in particularly wet places, beech on small sand hillocks. A pollen diagram from the edge of the mor shows that the forest has had the same composition at this place for 4,000 years - apart from the immigration of beech 2,000 years ago. (Photo by Inger Brandt). 

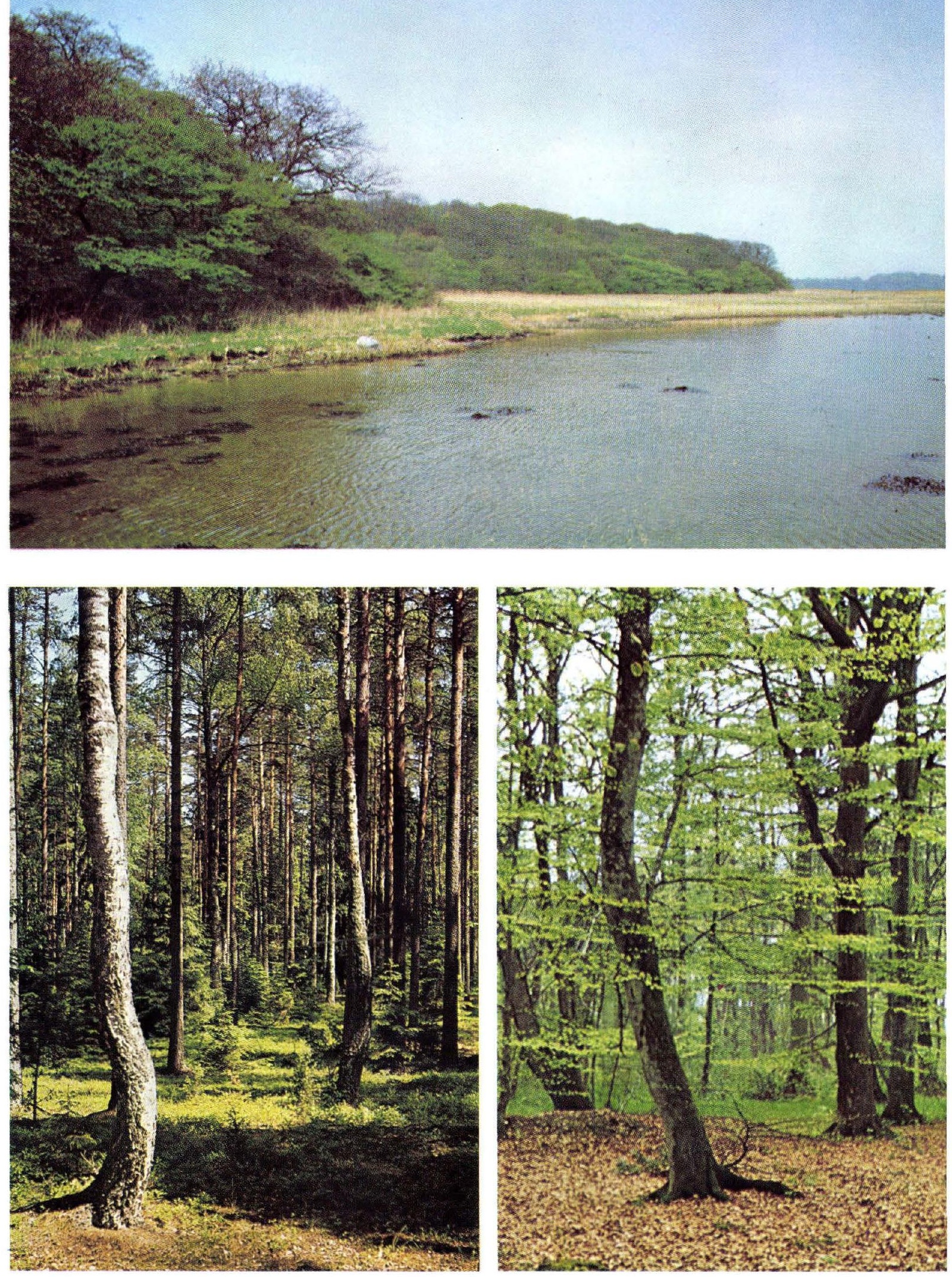
ible things. They can get along very well and are especially fond of moister ground with its oak trees. For other large mammals living conditions deteriorated, even though the same species as mentioned for the Hazel-Pine period lived on into the Lime period. On the Danish Islands, however, the aurochs and elk died out, but they survived in Jutland, perhaps because the forest was less dark in the poorer sand areas and along the larger streams. From here and from the south the population could be renewed after critical periods.

For man, too, the golden age was over. When the nut crop dwindled and the quantity of game decreased, the situation became critical for the Maglemose people, who had themselves contributed to the extinction of the two largest game animals in the Islands. The Maglemose culture seems not to have coped with the crisis, and apparently disappeared completely during the Atlantic period. The most numerous traces of men are now found along the Danish coasts, but these belong to a different culture, which the archaeologists connect with the already discussed Kongemose culture.

\section{The sea}

The oceans continued their rapid rise into the Atlantic period, since even though the ice had disappeared in Europe, a long time elapsed before the last ice-masses in Canada had also melted. Despite the continued uplifting of the previously ice-covered Scandinavia, the rise of the oceans was sufficiently great to cause the North Sea, Skagerrak, Kattegat, and the sounds to the Baltic to spread out over the surrounding land areas.
Oresund and the Belts are formed

Øresund and the Belts are key areas for an understanding of the history of the Baltic Sea, but unfortunately all the evidence concerning the early stages of the rise in sea-level (the transgression) here now lies hidden at the bottom of the present sea. Knowledge of the formation of $\emptyset$ resund and the Belts has thus been very incomplete. In order to make good this lack a few years ago the Danish Geological Survey began a systematic investigation of the problem, under the leadership of Harald Krog. By means of borings from a ship, submarine peat layers covered by deposits from the transgression have been discovered, and series of samples have been taken which can be dated from pollen diagrams and the C-14 method, whilst the diatom flora can also be studied. This flora gives the best information as to whether the samples were deposited in fresh, brackish, or salt water.

It appears from the preliminary results that in the year 6,600 B.C. a peat bog still existed in the middle of the Great Belt near the island of Sprog $\varnothing$, where the sea today is $30 \mathrm{~m}$. deep. Then the rising of the sea began in the Late Boreal period, although the water remained fresh right until the beginning of the Atlantic period. Seawater probably reached the Baltic Sea through the deep trench, however.

Towards the north and the east the Late Boreal rising of the sea can be traced at continually decreasing depths, as one might expect, and in northern Vendsyssel in fact it rose above the present sea-level. In the $\emptyset$ resund the salt water advanced from the north in early Boreal times, over a pine forest which now lies under 19 $\mathrm{m}$. of water, and at the end of the Boreal period it had risen to a level of $13 \mathrm{~m}$. below the present sea level. 
The threshold between Amager and Scania lies at $7 \mathrm{~m}$. and was probably crossed by the advancing salt water a little way up into the Atlantic period. $\emptyset$ resund and the Great Belt thus arose at about the same time, the Little Belt somewhat later.

\section{Litorina Sea and Tapes Sea}

These Danish results agree with Swedish investigations of the history of the Baltic Sea. The Ancylus Lake became slightly brackish in Late Boreal times - the so-called Mastogloia phase, named after a diatom. A little way up into the Atlantic period the salt content increased so much that the common periwinkle, Litorina litorea, could thrive right into the Baltic Sea. The Ancylus Lake became the Litorina Sea. The increase in salt-content, which became even higher than that of the Baltic today, has been interpreted in different ways. The quite abrupt change from brackish to salt water agrees best with an assumption, well-founded hydrographically, of a stronger tidal flow.

This also gives us a good explanation of the fact that all our fjords and sounds were significantly saltier and richer in nutrients in the "Litorina period" than today - a fact which is clearly shown, not only in the richer fauna, but also in the size of the mollusc shells. Furthermore, the sea temperature had risen; thus it is hardly remarkable that oysters, for example, could penetrate much further into our waters.

Just as the Baltic Sea had its Litorina period, so also the Kattegat and its fjords simultaneously had their Tapes period, characterized among other things by the presence of the carpet shells Tapes aureus and T. decussatus, together with the scallop Pecten varius, which now have disap- peared from Danish waters east of Skagen. V. Nordmann above anyone else should have the honour for having illuminated the rich mollusc fauna of the Tapes sea.

\section{Rises and falls in sea-level}

The great rise in sea-level during the Atlantic period is known in Scandinavia as the Litorina transgression. It was originally regarded as a single episode but Swedish geologists realized very quickly that it could be divided into two rises in sea-level with an intervening fall. It soon turned out to be even more complicated.

Here in Denmark the Litorina transgression has been divided into four stages, probably separated by small declines in sea-level: the Early Atlantic, the High Atlantic, the Late Atlantic and the Sub-Boreal sea level rises. The amplitudes of these oscillations of water-level in the Stone Age seas are not very significant, but the oscillations are of interest because they may be assumed to have been caused by oscillations in the climate of a similar amplitude to the Late-Glacial climatic oscillations - the Aller $\phi$ d oscillation, for example. Rises in sealevel must be correlated with increases, and falls in sea-level with decreases in the rate of melting of the remaining ice masses of the world.

In addition, it is of great importance in the study of our coastal dwelling sites that we keep them distinct from each other. Previously, the most high-lying shore deposits of the Litorina sea were regarded as being contemporaneous over the whole country. In fact those in north-east Vendsyssel were formed during the High Atlantic transgression, those in East Jutland and on Zealand during the Late Atlantic or Sub-Boreal transgressions, whilst in the south-western part of the 
country the highest Litorina period shoreline lies below the present sealevel. This difference is due to the fact that the north-eastern part of the country has risen uninterruptedly, and the rise has been uneven, increasing in size towards the north-east. The oscillations of the level of the oceans have, of course, been the same all over the world.

\section{Ancient coastal dwelling sites}

As we have seen, inland occupation ceased almost entirely when the primeval forest had become stabilized, and dwelling sites were now found chiefly on the coasts. The oldest ones known lie below the present sea-level, and are so similar to those of the previously-mentioned Kongemose culture that it is possible that people of this culture had their permanent dwelling sites on the coast already in the Boreal period. The distance from the summer dwelling places in Amose to the Kattegat is not great, at any rate.

A number of scattered dwelling site finds in North Zealand and East Jutland are somewhat younger. One closed, well-demarcated find, the Norslund culture, has been dated by the C-14 method to the period around 3,800 B.C. All the cultures and dwelling sites mentioned so far have the common characteristic that they lack pottery.

\section{Kitchen middens and the Ertebolle culture}

These more recent discoveries of ancient coastal dwelling sites form a link between the Kongemose culture and the classic Ertebølle culture, worldfamous for its kitchen middens. The chief honour for their discovery falls to J.J.A.Worsaae, because he, in the year 1850 , was the first to recognize the connection between these heaps of

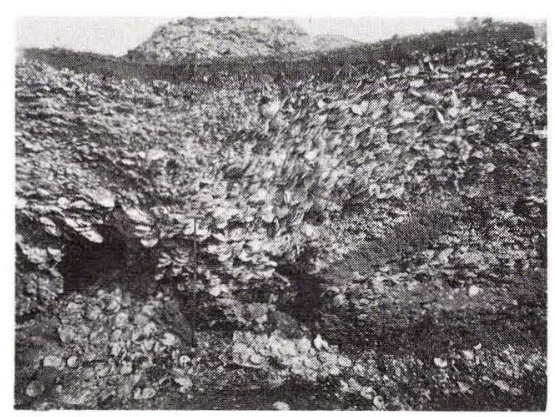

46. Section through the kitchen midden near the small Limfjord town of Ertebølle, which became famous when it gave its name to the classic Ertebølle culture. (Nat. Mus.).

oyster shells and their contents of stone and bone implements, charcoal, animal bones and pottery fragments. Scientists had earlier wondered about the origin of these strange accumulations of shells of marine molluscs, and a commission was formed in 1848 , consisting of the geologist J. G. Forchhammer, the zoologist Japetus Steenstrup, and the archaeologist J. J. A. Worsaae, to investigate how these shell-banks had arisen. Thus was inaugurated the fruitful cooperation between natural science and archaeology in Denmark.

Worsaae's opinion was fully confirmed. The shell heaps consist chiefly of the disjointed shells of three edible marine bivalves, oysters, common mussels, and cockles, which gradually accumulated whilst the Ertebølle people lived at that place all the year round over a long period of time. Archaeologists are not in complete agreement as to how much should in fact be attributed to the Ertebølle culture; when used in a more restrictive sense this title only includes the younger dwelling sites from the late Atlantic and early Sub-Boreal periods, when the technique of forming and firing 
clay pottery was known. There are some important problems connected with the Erteb $\varnothing l l e$ culture and these will be touched upon later. We shall here only mention one fact that all are agreed upon, namely that hunting and fishing were of fundamental importance for the existence of the Erteb $\varnothing 1$ le culture.

\section{The animals hunted by} the Ertebolle people

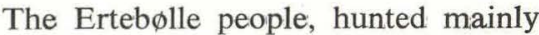
wild boar, red deer, and roe deer, and also aurochs in Jutland. Sea animals were also hunted to a considerable extent; bones of grey seal, common seal, harp seal, ringed seal, porpoise, beluga, killer whale, and baleen whales have been found. The whales were stranded, but the seals were caught with harpoons - harpoons have been found, at any rate.

Many of the birds already hunted on the inland lakes by the Maglemose people have also been shown to be present in kitchen middens, and the absence of some of them scarcely means that they did not still live by the lakes. Among the new bird finds there are sea-birds such as razorbill, guillemot, and gannet; there are also whooper swan and Bewick's swan,

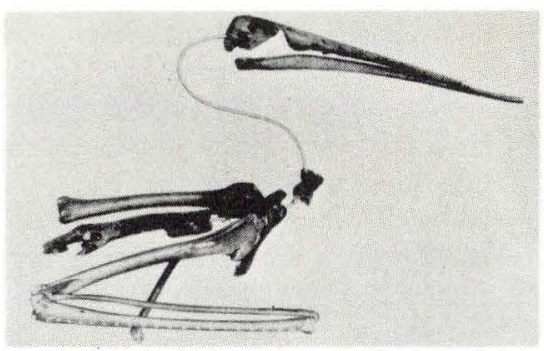

47. Skeleton of a Dalmatian pelican excavated near Syvhøje, west of Nykøbing, Zealand. Today this bird lives in southeast Europe. (U. Møhl).

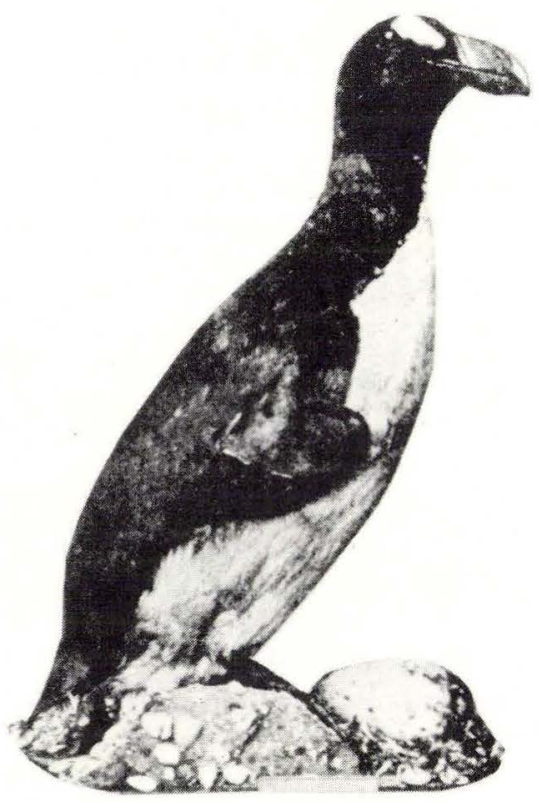

48. Mounted specimen of the now extinct Great Auk. The last survivor was shot in Iceland in 1844; only a very few exist today as mounted specimens in museums around the world. The specimen shown here comes from the Zoological Museum in Copenhagen.

which were winter guests from the north.

Two bird species deserve special mention. One of them, the great auk, Alca impennis, a species of guillemot but the size of a goose, is now completely extinct. It was a peculiar being, with wings so poorly developed that it could not fly; like the penguins it was completely adapted to life in the sea, brilliant at diving and swimming. The great auk had a northerly distribution, and the last ones were shot in Iceland in 1844. The Dalmatian pelican, however, the largest European bird, still lives today in south-east Europe.

Finally, fishery also played its part. Cod was fished more than anything 
else, definitely with hooks - powerful fish-hooks have been found in the dwelling site layers. As with the Maglemose fishers, nets were used, but elaborate fish-traps were used too; the oldest fish-traps which have been dated by pollen analysis go back to the early Atlantic period.

\section{Climate}

\section{The Atlantic oceanic climate}

The transition from the Boreal to the Atlantic period occurred simultaneously with an alteration of climate from dry to humid. Denmark got an oceanic climate.

On acid, moist ground, where pine had held its ground owing to the absence of competitors, paludification now occurred. The first raised bogs were formed in this way, and the treestumps were preserved by the rapidly growing peat moss. Such pine-stump layers at the bottom of certain raised bogs were studied already by Dau, and they still come to light when the peat is removed.

The change in climate caused a rise in water-level in the lakes. Here, too, pine-stump layers were formed. In Ámose, a great prehistoric lake whose fluctuations in water-level have been studied by the peat stratigraphers $J$. Troels-Smith and Svend Jorgensen, a quaking bog was formed in the first phase of the Atlantic period. Such quaking bogs appear when a reed swamp is torn loose from the lake bottom by a rise in water-level, carcied up by the buoyancy of the tightly interwoven root systems which are full of air-canals.

But the temperature rose too; this is obvious from the clearly increased pollen frequency of ivy and mistletoe. This combination of rising humidity and warmth, the oceanic climate, must have been related to the formation of the North Sea and the great rise in water-level in the western Baltic Sea, which first became brackish and later, salt.

\section{A peculiar phase in the pollen diagrams}

After the stable primeval forest had arisen, the pollen curves followed a very even course to begin with. Towards the middle of the Atlantic period, however, they suddenly become disturbed (see fig. 34), and when they soon afterwards become stabilized again the levels of oak, ash and alder, the trees of the damp marginal forest, are now higher, whilst those of hazel, pine and birch are lower.

This interplay in the pollen diagrams has a very regular course, as has been shown by detailed diagrams from Åmose. Much evidence seems to

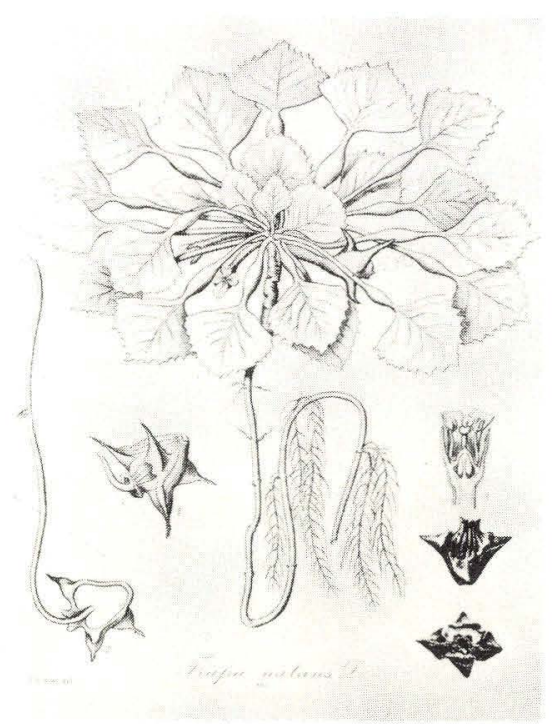

49. The warmth-requiring aquatic, waterchestnut, with its fruits. The fruits pictured here were found in a bog on Lolland in layers from the Older Lime period. 
show that a pioneer forest of birch, pine and alder grew on those marginal areas which in the Boreal period lay dry, but then became submerged, and later again became dry. Subsequently birch and also pine were completely ousted by the climax trees, particularly oak. Perhaps the most characteristic feature of this interplay is the marked decline of hazel which had previously blossomed richly in the forest margins along the lakes; this indicates that here there could not have been a typical damp marginal forest. This first arose after the fall in water-level; only alder grows in the outermost zone of a damp marginal forest, not hazel.

The details of this interpretation can be debated, but it seems certain at any rate that this interplay inaugurated a dry, warm period.
The culmination of the warm period Taken as a whole, the Older Lime period must be acknowledged as the warmest of the great Post-Glacial periods, and the warm period reached its culmination in its later half.

Ivy and mistletoe reached their greatest frequency and pond tortoises were common; the temperature was at least $2^{\circ}$, probably $3^{\circ}$ higher than today.

Finds of the large and remarkable fruits of the warmth-requiring aquatic water-chestnut, Trapa natans, in the sediments of east Danish lakes also fit into the picture. Nor is it impossible that the south-east European Dalmatian pelican occasionally nested in Denmark at this time, although the possibility that the bones found at the dwelling sites originate from vagrant birds cannot be dismissed.

\section{The Younger Lime period, 3,000-500 B.C.}

The boundary between the Older and the Younger Lime period (the Atlantic and the Sub-Boreal periods), is fixed in the pollen diagrams at a marked fall in the elm curve. In Danish diagrams a pronounced decline in the pollen frequency of ivy occurs at the same time, so that ivy is not only a characteristic plant for an Atlantic climate but in Denmark is also characteristic for the Atlantic period.

The Older Lime period is notable for the great equilibrium of the forest, which was only locally disturbed by changes in the ground-water-level, etc. In contrast, the Younger Lime period is characterized by drastic changes. Climatically speaking it still belongs to the warm period, but the first signs of a decline in temperature show themselves clearly in various ways. Furthermore, on poor sandy soils the first definite symptoms can be traced of a deterioration in soil quality as a result of the leaching of nutrients. Most decisive of all, however, a completely new factor began to exert an influence which was soon to become more important than all the others combined; the direct and indirect interactions of mankind with nature in Denmark.

\section{The forest is transformed and exploited by man}

\section{The primeval forest as an enemy}

We have seen how mankind was forced to give way to the dark primeval forest in the Older Lime period. Life was good while conditions were favourable, but when the dark shadetrees advanced, strangling the hazel 
and reducing the quantity of game, this was accepted passively. The thought of accepting the challenge and offering resistance can hardly have occurred.

True enough, there were no axes available at that time effective enough for the felling of large trees, but there is a simpler method of overcoming them - by peeling a belt-like strip of bark away from the trunk.

Two circular and one vertical incision, cut or chopped through the bark in the spring is sufficient; the strip of bark can then simply be peeled off. This interrupts the flow of organic materials which are formed in the leaves with the help of sunlight, and pass through the bast of the trunk to the roots to enable these to grow. The root system degenerates after the bark is peeled, but the flow of water from the roots up through the vessels in the wood still functions. The tree can thus vegetate for some years - how many depends on the species - but finally it expires. Hunting peoples practise this method today in the primeval forest in order to lure game to the green oases which arise as a result. The Maglemose people had presumably not discovered the method, but there is much to indicate that the Ertebølle culture had learned it.

\section{The role of the transformed forest in primitive agriculture}

The same method is employed by herdsmen in primitive areas to enable the cattle to find food in dense forest. Thus poor peasants in the Balkan peninsula have continued, in spite of prohibition, to use bark-peeling in the mountain forests right into the present century in order to produce undergrowth for food for the forest cattle.

It is important to make it clear that for primitive cultures in areas of de-

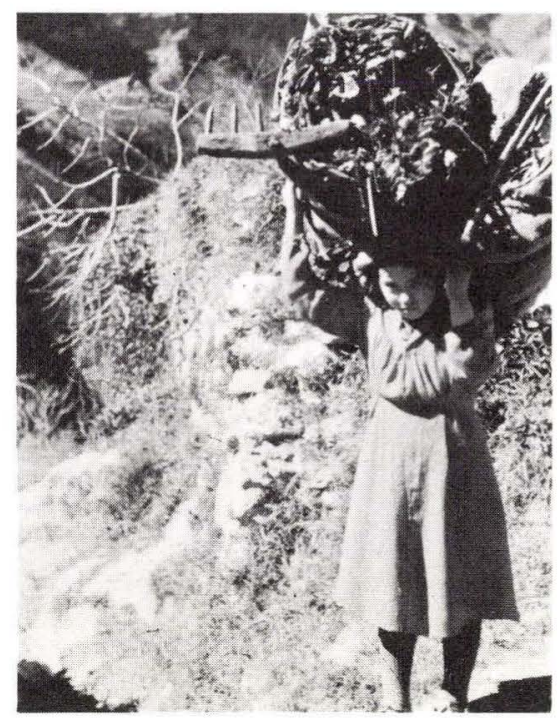

50. Young woman near a mountain village in South Italy, gathering leaf-hay for the cows in the stall just as it has been done for thousands of years.

ciduous forest, tree leaves have been the prime source of food for cattle. As winter fodder, too, leaf litter was originally used almost exclusively; hay cutting on meadows is a later and more demanding agricultural method. I myself participated as a schoolboy in South Jutland during the First World War in the organized collecting of "Laubheu" from the forests, probably for the horses at the Front. It is likely that the most primitive method was to confine domesticated animals all year round in a little enclosure, collecting leaves for them in summer and feeding them on leaf litter in the winter. Cows are still kept in this way by underdeveloped peasant societies in the southern European mountains. Goats and sheep, on the other hand, wander freely around in the scrub forest, watched by herdsmen and dogs. The high forest here has in fact been transformed to low 
forest, which is suitable for leaf-gathering and foraging by the forest-going cattle.

\section{Leaf-fodder trees}

The food value of the leaves of the various trees is very different. Elm and ash have always been famed as the most valuable everywhere they grow. Both species were therefore frequently planted near farms as sources of leaf-fodder, which were usually lopped every second, third, or fourth year, following which the leaves were dried for winter fodder. Such regular pollarding means that the elm trees never flower, since the twigs must be seven to eight years old before this can occur. Ash flowers two to three years after lopping, and when this is less intensive the pollen curve of ash will thus be less affected by leaf-gathering than that of elm. The leaves of the lime are also readily eaten by cattle; the same is true of the leaves of other tree species, but alder leaves are unusable.

\section{Mast trees}

The word mast was previously used to include all the edible forest fruits, but first and foremost acorns, beech mast, and nuts. In the Lime period oak and hazel were the most important mast trees; the importance of hazel has already been mentioned. Acorns are not suitable for human consumption because of their high tannin content, but they have been resorted to in the times when other food was scarce, as they are also used even today when there is famine. But as the best food for swine oak mast has been of immeasurable significance - in fact, only a few hundred years ago the value of a forest was measured by its production of mast, and it was oak mast which counted for most. Since the exploitation of mast did not harm the trees, and since it was the old trees which produced the most, primitive agriculture was especially favourable to the occurrence of the mast trees.

\section{The use of bark}

On the other hand, primitive agriculture was very hard upon those tree species whose bark is used to a great extent, especially when the bark of the trunk was used. The lime must here be mentioned above all others - the bast-tree, the only tree species in Europe which has been used systematically from the Stone Age to the present day for the production of bast. Many place-names such as Bastholm, etc., are connected with the use of lime as a bast tree. The best-suited trees for bast production are those with stems between 30 and $40 \mathrm{~cm}$. thick; the method is simply to remove the bark in the spring, which naturally enough kills the tree. Bast was used for many important things such as rope, mats, etc.; great quantities of lime bark were also used as insulation - for example, in a Swiss Younger Stone Age settlement, lime bark was used as a floor covering, often 15-20 layers on top af each other. We know from many sources that in more recent times lime has been wiped out over great areas as a result of the use of bast; this is especially true in Russia, the only country where great lime forests still exist.

The bark of elm was also used in primitive housekeeping, although for other reasons. The bark is especially rich in a number of nutrients, including mucilagenous substances, which as well as being easily digestible have the important quality of being able to bind the considerable starch content of the bark into a tough dough. Elm bark has thus been used right up to 
the present day as a bread-reserve in years of want. But this nutritional value of the bark has naturally been most utilized by feeding the bark to domestic animals, particularly pigs and sheep, as winter fodder. Pigs in particular have a great love for elm, both the leaves and the bark.

\section{Danish animal husbandry in prehistory}

With the exception of the dog, the other domestic animals were brought to Denmark, like the various cereal species, in connection with the first agriculture. Conceivably, already before this time the hunters would occasionally bring wild boar piglets or aurochs calves home and fatten them before slaughtering them. True animal husbandry, however, first began with introduced and already domesticated animals. But what domestic animals were there in the Stone Age?

We know a great deal concerning this point, thanks to the close cooperation of Danish archaeology and zoology. The chief source of our information is the rich bone material of the dwelling sites, which has been analyzed by Danish zoologists. This development began with Herluf Winge's contribution in the classic investigations of Stone Age shell heaps, and the work was later continued by Magnus Degerb $\phi l$ and Ulrik M $\phi$ hl. The results of these investigations will be discussed in the next section and we will content ourselves here by noting that the most important domestic animals of the Stone Age peasant were the cow and the pig. Sheep and goats were known but they played a more subsidiary role.

\section{Methods of studying prehistoric cereal cultivation}

The study of prehistoric cereal spe- cies in Scandinavia began very late. Corn is not preserved unchanged through millennia here as it is in the drier climate of southern lands. It was only when the Jutland teacher Frode Christensen in 1894 discovered grain impressions in a pottery sherd from the Bronze Age that a fruitful research method was acquired. It was immediately taken up by archaeologist Georg Sarauw, who undertook a systematic search for cereal impressions in the prehistoric clay vessels and pottery sherds in museum collections. The mass of material which he accumulated was never published, but was utilized by other researchers both here and abroad.

After Sarauw's death the task was taken over by Knud Jessen, who searched not only for cereal impressions in pottery sherds but also for charred grains which could have been formed when prehistoric houses containing stores of corn burned down. A large body of material from the British Isles was also included in this extensive investigation by Jessen and his co-worker Hans Helbak, and it is through this work that our knowledge of prehistoric cereal cultivation in northwestern Europe has been so clearly illuminated.

\section{Prehistoric cereal types}

Species of the wheat genus, Triticum, were especially cultivated in Denmark in the Stone Age. These were not at all like our greatly improved varieties, however; they were far more primitive species which have now gone almost completely out of use in our part of the world.

Two species are so different from our modern cultivated wheat that, although they belong to the wheat genus, they are not called wheat but respectively small spelt, Triticum mono- 

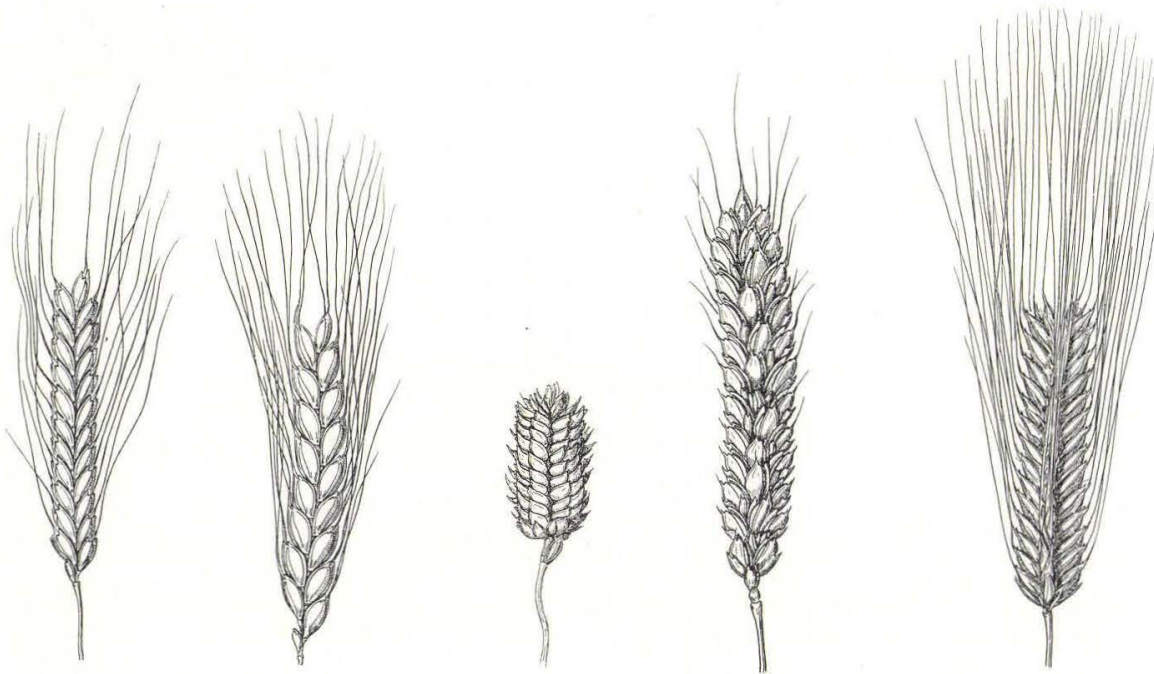

51. Stone Age cereals. From the left: lesser spelt, emmer, dwarf wheat, common wheat, and six rowed barley. (From G. Hatt).

coccum, and emmer, Triticum dicoccum. They differ from true wheat in that, among other things, the rachis of the ear is brittle and can easily be snapped when ripe, so that the individual spikelets with the grains and their tightly enclosing glumes are released by threshing. True wheat was also cultivated, but it was presumably mainly or exclusively the more primitive club wheat, Triticum compactum, which is very difficult to distinguish from bread wheat, Triticum aestivum, from impressions and charred remains alone.

The barley that occurs in Danish prehistoric finds is six-rowed barley, Hordeum vulgare. In the Stone Age a special form was usually cultivated, naked barley, where the grains are loosened from the glumes. In fact, the prehistoric wheat species, small spelt and emmer, resembled the modern two-rowed barley superficially, and the Stone Age naked barley resembled our wheat.

\section{Traces of primitive agriculture in the pollen diagrams}

Significant contributions towards the elucidation of prehistoric agriculture have come from pollen analysis as well as from the method discussed above.

It is clear that agriculture causes characteristic changes in the forests, which are reflected in the tree-pollen curves. But the effect of the most primitive agriculture on the forest will be relatively slight and difficult to recognize, or at any rate, it will be hard to prove that such manifestations in the pollen diagrams result from human activity. It is necessary to confirm this interpretation from independent evidence, and such evidence can be found in the characteristic occurrence of culture-dependent plants.

Great plantain, Plantago major, "the white man's footprint", is such a plant, and has followed man everywhere where he cleared the primeval forest. The same is true of ribwort 
plantain, which will be discussed later.

Mugwort, Artemisia vulgaris, and species of the goosefoot family, Chenopodiaceae, are also closely associated with farming cultures. But since some species of the same genera were very common by the sea coasts and were in addition wind-pollinators with a very high pollen production, it is always possible to explain scattered inland finds of their pollen as having been carried there from the coast by the wind. It is only when they occur with greater frequency that they indicate agriculture in inland areas.

Greatest interest, however, is attached to those species which do not just follow agriculture, but are "indicators" of agriculture and animal husbandry respectively.

\section{Traces of cereals in the diagrams}

The most important indicator plants for agriculture, of course, are the cultivated plants themselves - first and foremost, the various types of cereals. All the grass species have the same pollen type in principle, but most cereals can be distinguished from common grasses by the pollen size, among other things. This is especially true of rye and the wheat species (including emmer), whilst barley, oats and small spelt are more difficult to distinguish from certain wild grasses.

Rye is the only modern cereal which normally disperses its pollen into the air. The other highly improved cereal types are self-pollinating, and their pollen normally remains between the awns.

The primitive cereals of the Stone Age Danish peasant, however, were wind-pollinated to a greater degree than the modern ones; this is especially the case with small spelt, but is also true of emmer, which appears to have

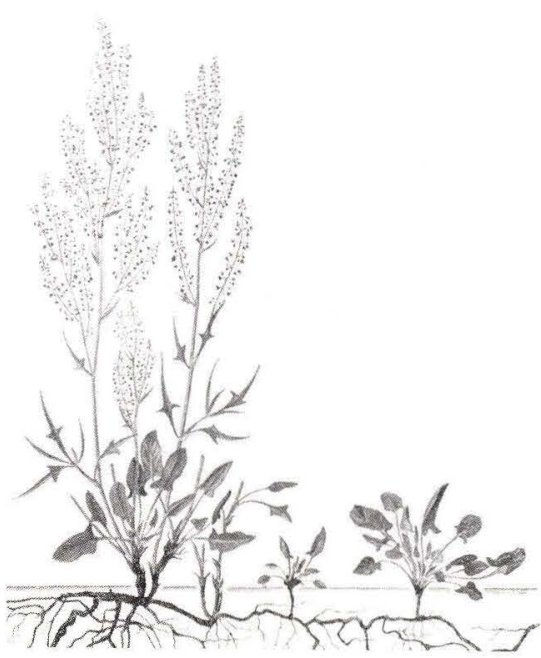

52. Sheep's sorrel, the curve of which registers prehistoric land cultivation in the pollen diagrams. (Ingeborg Frederiksen, from H. I. Petersen).

been the most cultivated species. Before the introduction of rye, cereal pollen is too sparsely represented in relation to the total area of the fields.

Field weeds as evidence of agriculture

Among the field weeds a species such as fat hen would be a valuable indicator plant in the diagram, if only its pollen could be distinguished from that of the other goosefoot species; this is unfortunately impossible, however.

The only wind-pollinator among the other weed species especially typical of cornfields is one of the two sorrel species, namely sheep's sorrel, Rumex acetosella. This was, and still is, extremely common on fallow fields, especially sandy ones, which can be coloured quite red by this small herb. The other closely-related species, common sorrel, Rumex acetosa, grows on meadows and rough pasture. The combined curve for these two species 


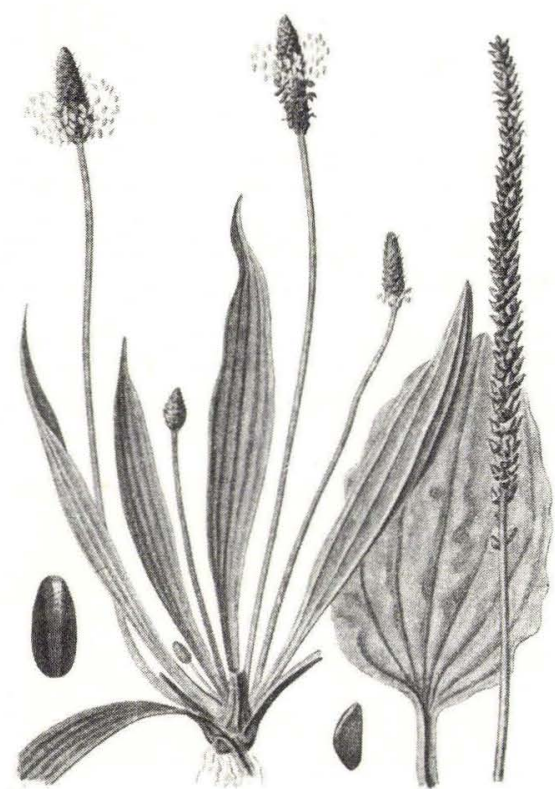

53. Ribwort plantain (left) and great plantain (right). The pollen of both species is certain evidence of farming in Post-Glacial pollen diagrams. The first is the most important indicator plant for rough pasture. (Ingeborg Frederiksen, from $\mathrm{H}$. Frederiksen).

is an excellent indicator for farming. By careful investigation the pollen of the two species can be distinguished from each other, and the curve of sheep's sorrel is then an indicator for arable land.

Before hormone-spraying altered the weed flora of our fields, several species of the Cruciferae were extremely common amongst cereal crops. Previously the whole landscape could be coloured yellow at blossoming time by charlock, turnip, and wild radish. The presence of these and other Cruciferae has also been demonstrated in the Younger Stone Age and Bronze Age by their seeds; their oily seeds were undoubtedly used as food for men and animals.
The Cruciferae are insect-pollinated and they play no part in natural plant communities, not even on rough pasture. A frequent occurrence of their pollen in deposits will therefore indicate agriculture. The same is also true of the pollen of the annual species of Polygonum, which have only a poor pollen dispersal, however.

\section{Indicator plants for animal husbandry}

It would be almost impossible to find unambiguous traces in pollen diagrams of cases where domestic animals were kept all the year round in a stall or small enclosure. Forest grazing without effective forest clearance will also be very difficult to detect in the pollen diagrams, unless analyses can be obtained from the forest sediments forest peat or mor.

As soon as proper clearance takes place followed by grazing, so that open patches arise, illuminated by full sunlight, we find indicator plants for rough grazed pasture.

The most important of these indicators is ribwort plantain, Plantago lanceolata. This wind-pollinated plant arrived in this country together with the earliest agriculture, and it is one of the most important of all plants on old-fashioned rough pasture. Ribwort plantain demands full sunlight, in contrast to great plantain; it will not grow in grazed forest. White clover, on the other hand, will do so if the shade is not too close but it flowers more richly and is more frequent on open pasture. However, in normal pollen diagrams from lake sediments clover appears only exceptionally; it is, as is well-known, a typical insectpollinator, and its pollen is not released into the air. If pollen of white clover occurs in forest peat, one can be certain that cattle have grazed there. 


\section{The elm decline}

When the boundary between the Atlantic and the Sub Boreal period was placed at the pronounced fall in the elm pollen curve, this decline was regarded as something of a mystery. In the 25 years which have since elapsed, this peculiar elm decline has been discussed more and more, not least since it was realized that the decline occurs in pollen diagrams from all over northwestern Europe, and - according to a great number of $\mathrm{C}-14$ datings at about the same time everywhere, around 3,000 B.C.

\section{How can the elm decline be explained?}

Four explanations for the elm decline have been put forward. The most obvious one was to suppose that the climatic change in Denmark, which was suggested by the fall in the ivy curve, had also affected smooth elm, which undoubtedly grew here in the warm period (see p. 68). But when it was realized that the elm decline had such a wide geographical extent that it had occurred both in areas which are so cool that smooth elm could never have grown there, and in areas so mild that a slight fall in temperature would not affect it, it was clear that the elm decline as a whole could not be explained on this basis.

A slow deterioration of the soil has undoubtedly reduced the distribution of elm, but this could not have been the cause of the sudden fall shown in many pollen diagrams.

Dutch elm disease, which in recent decades has nearly exterminated the elm in large areas of Europe and North America, is an explanation which can solve the problem in a most elegant way. Dutch elm disease is caused by the attack of a fungus transmitted by two species of beetle, which fortunately for Danish elms have their northerly limit of distribution at Denmark's southern border. It is unknown where the disease originated, but it spread from Holland in 1919, crossed the Atlantic, and began to ravage North America in 1929, while in an easterly direction it reached Central Asia in 1939. It is tempting to imagine that Dutch elm disease ravaged $\mathrm{Eu}$ rope in a similar way 5,000 years ago, but it is difficult to prove.

\section{The use of leaves for fodder as cause of the elm decline}

Earlier it was explained how primitive animal husbandry in a deciduous forest area such as Denmark must originally have been based upon leaves from the forest, and that elm and ash provide the best leaf fodder. It was suggested early on by Norwegian workers that the fall in the elm curve could in part be due to extensive use of leaves for fodder, which would have a particularly severe effect upon elm pollen production. This theory was from then onwards strongly championed by J. Troels-Smith, who was able to support it by bog stratigraphical investigations in Swiss lake settlements from the Younger Stone Age. The elm decline here shows a clear correlation with the settlement, and archaeologists have in fact found collections of leaves from various trees, elm included, on the floors of the houses; one-to four-year-old ash branches were also found. It can thus be taken as proved that leaf fodder was used in Switzerland at the same time as the elm decline set in. The pollen analyses show that the forest became lighter and oak and hazel common, but there was no rough pasture. There was furthermore a certain amount of agriculture.

Through these investigations we ob- 
tain a living picture of this primitive farming based on confined livestock fed on tree leaves and a little agriculture. One may wonder, however, how such a primitive leaf-fodder culture could suddenly affect the elm curve so strongly and simultaneously over major parts of Europe.

\section{Ecological aspects of the elm decline}

If one attempts to make a completely unprejudiced ecological judgement of the course of the curves around the elm decline, one thing in particular stands out. In all the detailed Danish diagrams oak gains at the expense of elm. These two trees must have stood side by side, and the flourishing of oak would then be favoured by the decline of elm. Only common oak grows together with elm (see p. 68), and in primeval forest conditions this presumably happens only on moist, fertile ground; that is to say, in the marginal forest of lakes and in floodplain forests between the zones of lime and alder. One would particularly expect to find Ulmus laevis and smooth elm in this community, with wych elm too in the higher part of the marginal forest.

Changes in the level of the groundwater-table, particularly a fall, could cause a temporary catastrophe for elm species on this type of soil; one would expect in such circumstances that alder rather than oak would be favoured - but on the contrary the alder pollen frequency usually decreases at the time of the elm decline.

On the other hand, it is clear that lopping of elm would result in an increased oak pollen production. It would, however, appear to be an enormous enterprise to lop so many elms; it would be necessary to clamber right up the tall, rangy forest trees - by no means an easy task. It would be far easier, both in the beginning and later, to stand on the ground and peel the bark from ash and elm at a convenient height. The younger ash trees, at any rate, would then sprout immediately below the peeled ring, as has been demonstrated experimentally. Such leaf-fodder trees would from then onwards be easy to trim. Simultaneously, too, a flourishing growth of elm, oak, and especially ash would spring up, from which leaves could also be gathered, and where freely roaming goats and perhaps cows could find food. And whilst a valuable fodder-producing scrub forest was created in this way, the production of mast would simultaneously be increased greatly because the oaks now would stand in better light.

The elm decline can thus be explained excellently on an ecological basis, as the influence of a primitive peasant culture with domesticated animals. It has already been mentioned that such a culture would only leave very faint traces in the form of pollen from culture-dependent herbaceous plants, but it is worthy of mention that the first traces in this country of ribwort plantain, great plantain, and cereals have been found either in or immediately above the elm decline.

\section{The first great forest clearances - the landnam phase}

A little way above the elm decline a phase is found in Danish pollen diagrams which shows drastic and regular curve displacements. The course of the tree pollen curves alone strongly suggests that they are registering great clearances of the primeval forest by axe and by fire, and this is fully confirmed by the curves for the indicator plants, previously discussed, of rough pasture and corn fields. This characteristic phase in the diagrams, 


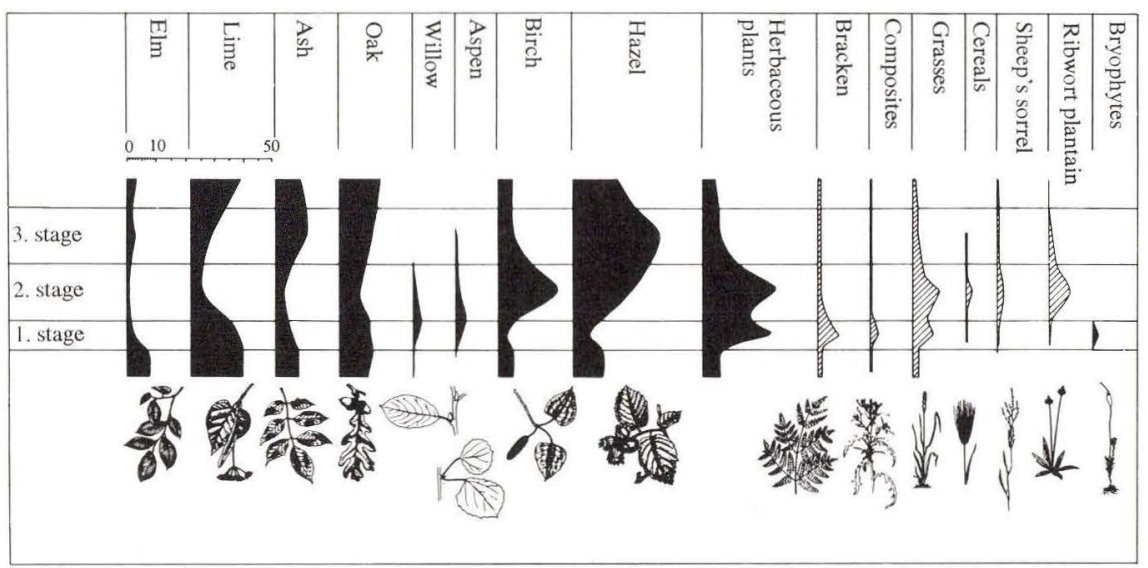

54. Generalized pollen diagram for a Stone Age landnam with its 3 phases. (From Johs. Iversen 1956, with alterations).

the so-called landnam phase, is usually some few centuries younger than the elm decline. In this country we have a C-14 dating of 2,500 B.C. from south-west Jutland, whilst at the same place the elm decline has been dated to 3,000 B.C. In a few diagrams from Zealand and Scania the landnam may have ocurred earlier, since the elm fall is included in the landnam, and a Scanian C-14 dating indicates 3,200 B.C. The landnam phase is equally old in Ireland, where the first elm decline is simply a landnam phase.

\section{The three stages of the landnam phase}

In all detailed pollen diagrams the landnam phase can be divided into three stages, which are especially clearly shown in diagrams from smaller lakes.

The first stage consists of a sudden increase of herbaceous plants, especially grasses, bracken, and compositae, whilst the trees of the high forest show a slight decline, with the exception of alder. This stage in the diagrams corresponds to the actual forest clearance, which immediately resulted in a short-lived flourishing of herbaceous plants; occasional pollen grains of the plantain species and of cereals appear already here.

Two things occur in the second stage. First comes a small, short-lived maximum of willow and aspen, succeeded by a far larger maximum of birch. This succession, in particular the birch maximum, is extremely characteristic of the landnam phase and is an argument weighing heavily in favour of the idea that the forest clearance was accompanied by burning. Only in this way could birch have had a chance to characterize the regeneration on the common forest mull. The pollen curves of lime and elm simultaneously fall to very low values, herbaceous vegetation then undergoes a characteristic change; indicator plants for rough pasture spread, and ribwort plantain in particular becomes very frequent. After a short decline the combined curve for herbaceous plants reaches its greatest maximum in this stage, apparently because the increasing numbers of livestock held the regeneration partly in check. 


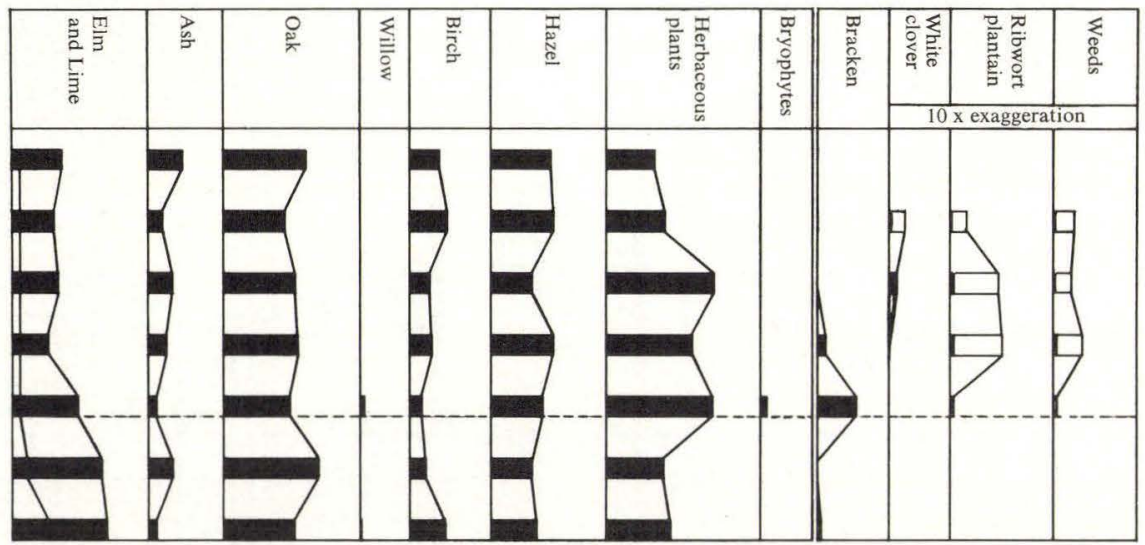

55. Pollen diagram from a South Jutland bog with a local landnam phase. The lowest analysis comes from the peat immediately above the firm sand bottom. A charcoal layer caused by clearance burning is indicated by the stippled line. Notice the elm decline immediately before the burning. (C. Vang Nielsen and Johs. Iversen, D.G.U.).

The third stage is characterized by a large maximum of hazel, which had already shown an increase during the preceding stage. The high forest gradually regenerated, but in an altered form. The light-demanding trees, oak and particularly ash, are more frequent; owing to the favourable light conditions they must also have advanced up on to higher ground. At the same time the rough pasture plants, cereals, and weeds disappear almost completely. In some diagrams the landnam phase then ends with the high forest forcing the hazel out and again becoming dense.

\section{Direct demonstration of clearance by burning in the landnam phase}

The landnam phase can normally only be studied in lake and raised bog deposits at considerable distances from the area where the forest clearance took place. Through a fortunate coincidence it has recently been possible to demonstrate a landnam phase on the burned area itself, albeit on its outer zone. Today the area is covered by bog and heath, but in the Older Lime period it was wooded. At the transition from Older to Younger Lime period peat was beginning to appear on the damp forest ground. A few centi-

Upper: Forest clearance with Stone Age flint axes. The archaeologists Svend Jørgensen and J. Troels-Smith fell a lime tree using a method of chopping which they developed by experiment as being the most effective. Since the felled trunks should preferably lie in a north-south direction so as to dry as well as possible, the trees were chopped with an undercut as shown. It took half an hour to fell the lime, but the archaeologists think that trained Stone Age peasants could have done it much quicker. (Photo Johs. Iversen).

Lower: the clearance fire has been started, using a primitive technique. Belts about $10 \mathrm{~m}$. broad were burned; the fire lasted 3-4 days and was directed by professor K. Vilkuna from Helsinki. The fire was regulated carefully day and night to achieve an even burning of the ground. In the foreground a spared lime tree can be seen; in the background are mostly oak trees. (Photo Harald Krog.). 


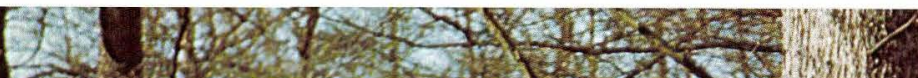

-

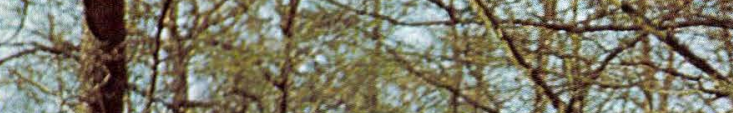

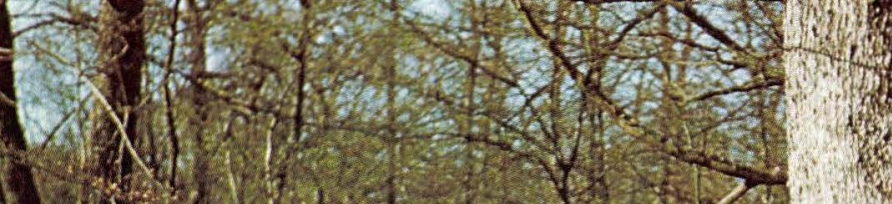

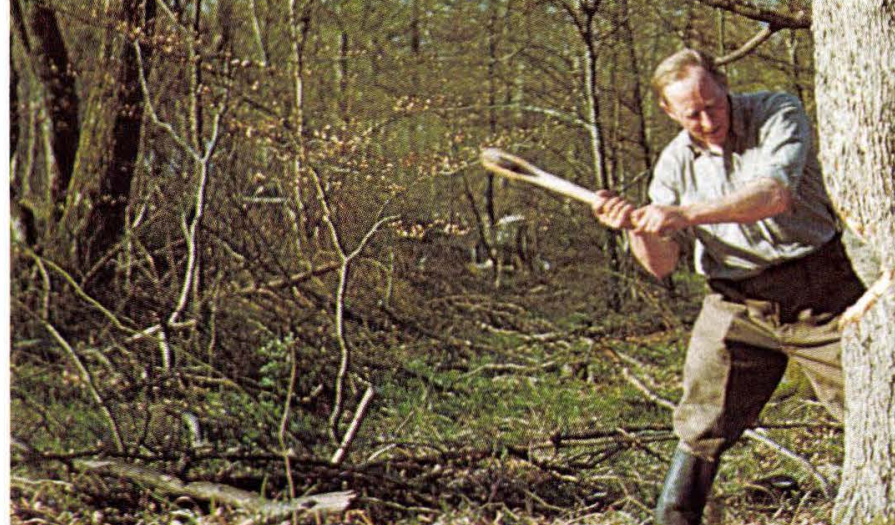

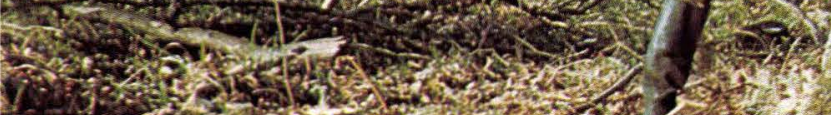

-

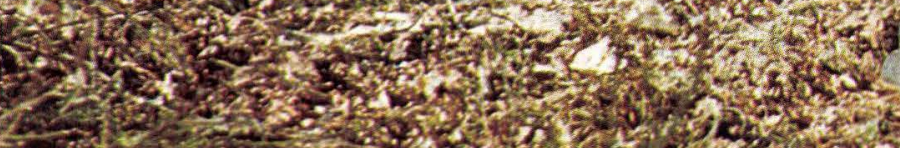

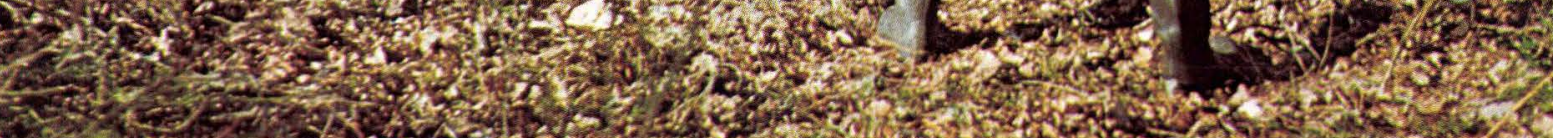

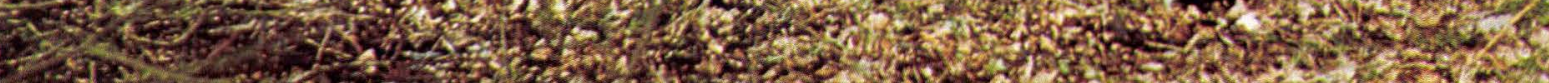

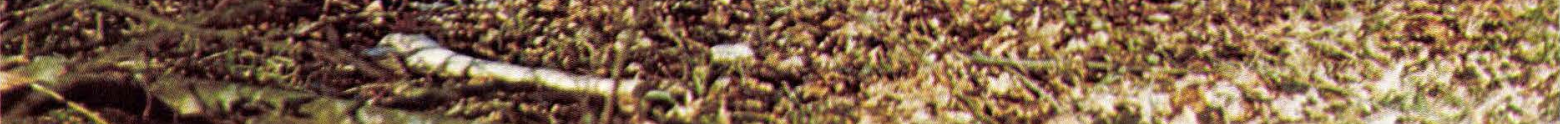

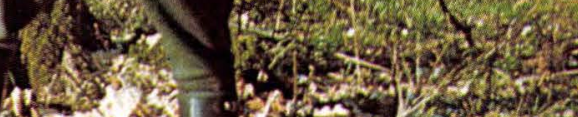

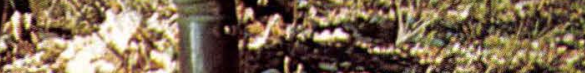
Kos 350.00

C.

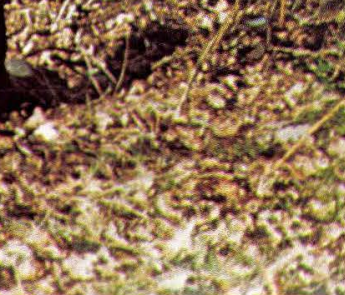

350 .

7.

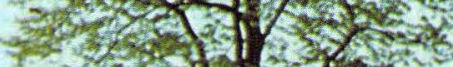

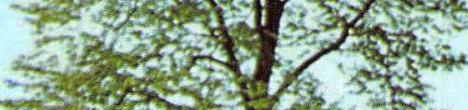

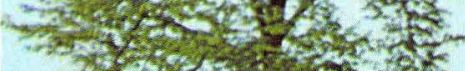

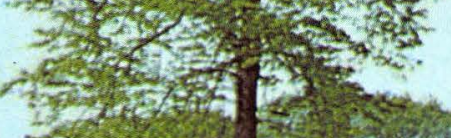

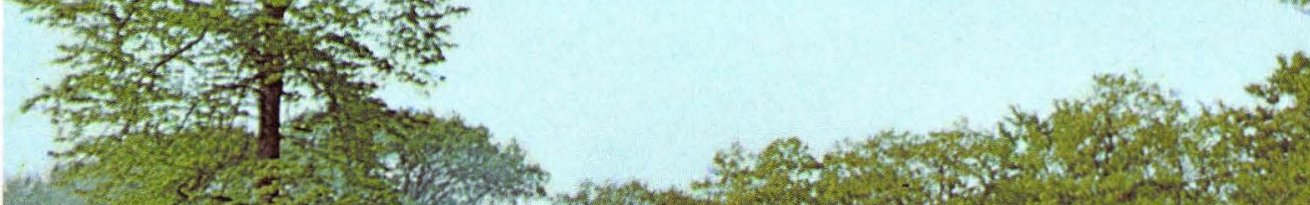
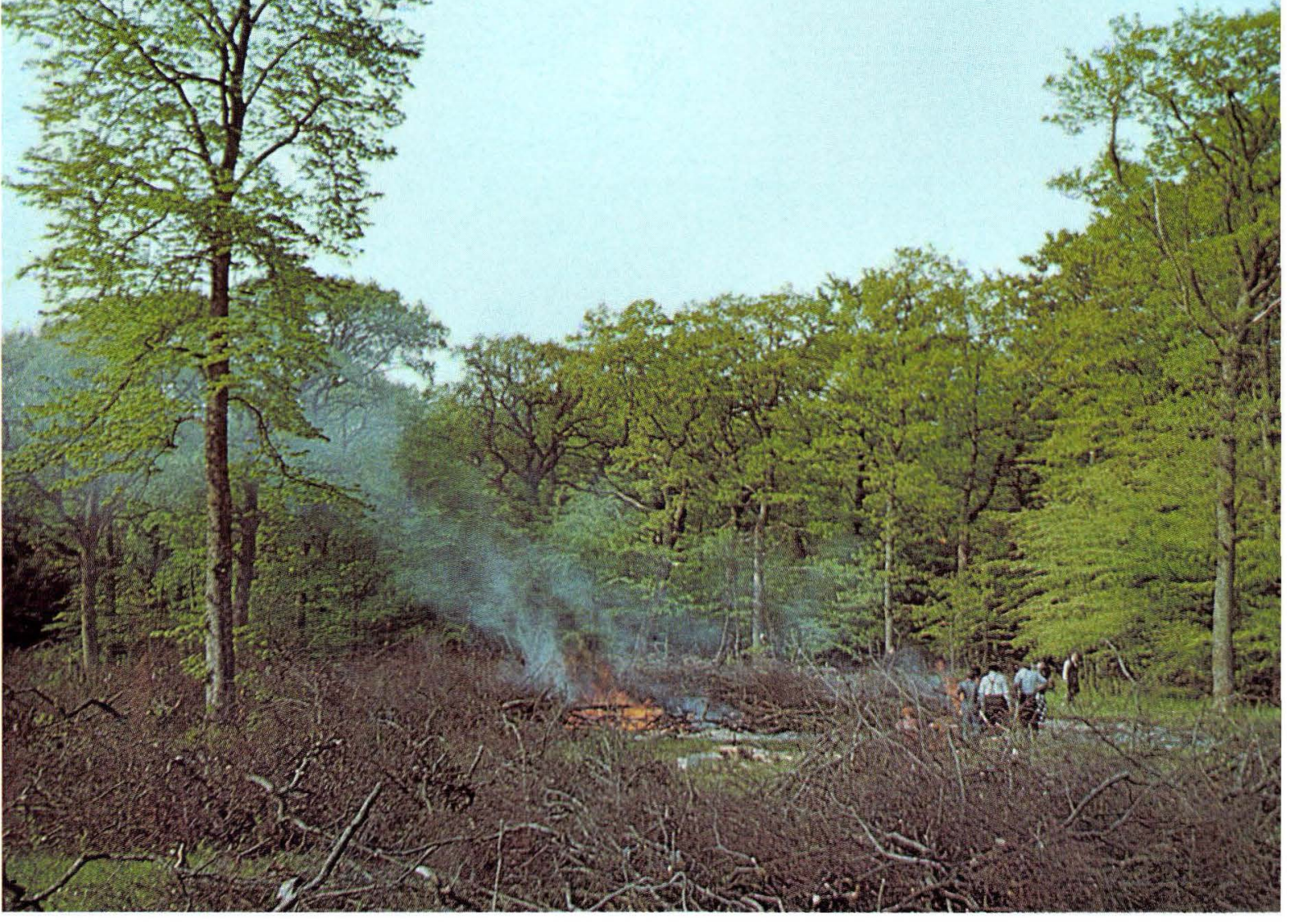
meters up in the peat a distinct charcoal layer was found, and at this point in the pollen diagram the landnam phase began, see fig. 55 .

Bracken and mosses have a sharp maximum in the fire layer itself whilst willow has a lesser peak. The curves of the high forest decrease and the curve of hazel begins to rise. Ribwort plantain and weeds appear for the first time in the fire layer, but they only become significant in the second stage. Finds of several pollen grains of white clover are especially important, because they can be interpreted as evidence of cattle-grazing on the area. The landnam phase ends as usual with an increase in the curves of lime, oak, and especially ash, at the expense of the herbaceous plants. The evidence that the landnam phase here was due to local burning (the fire layer!) and cattle grazing (white clover!) appears to be decisive.

At the same time, it should be noted that the clearance here at the edge of the burnt area, far from the settlement, could not have been total in any way. In that case the herbaceous plant pollen curve would have risen much more. Apparently only the smaller trees were cut and burned. Cattle grazing created open patches in this light forest, but no real rough pasture vegetation.

\section{Experimental clearance by burning}

Clearance by burning has been practised all over the world and is still much used in underdeveloped countries. But we must still ask whether it was really possible to carry out largescale forest clearance with the primitive tools of the Stone Age. To shed light on this problem, and to verify that the succession after clearance by burning with subsequent grazing real- ly follows the course registered in the landnam phase, the Danish Geological Survey in cooperation with the National Museum carried out a clearance burning.

First a suitable area with forest of the Stone Age type was chosen, and the trees, herbaceous vegetation, and soil conditions were carefully recorded. The soil fauna was also investigated. At the same time, archaeologists experimented to find the correct method of hafting flint axes and the most suitable chopping technique, and obtained the primitive cereal types, etc.

Clearance of the forest area of about 1 hectare was carried out in 14 days by 5 men led by archaeologists (see plate p. 88). The efficiency of the flint axes surprised everyone, especially the woodmen. The illustration demonstrates the most effective mode of chopping, which produces characteristic wood-chips; exactly the same type of chip has been found in Swiss lake settlements from the Younger Stone Age. Old oak trees were "ringed" with a 5-6 $\mathrm{cm}$ deep ring-shaped cut through the bark and outer wood, which interrupts the flow of sap and causes death. The trunks were then sawn through and removed as timber.

Half of the area was burnt in two broad strips. The burning was supervised by an expert from Finland, where the method is still in use in a few places. The burn-clearance was carried out at the end of May and lasted some days and nights under careful supervision.

The primitive Stone Age cereal species, small spelt, emmer, club wheat, naked barley, etc., were then sown in the ashes within the burned strips; for comparison, the crops were also sown in the cleared but not burned area, in small, carefully weeded beds. 


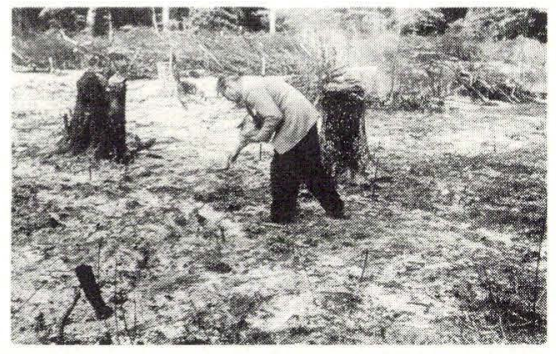

56. Professor Axel Steensberg sows the primitive Stone Age cereals in the ash whilst experimenting with two methods. Here he "broadcasts" the grains, after which it is buried by means of a wooden rake. The other procedure was to sow the grains in small holes made with a little planting-stick. The last method turned out to be the most efficient since only half as much seed grain was required. (25.5.54. D.G.U.).

\section{Cereals thrive on the burned forest ground}

The clearance by burning showed an enormous effect on the growth of the sown cereals. The nutrient content of tree-ash, its favourable effect on the acidity of the soil, and the effective elimination of competing regenerative growth and herbaceous plants, all combined to improve the growth conditions of the cereals to the highest degree. But the favourable influence was shortlived; even in the second year the growth of the crops was greatly reduced, while other plants spread. The cereals tested would not grow at all on the unburned forest soil. On less acid forest soil the difference would perhaps have been less drastic, but there is no doubt that the Stone Age cereal types would under any circumstances have had difficulty in thriving without burning; rye and oats can manage much better on acid soil.

\section{The vegetational succession on} the burned area

The vegetation on the burned area was very different from that on the unburned in the first few years. Burnedground mosses, dandelions, and a few other compositae together with some great plantain and knotgrass species grew on the burned ground only; birch sprouted in quantity after the burning, but only very sparsely outside the burned area. The regeneration of other trees and most forest floor plants, on the other hand, was killed by the fire. Bracken formed an exception, however; its deep-lying roots were not damaged:

Now, 13 years after the fire, there is a thick undergrowth, mainly of birch and willow on the burned area, and of rowan, alder buckthorn, and
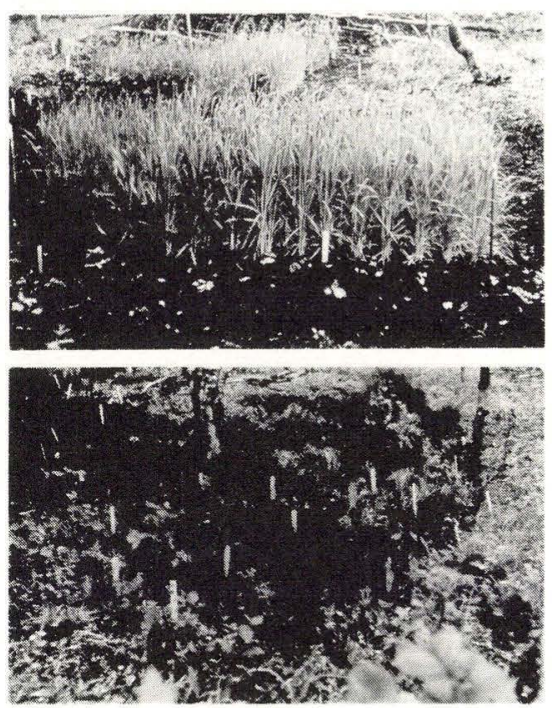

57. The success of the cereals on the burned and on the unburned but prepared forest ground was very different, as shown by these two photographs taken in the same year as the clearance fire. Axel Steensberg had here used the planting-stick method in both cases. (D.G.U.). 
oak on the unburned area. It appears quite clearly at this stage already, that the succession of the landnam phase exactly corresponds to the one which can be observed on the burned area. Since willow, hazel, and aspen are in full bloom, whilst only very few birches have begun to flower, the present situation corresponds to the transition between the first and the second stage of the landnam phase.

In one of the burned strips and in half of the intervening unburned strip there has been light annual grazing by heifers, and by goats in one single year. The grazing has held the undergrowth down somewhat, but would probably have to be more intensive in order to produce the scrub pasture characteristic of the landnam phase. Of the indicator plants for pasture, white clover has appeared with the cows on the grazed area. This is beginning to become overgrown, since in many places the grazed undergrowth is beginning to grow above grazing height.

\section{Lessons of the experiment}

The experiment has been richly instructive in many other aspects apart from the chief aim of confirming the interpretation of the landnam phase in the pollen diagrams. The amazing, almost smothering frequency with which the burned-ground mosses appeared, particularly the bryophytes Ceratodon purpureus and Pohlia nutans, was a surprise, although it ought not to have been. They occur over the whole world on burned ground in the short interval before herbs and regeneration have established themselves. Since these mosses develop sporangia to an unusual extent, they form many more spores than most other mosses, and should be suitable for an accurate localization of a clearance by

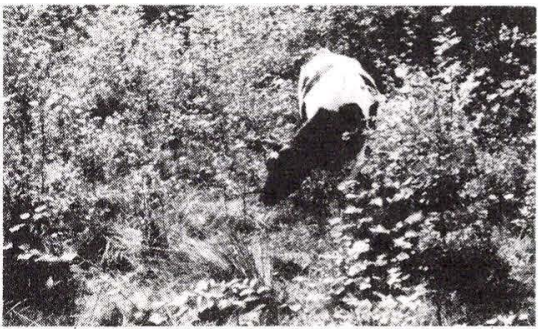

58. Six years after the clearance fire a luxuriant renewal growth of trees and shrubs as well as dense herbaceous vegetation has appeared. Heifers forage 2-3 weeks per year in this area and inhibit the renewal. September 1960. (D.G.U.).

burning in the pollen diagram. The first diagram in which moss spores were counted was the new local diagram with a landnam phase, discussed on p. 89 (see also fig. 55), and rightly enough the moss spores formed a sharp maximum in the fire layer; the same is the case in the only lake deposit diagram with a landnam phase to have been checked for moss spores.

Many other uncertain points have been illuminated by these experiments, and it is now possible to construct a more securely-founded picture of these first extensive forest clearances of the Stone Age.

\section{The way of life of the landnam people}

There can scarcely be any doubt that the chief purpose of the great clearances was to obtain food for freely roaming cattle, which previously had foraged on other grass pastures or on leaves. One must assume that the clearances were carried out by the people of a settlement when the increasing number of livestock made it necessary either to move or to extend their pasture. The lighter grazing or complete abandonment of the older scrub pasture led to its becoming overgrown by a hazel scrub forest, where 
nuts could be gathered. Since cultivation of the land was relatively slight, to judge from the pollen flora, it is probable that nuts again played a decisive role in the diet, as in the Maglemose period. In many diagrams hazel pollen reaches such a high frequency over a long period that it can hardly be explained merely as a stage in the succession. The hazel groves must have been actively maintained by suppression of the high forest, probably by bark peeling (in lime) or by ring cutting through the bark and outer wood.

The landnam culture was thus based on freely wandering cattle, which fed on leaves, grass, and mast, whilst nuts were harvested and cereals were cultivated. During the winter the cows were probably fed, in part, on leaf hay.

Do the elm decline and the landnam phase indicate two farming cultures?

If the elm decline on the boundary between the Older and the Younger Lime period was caused by man, an opinion which the present author shares, is it then an indication that two fundamentally different farming cultures existed simultaneously in the early Younger Stone Age? The difficulty in answering this question lies in the fact that up to now it has not been possible to identify with complete certainty the pollen-analytical evidence of primitive agriculture with the archaeologically determined Stone Age cultures, known from dwelling places and graves.

\section{Two archaeological interpretations}

According to one body of opinion, the elm decline was caused by the Ertebølle people, who in that case must have developed a semi-agricultural life with the use of leaves for fodder, whilst the landnam people were un- doubtedly immigrant herdsmen. According to the other body of opinion, the Ertebølle culture as a whole was purely a hunting culture. If we exclude an evaluation of the archaeological factors, as here, and attempt to hold to the standpoint of vegetation history only, a defence of both these interpretations can probably be found. The clearance by burning of the landnam people was chiefly carried out on dry ground, although they may also have cleared the damp, but not soft, parts of the marginal forest. The same people who lived on the high ground, having fields surrounded by scrub pasture and nut groves, and bordered by grazed forest and primeval forest, may also have collected leaf hay in the ashelm stands by the lakes and streams. The first, less pronounced landnam on higher ground did not need to produce large pastures; the cattle could have fed to a great extent upon the regenerating lime suckers and undergrowth. Pasture, as the experiment showed among other things, first occurs after fairly heavy cattle-grazing.

On the other hand, however, there are pollen diagrams from areas outside Denmark where there is evidence for considerable and long-lasting occupation of Younger Stone Age date with no sign of a typical landnam phase - in Switzerland and in midSweden, for example. Thus there is much in favour of the idea, reasonable enough in itself, that two different farming cultures lived side by side in Denmark, a technically more advanced and numerous immigrant herdsman people, and a perhaps homegrown, more primitive culture, which adopted the simplest form of feeding animals, together with a little agriculture. The flake axes of the Ertebølle people were admirably suited to a leaf-fodder culture. 


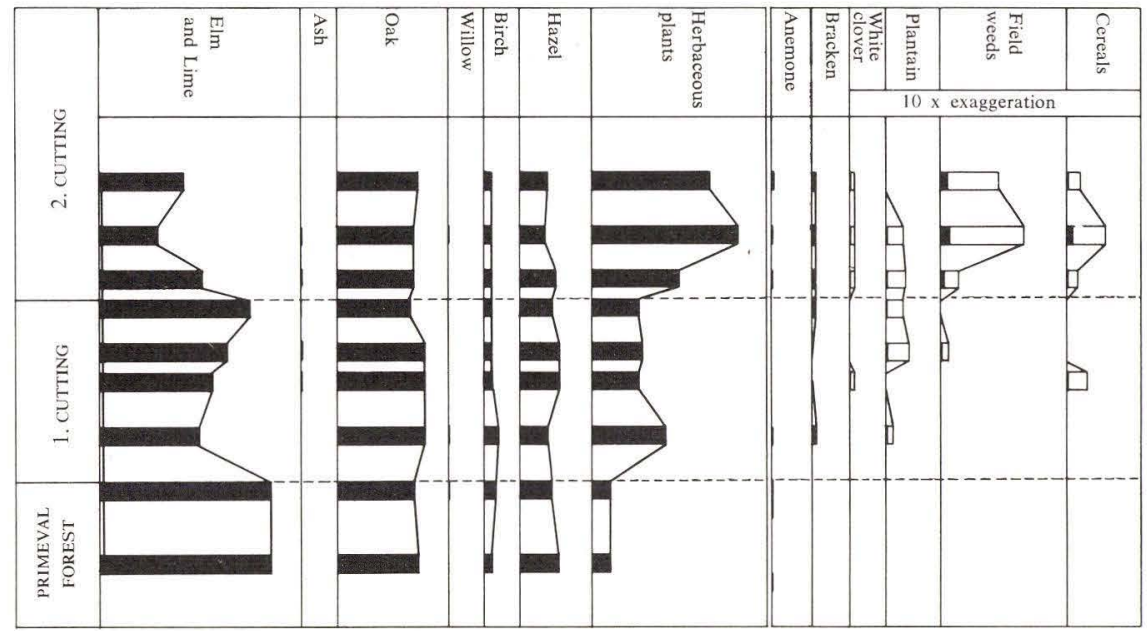

59. Pollen diagram from Troldebanken. The analysis was made in a layer of mor (forest humus) on the small islet. The diagram shows that the limes were twice felled or lopped in the course of the Lime period, in connection with a little cattle grazing and cultivation. The oaks were spared. (C. Vang Nielsen and Johs. Iversen, D.G.U.).

Primitive agriculture on Troldebanke, north of Tønder

A pollen diagram from Troldebanke, an island-like sand mound near the edge of a bog, contains evidence of a primitive agriculture deviating from that of the landnam phase. In the Younger Lime period this islet was covered by forest, and mor (see p. 100) built up on the forest floor. As usual, the layer of mor was in most places completely removed by human activity, but in one place a mor layer 15 $\mathrm{cm}$. thick was preserved. A pollen diagram from this layer tells the history of this little mound in the Younger Lime period (see fig. 59).

At first the islet was covered by a primeval lime forest mixed with some oak. Then man arrived and chopped or lopped among the lime trees, so that the forest became lighter, and herbaceous plants, particularly grass, appeared on the forest floor. White clover pollen is evidence of forest grazing on the islet and a little cereal pollen shows that there was some field cultivation nearby, perhaps even on the islet itself. Then it was deserted for a while, and lime expanded again until a new chopping and lopping took place among the limes, this time more thorough than the last one. Now cereals and field weeds (cruciferae, knotgrass, sheep's bit, etc.) appear in such frequency that there must have been small fields on the islet at this time. Since white clover and buttercups grew among the forest anemones we can conclude that animals were also kept.

A comparison of this short local diagram with the previously discussed and just as local diagram from the forest peat (see p. 89) which includes clearance by fire and a landnam phase, shows a striking difference; the fire layer and characteristic succession with three phases is completely missing. As with the lake settlements in Switzerland, ribwort plantain plays a smaller role than cereals and field weeds: pasture was very distant. 
One can imagine a very small dwelling site with a piece of enclosed arable land, surrounded by a forest of oaks and (lopped?) limes, together with mistletoe, ivy, holly, and honeysuckle. Some cattle wandered in the forest - perhaps a few cows which never left the islet and were additionally supplied with leaf hay? Let us hope that archaeological finds can provide more detail, but the traces may have been wiped out, for the islet in much later times became a refuge surrounded by ramparts.

\section{Later forest clearances}

Throughout the Younger Lime period the activity of the peasants characterized the pollen diagrams, but the influence of culture moved from place to place. Thus we find that in some localities there was uninterrupted scrub pasture. Clearly enough it was necessary to control the high forest now and again when it threatened to close its canopy, but a true clearance by burning and with a phase of birch is never repeated. Taken as a whole one must say that forest and scrub, not open pasture, characterized the Danish landscape in the Younger Lime period. But the shade-trees, lime and elm, were forced back by these cultural interventions; the light-trees oak and ash were favoured, and hazel coppice was common. It is tempting to suppose that the forest was to a great extent a low forest, perhaps with oak standards here and there.

\section{Dwelling sites}

The universal transformation of the Danish landscape in the Younger Lime period, from dark primeval forest to lighter woods and hazel groves, interrupted by scrub pasture and fields around the settlements, corresponds with the dispersal and strong develop- ment of the peasant culture in Denmark, as has been demonstrated by archaeologists.

Starting from the boundary between the Older and the Younger Lime period a wave of more or less related farming cultures seems to have spread over northern Europe, from Ireland in the west to mid-Sweden in the east. These cultures are characterized by various forms of pottery with grain imprints. In some cases new peoples undoubtedly immigrated bringing cereals and domestic animals with them; in other cases it was more a matter of cultural transmission by influence. These are difficult archaeological problems, which are eagerly being discussed today.

The archaeological problems are obviously closely connected with the various types of human intervention in the forests, as revealed by pollen diagrams. But the relationship between

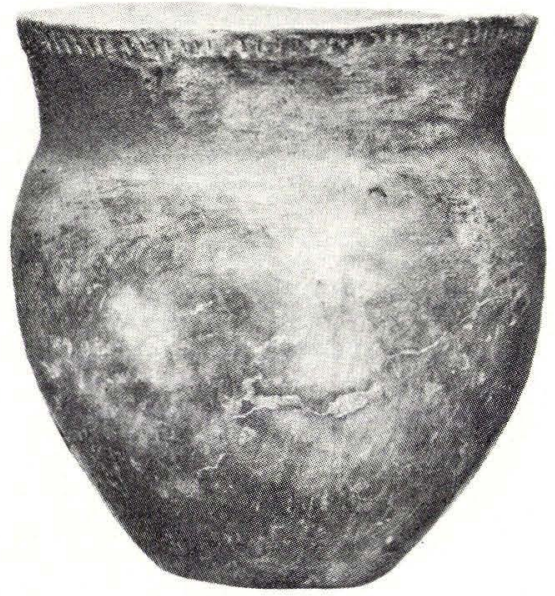

60. Clay vessel from the oldest Stone Age farmer culture. The vessel was found in Amose and dated by the Carbon-14 method to ca. 2,800 B.C. There are impressions of naked barley on the vessel. (J. Troels-Smith 1953). 
the changes in nature caused by forest clearance, the search for food by cattle, and cereal sowing, and the archaeological evidence, which is built up on pottery, tools, and methods of burial, is far from being cleared up. In this presentation of the developments in natural history it is necessary as regards archaeological cultures and problems to refer to the comprehensive presentations of the archaeological point of view found e.g. in Politiken's History of Denmark, vol. 1, p. 97. A few dwelling sites will be mentioned here, however, because they are especially important in connection with vegetational history.

The oldest hunter dwelling places, with traces of cereals and domestic animals

In its narrower meaning the Erteb $\varnothing l l e$ culture belongs to the last part of the Older and the first part of the Younger Lime period - exactly the time when the first spread of agriculture in North Europe began a new era.

We have previously mentioned the hunting and fishing of the Ertebølle people as it is known from the shell mounds by the coast.

Contemporaneously with these coastal dwelling sites we now also find many inland Ertebølle hunter dwelling sites by lakes and streams. One of these, the Muldbjerg dwelling site in Åmose, has been dated by pollen analysis to be slightly younger than the elm decline, which agrees with the C-14 dating ( 2,800 B.C.). It lies upon a peat islet and is a typical Ertebølle dwelling site, with its characteristic flake axes and thick-walled, tapered clay vessels. But as well as these, many fragments occur of thinwalled vessels, which are thought to be the earliest type belonging to the advancing peasant culture. Impressions of wheat were found in one

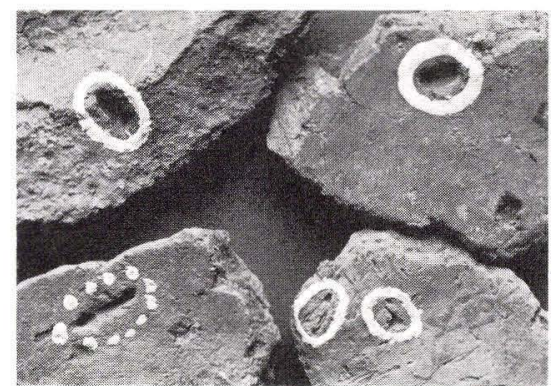

61. Sherds of clay vessels with impressions of the grains of several cereals. The sherds were found at the dwelling site near Ørum $\AA$ on Djursland, and at the Kornerup dwelling site near Roskilde. Both sites are from the Younger Stone Age. (Nat.Mus.).

sherd; moreover, as well as many bones of hunted game, a couple of cow bones and some sheep teeth were found.

\section{Ertebølle culture - peasant culture}

This find is the most important argument for the opinion that the Erteb $\phi 1$ le people as well as hunting, fishing and gathering, had begun to sow cereals in small fields and to keep a few cattle which were fed on leaf fodder. Some archaeologists, however, suppose that the clay vessels and domesticated animals had been stolen or procured from a contemporary immigrant peasant culture.

The same early type of thin-walled pottery is found in large quantities at another West Zealand dwelling site, Store Valby, on high ground. Here, impressions of small spelt, emmer, dwarf wheat, and barley have been found; bones were not preserved. It is quite certain that there was agriculture connected with this dwelling site, but Ertebølle types occurred among the flint tools. Here again the archaeologists are divided; is this an Erteb $\varnothing$ lle dwelling site with agriculture, or is it 

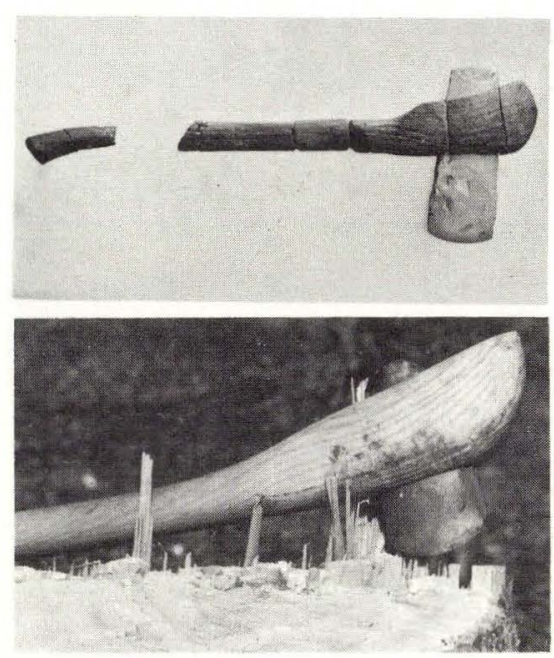

62. Above: the famous hefted thin-butted flint axe from Sigerslev Bog on Zealand. The shaft was made of ash like presentday axes.

Below: one of the axes used in the experiment. The shafts were prepared by the National Museum with the Sigerslev axe as a model. For axe-heads, original Stone Age axes were used. (Nat. Mus., D.G.U.).

the dwelling site of immigrant peasants who had got hold of some Erteb $\emptyset$ lle implements? These questions have not yet been answered and they can probably only be answered finally when a dwelling site of this type, lying on high ground where cereals could be sown and domestic animals kept, has been investigated pollen analytically.

\section{Barkær}

The oldest Danish agricultural dwelling site which can be set in its natural surroundings with reasonable certainty, is the settlement Barkær, excavated by $P$. V. Glob, and lying on an island in Korup Lake. At that time the lake was connected by a narrow fjord with Kolindsund on Djursland.

Characteristic for Barkær is the sharp, thin-butted axe. This type appears for the first time in Åmose, together with the landnam phase, and there seems to be general agreement that it was the thin-butted axe that the landnam people used. Its efficiency was demonstrated in the previously described clearance experiment. A pollen diagram has been obtained from Korup Lake which has an especially marked and temporally restricted landnam phase; there can scarcely be any doubt that this reflects the Barkær people's forest clearance and cattle grazing. Agriculture is registered in the landnam phase by a not inconsiderable quantity of cereal pollen; emmer and barley have been found in pottery fragments from Barkær.

The village consisted of two parallel, $85 \mathrm{~m}$. long houses of wood; between them there was a $10 \mathrm{~m}$. broad cobbled street, edged with pavements. Every "longhouse" contained 26 similar dwellings, of which only four have later been added. It is exactly this sort of collective community as described by the excavator that one would expect to find behind such a large enterprise as the landnam around Korup Lake. This was already demonstrated by means of the pollen diagram; and

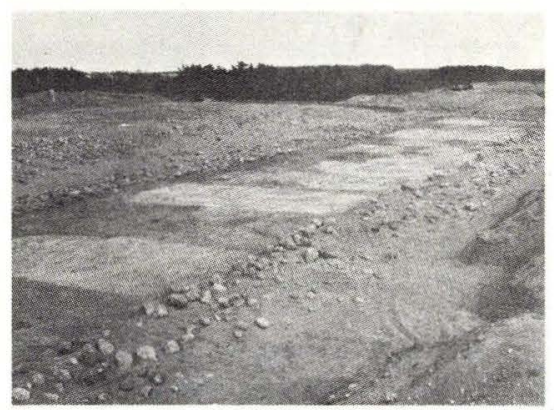

63. Part of the ground plan of one of the Barkær long houses. The square patches indicate the individual dwellings. (From P. V. Glob). 
confirms the speculation that the landnam was executed as a great collective clearance by burning, carried out simultaneously with the establishment of a settlement. As pointed out by the excavator, Barkær must in fact have been planned and built as a unit, and it was also abandoned in good order when the tribe moved on.

If the Barkær village is associated with the landnam phase, there is a striking correlation between the conclusions which have been reached independently by natural scientific and by archaeological methods.

\section{Bundsø}

Bunds $\emptyset$, on Als, was, like Korup Lake, the innermost lake-like widening of a narrow fjord. A pollen diagram shows that, unlike the situation in Barkær, peasants lived in the vicinity from the landnam period until long into the Iron Age. In the Younger Stone Age the high forest almost gained the upper hand several times, but it was immediately cleared each time and the scrub pastures continued again.

From this prehistoric centre of settlement a single Stone Age dwelling place from the Younger Passage Grave period, i.e. from a much later period than the Barkær settlement, has been excavated by Therkel Mathiassen. The usual cereal species, small spelt, emmer, wheat and barley, have been found in the pottery. Of the no fewer than 10,000 excavated bones, only a few hundred come from huntable game; most of them are from red deer, but there are also bones of roe deer, wild boar, aurochs, bear, marten, polecat, and otter, as well as game birds such as white-tailed eagle. There can be no doubt that the game, too, had obtained better living conditions in the forest after the clearances of the peasants.
The overwhelming number of bones of domestic animals, first and foremost cows and pigs, shows that the rearing of livestock must have been the chief occupation. This is in good agreement with the picture of the landscape obtained from the pollen diagram. The whole forest was affected by man; the shade-trees lime and elm were replaced by ash and oak, and hazel groves and scrub pasture were very important.

\section{The single grave culture}

Round about 2,000 B.C. - that is to say 1,000 years after the farming culture took root in Denmark - a new people immigrated from the south up through Jutland. These were very different from the homely peasants, whose great stone tombs, first dolmens and then the passage graves, have won them a monumental reputation. The new people's graves were not great communal graves as with the contemporary passage grave people, but small individual earth graves, men's graves and women's graves; hence their name, the single grave people. Their weapon was the battle axe, usually of greenstone, never of flint; the flint axe was only used for tree-felling.

The single grave people were mobile herdsmen like the landnam people, with cows and sheep but only a little agriculture. These herdsmen undoubtedly influenced the vegetation of the heath areas of Jutland, which they first colonized. The forest here was more open, and the density of population was low; the landscape was more suitable for livestock than for agriculture. Later, though, they penetrated further throughout Jutland, and other tribes invaded the Islands.

A very marked and thorough forest clearance has been demonstrated in a 
few places in Djursland; it is clearest in a diagram from Dyrholm. A find dated pollen analytically suggests that this clearance was the work of the single grave people. It differs from the landnam phase in that the clearance or the grazing was more effective. It was particularly hard on the hazel groves and lime forests, and the livestock appears to have prevented regeneration. We have here the first evidence of more extensive grass pasture without a strong admixture of hazel scrub, etc.; but this phase, too, was only short-lived.

\section{Bronze Age farming}

A splendour hangs over the Danish Bronze Age, with its magnificent and

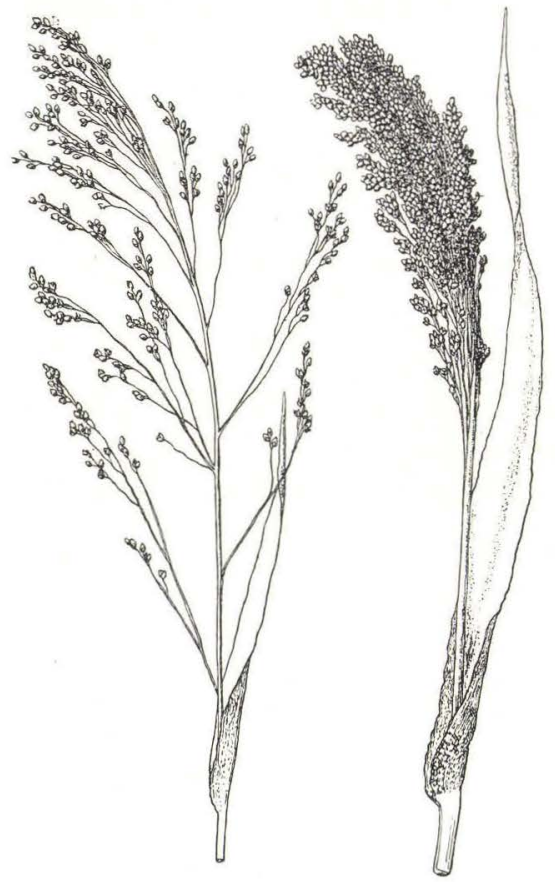

64. Two varieties of millet which were cultivated in the Bronze Age together with the Stone Age cereals. (From G. Hatt). world-renowned finds - the sun chariot, the lur horns, the well-preserved woollen garments, etc. But most of our knowledge about the everyday life of the Bronze Age peasants comes from the few known dwelling sites.

The Bronze Age peasants grew the same cereal species as the Stone Age peasants; but now barley was the most important, both in its naked and awned form. Small spelt and emmer still occurred, however, as well as wheat, and there is one find containing spelt, Triticum spelta. Spelt, too, is a primitive wheat species with a weak ear-stalk like emmer and small spelt, and with its grains tightly enclosed in the awns. Another newly-arrived species is millet, Panicum miliaceum, but this was not particularly common. Millet is best known to us today as bird-seed, but in warmer countries, especially in Asia, it still plays an important role as bread corn. A third new cereal species, still rare, is oats, Avena sativa. Peas, Pisum, and beans, Vicia faba, were also cultivated together with the oil plant gold of pleasure, Camelina sativa; the latter gained great importance in the Iron Age.

The horse, too, at last appeared among the domestic animals. It was only small, and was presumably used for riding; moreover it is likely to have been reserved for the upper class. The ox was used as draught animal for ploughing with the primitive ard, as can be seen in the rock carv. ings on South Swedish rock surfaces.

\section{Bronze Age honey}

A dark, dried-up mass was found at the bottom of a jar and a birch-bark bucket from Bronze Age graves, and microscopic analysis showed this to consist of pollen of plant species visited by bees when collecting nectar 
and pollen. These finds are not only evidence of the presence of bees in the Lime period, but they also help to sketch a picture of the Bronze Age landscape. One of the samples consisted almost exclusively of lime pollen; the other consisted of pollen from white clover (33\%), St. John's wort, bindweed, sheep's bit, and other lightloving herbs - the two samples are thus evidence of lime forest and rough pasture.

\section{Field and pasture in the Bronze Age}

The few known Bronze Age dwelling places give no scope for studies of the surrounding landscape. In compensation, however, the investigation of three South Jutland burial mounds from the Older Bronze Age has given detailed information of the contemporary plant growth in the poor area surrounding the mounds. Even at that time a hard pan had formed in the area, which affected the soil drainage, and after the mound was built the downward percolating water created another impermeable hard pan over the grave itself with the oak coffin; this prevented oxygen from entering. In the damp oxygen-free conditions both the coffin and the garments it contained as well as the vegetational remains were well preserved.

Two of these mounds were built on poor pasture with heath grass and other poor grasses, heather, pill sedge, tormentil, field pansy, sweep's brush, and a lot of moss. Such a plant community only occurs under very heavy grazing. The presence of weed-plants in nearly all of the samples is strange. The fruits of sheep's sorrel were especially common; this plant may grow on very poor pasture, but fruits were also found of species characteristic of fields: species of knotgrass, and fat hen. This indicates that the area was

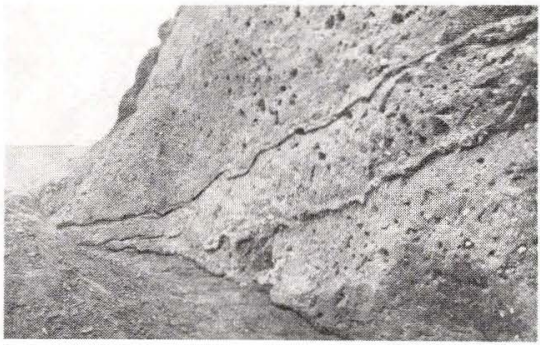

65. Section through a Bronze Age burial mound in South Jutland. The burial chamber and oak coffin were sealed by a hardpan (the horizontal stripe under the mound) and two iron pans, formed later, which can be seen as two dark curved lines. (Nat. Mus.).

probably abandoned arable land, which due to grazing had developed into pasture. The seeds of fat hen, knotgrass and sheep's sorrel have a tight, tough seed-case, and they can lie in the ground for a long time before germinating when the soil is ploughed up again.

\section{Heath arises through grazing}

One mound, however, was definitely built upon pure heath, and was built of heath turf. The mound has been dated to the period 1,500-1,100 B.C., in the Older Bronze Age, so that we have here the earliest certain example of heath in Denmark. There can scarcely be any doubt that this heath arose after forest clearance and grazing; we will give an example of such a process later.

In the diagram in fig. 29 a temporary decline in grasses, plantain and sheep's sorrel can be seen in the middle of the Younger Lime period; the peasants had left the area for a while. Heath spread immediately across the abandoned pasture and fields, and regeneration of lime forced the lightdemanding trees back. 


\section{The deterioration of the soil begins}

\section{Mull}

In the lime period the normal soil was mull, the most favourable of all the soil types. Forest mull is the home of a rich soil flora and fauna, which assists in the rapid decomposition of all the forest litter to carbon dioxide, soluble nutrients, and humus, amongst other things. These processes are fully described in Danmarks Natur, vol. 6 . In mull, clay particles and humus form a combination which is the basis for many extremely complex weathering processes. In this way the organically bound nutrients are produced which form the great nutrient capital of the mull. Mull is thus the centre for a whole complex of biochemical processes. It also has other qualities which are beneficial for the forest. The crumb structure of mull permits adequate aeration and a favourable water-balance; precipitation is bound by the humus content and the excess water easily drains away between the crumbs, which are in fact worm casts.

\section{From mull to mor}

Mull changes in character as the millennia pass; the change is extremely slow in clay soil but faster in poor sandy soil. First the lime is leached and the mull becomes acid. Moderately acid mull can also be very fertile, but if it becomes too acid the earthworms and the bacterial flora can no longer thrive; the soil begins to deteriorate. The rich mull changes to a poor mull. The larger earthworms which constantly pull organic matter deep into the soil and deposit their casts on the surface, thus turning the earth over every few years, are the first to disappear. The smaller earthworms, which only turn over a shallow layer, follow after them, and so only the smallest earthworms, which stay near to the surface, are left. At about this stage the bacteria which attack the pollen exines also seem to disappear, and pollen then accumulates together with humus on the soil surface. A critical threshold has thus been passed: mull has become mor.

This account of the formation of mor is very simplified; it is in fact a very complicated process, which has not yet been completely elucidated. The vegetation is also of great significance; coniferous trees such as spruce hasten mor-formation, whereas the tree species of the Lime period tend rather to delay it.

\section{The formation of podsol profiles}

In pronounced mor the breakdown of organic matter is mainly carried out by fungi. The mor layer causes the

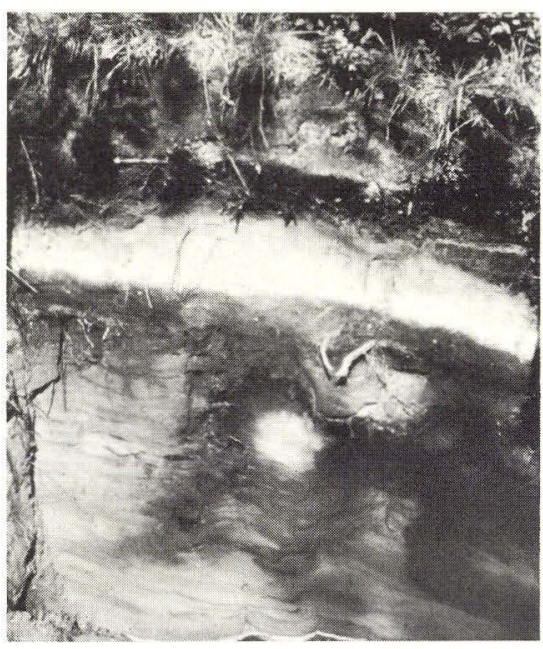

66. Podsol profile in Draved Forest. The almost white layer of washed-out sand can be seen between the overlying, dark mor and a thick, dark, stony hardpan which alters to yellowish sand further down. (D.G.U.) 
downwardly percolating water to become very acid, and thus the iron in the upper soil layers is dissolved and is re-precipitated lower down together with dissolved humus, forming a hard pan. This can be rock-hard and nearly impenetrable both for water and for plant roots, since the mineral particles are glued together by humus or by iron salts. The humus is deposited first and forms the chocolate-coloured humus pan; under this an ochre-coloured iron pan is usually found. The combination of mor, hard pan, and the intervening ash-coloured leached sand, extremely poor in nutrients, makes up a podsol profile.

\section{Fossil pollen-mor}

The oldest mor-layer found so far dates from the transition zone between the Older and the Younger Lime period. Apparently mor can also be formed in a primeval forest of oak and lime on poor Late-Glacial eolian sand, but this mor has a "mild" character and, to begin with, a loose structure. But since nearly everything except pollen becomes broken down, a dense greasy mass is built up in the course of time - fossil pollen-mor, which lacks the relatively good aeration of normal coarse mor. Above this dense fossil mor there has always been a less decomposed, crumbling layer of "living" mor.

Thick layers of fossil mor are very rare in the lowlands of Europe, and they have only been discovered very recently. The most extensive and best known examples are found in Draved Forest near Løgumkloster, and can be up to $1 \mathrm{~m}$ thick. The fine stratification of fossil mor is usually completely undisturbed, since earthworms are absent and tree roots penetrate through the humus without causing any disturbance. It is thus possible to study the development of the vegetation on the very spot by means of pollen analysis, from a distant past until today.

\section{From lime forest to oak forest}

The few centimeters of the sand immediately beneath the mor-layer are extremely rich in pollen, and even though the pollen grains are less well preserved, they still give a reliable picture of the composition of the forest at the time of the transition from poor mull to mor. At this time the large flat eolian sand banks in Draved were covered by a primeval forest of lime and oak, with hazel as the pioneer tree.

Pollen diagrams taken from these mor-layers, up to 5,000 years in age, show right at the bottom the last stages of the transformation of the lime forest to an oak forest, caused solely by the gradual deterioration of the sandy soil due to leaching. The role of hazel as the local pioneer tree after the fall of old trees was simultaneously taken over by birch. The forest became poorer and poorer, and thus lighter. At a certain point in the succession holly appears in the mor diagrams as an important component, presumably because the forest was now light enough to allow it to maintain itself as a flowering tree in the oak forest. Unlike holly, alder buckthorn only occurred as a pioneer, together with bracken and grasses.

There is a total absence of the pollen of indicator plants for agriculture in the lowest analyses. Later on, an extremely sparse occurrence of ribwort plantain indicates that the Stone Age peasants had begun their landnam in that area, around 2,500 B.C. The local forest seems to have preserved its primeval character, however; this was altered very suddenly by a landnam in the Beech period, as we shall see. 


\section{Swampy soil and forest peat}

A special type of soil is formed on very damp ground, which differs from mull in its poor aeration. Earthworms do not thrive and the soil does not acquire the loose, crumbling character of mull; instead it forms cracks and fissures when it is dry. Immediately below the dark, humus-rich surface the soil is often blue-grey with reddishyellow rust patches - the "gley horizon". The two colours are caused by the occurrence of iron either as an oxidized red compound (ochre), or as a reduced, blue-grey compound. Further down the reduced form is dominant and there are no red patches. The luxuriant mixed forest of common oak, ash, alder etc. depicted on p. . . belongs to this swampy soil, also known as "anmoor".

The soil is normally fertile, since no true leaching takes place. However, a deterioration still occurs here in the long run. As in mor soil, the organic matter does not become completely decomposed, and peat builds up. It can be difficult to determine whether the formation of peat originally began as a result of paludification in a more humid climate, or whether it is only due to the increasing poorness and lower lime content of the circulating ground water. Once peat formation has begun, its nutrient content is quickly reduced during its continuing growth.

\section{From luxuriant mixed forest to acid birch forest}

The alteration of forest vegetation by peat formation is illustrated in a pollen diagram from Draved. At the commencement of the peat formation in the Younger Lime period the forest was a luxuriant mixed forest of oak, alder, lime, ash, hazel and honeysuckle, with a herb flora of anemone, devil's bit, creeping buttercup, and grasses; the ground was damp and wet in patches. As time passed ash and alder became more common, lime less common, and in the ground vegetation grasses and sedges occurred more richly; bittersweet occurred and anemone was still present. The change was not great, but the soil was perhaps a little damper. But then a drastic change occurred: alder and ash were replaced by birch, the sparse hazel by alder buckthorn, and anemone by shield fern and royal fern. Acid birch forest had replaced the luxuriant mixed forest. By this time we have reached the Beech period, and soon human influences can be traced, but this succession registers the natural soil deterioration on damp ground.

\section{A portent of a climatic deterioration}

We have seen that pollen diagrams clearly register human intervention in the composition of the forest, and that they also give a clear expression of local changes in the soil. It is much more difficult to demonstrate moderate oscillations in temperature since we do not have any wind-pollinated indicator plants for a warm climate. Only ivy produces and disperses so much pollen that it is possible to obtain a reliable pollen curve from very thorough counts.

\section{Ivy as an indicator of mild winters}

In this country ivy must be regarded as an indicator of a mild climate. This is shown by its distribution in relation to temperature, and it is confirmed by observations in nature. Ivy cannot tolerate very cold winters such as those of $1939 / 40$ and $41 / 42$, when most of the tree-climbing ivies in our forests perished. The distribution of plants is to a great extent determined by the ex- 
treme climatic conditions that occur at long intervals. Thus conclusions regarding the dependence of plants on the climate must be based upon observations made over a long period of years.

In the Atlantic countries such as Ireland and England, ivy stems can be seen everywhere, hanging down from the crowns of trees. Danish diagrams show clearly that in the Atlantic period ivy throve just as well on the Danish coasts; the pollen frequency is just the same as in the Irish and English diagrams. In analyses from the interior of Jutland, however, where the temperature was a little lower, ivy pollen is only sparse. This indicates that the ivy curve would be seriously affected even by a slight decrease of the winter temperature.

\section{The ivy curve in the Younger Lime period}

As already mentioned, a catastrophic fall in the ivy pollen curve occurs in Danish pollen diagrams at the transition between the Older and the Younger Lime period; this fall is especially striking in coastal areas. One gets the impression that now for the first time really hard winters had appeared, in which the fjords froze over and the raising of the winter temperature which they normally caused was suddenly changed to the opposite effect - the ice-covered fjords became cold centres where cold air could collect. It is interesting that the tides, which raise winter temperatures in coastal regions, had a minimum at this time, according to the calculations of a Swedish oceanographer.

This ivy decline in the Sub-Boreal period occurred also in Scania and in Holstein, but not in the Atlantic countries with mild winters - West Norway, Holland, the British Isles, and

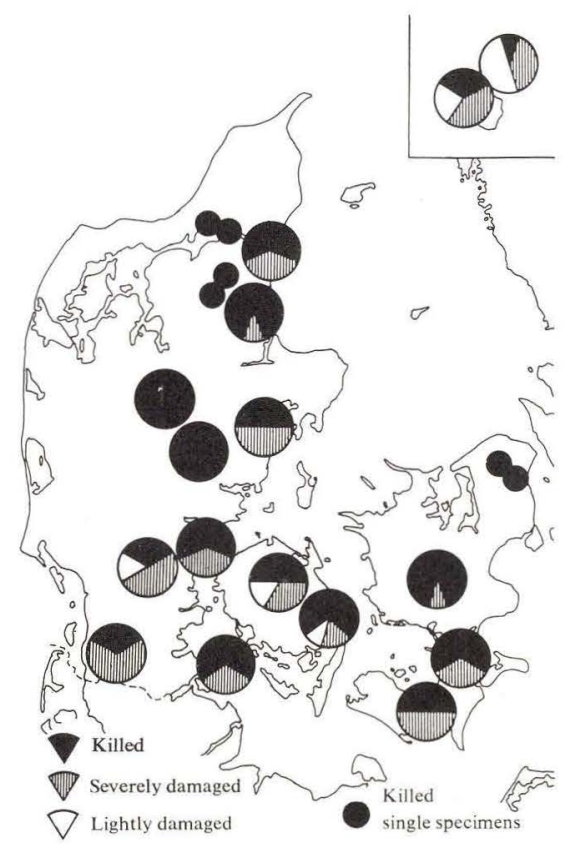

67. Map showing the effect of the cold winters of 1939-42 on ivy. Only on Christians $\varnothing$ in the Baltic, where the minimum temperature was a little higher, could a majority of the stems survive.

north-west France, where the ivy frequency in fact rises, except in the landnam phase where this occurs. Ivy does not survive clearance by burning, but apart from this it is favoured by human intervention in the primeval forest because the light conditions are improved. On the other hand the collection of ivy shoots for cattle-fodder in spring, when leaf hay is about to run out, could locally affect its pollen frequency.

\section{The warm period continued}

Even though the warm optimum occurred in the Atlantic period the succeeding Sub-Boreal period, the Younger Lime period, must still be referred to the Post-Glacial warm period. The minima in the temperature curve can 


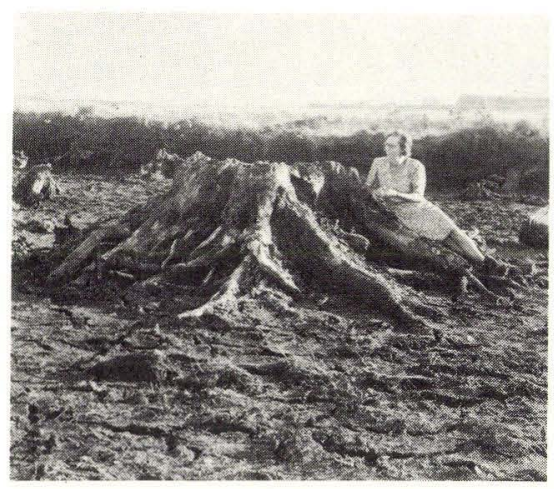

68. A large oak stump in the fossil forest at the bottom of Lundergård Bog. The forest was killed by paludification in the middle of the Older Bronze Age. The stumps were preserved by the quickly growing Sphagnum peat. Oak was dominant but stumps of birch and alder also occur in the forest.

now be detected, but they are not yet sufficient to drive out the warmthloving plants and animals permanently. The ivy curve rises again, even though it never reaches the value it had during the Atlantic period. Mistletoe was still quite widespread, and water chestnut had not yet died out. The pollen of the grape vine, Vitis silvestris, has now also been demonstrated. This warmth-loving, twining shrub perhaps grew wild in the marginal forest. It would then be strongly favoured by the human interventions which improved the light conditions; also because the summer temperature in the lower forest layers increases in a lighter forest.

The Sub-Boreal fauna, too, still bore the mark of the warm period; thus pond tortoises still flourished in the lakes. The beetle Cerambyx cerdo, Europe's largest stag beetle, whose northern limit today lies just south of Danmark, has been found in SubBoreal peat on Zealand.

The mollusc fauna of the North
Jutland sea also retained its relatively southern nature. A few species disappeared but more arrived, including the bivalve Dosinia, which has given its name to the shell deposits from that time - the Dosinia layers. These have been dated by $\mathrm{C}-14$ determinations to ca. 2,500 B.C.

\section{A paludified oak forest from the Older Bronze Age}

After the peat had been removed by hosing, a well-preserved tree-stump layer from a forest of great oak trees mixed with alder and birch, came to light at the bottom of the flat Lundergård bog in Vendsyssel. The forest must have suddenly perished as a result of paludification, and the treestumps and the straight, fallen oak trunks have been preserved by the quickly-growing wet Sphagnum peat. This fossil oak forest is a particularly beautiful example of the oak-stump layers which according to Sernander were contemporaneous, resulting from the great climatic change between the dry, warm Bronze Age and the cold, wet Iron Age.

Pollen analyses and an archaeological find, however, suggested that the paludification here was of an older date, and a C-14 determination has shown that it occurred in the middle of the Older Bronze Age, 1,290 ( \pm 100$)$ B.C. This is a good example of the fact that the "Blytt-Sernander climatic scheme" was in need of revision. True enough, the Sub-Boreal period still belonged to the warm period, but the climate was not uniform. Its wave-like course was first ascertained from investigations in Swedish raised bogs, and right in the middle of the Older Bronze Age a precursor was found of the classical climatic deterioration at the transition to the Sub-Atlantic period, the Beech period. 


\section{The Beech period. From 500 B.C.}

The boundary between the Sub-Boreal and the Sub-Atlantic period was placed by Sernander at the climatic deterioration around 500 B.C. Since the first increase in the step-wise advancing beech curve also occurs about here whilst the lime curve declines continuously, it seems natural to place the division between the Lime period and the Beech period here too.

In the Beech period the processes that began to appear in the Younger Lime period gained the upper hand. Man influenced the forest picture more and more, and clearances were carried out on an ever-increasing scale; the open countryside appeared. At the same time soil deterioration became a serious factor, strongly promoted by human exploitation of the land. As far as the climate is concerned, there can now be no doubt that the Post-Glacial warm period was over, even though the temperature became distinctly milder several times, which is reflected in the raised bogs.

\section{Climatic deterioration in waves}

\section{Raised bogs as climatic indicators}

An undamaged raised bog rises above its surroundings like a huge sponge saturated with rainwater. The sponge consists of peat moss, Sphagnum, which absorbs the rainwater through pores in its leaves and stores it there. The surface of the raised bog shows a strange pattern of vegetation, a system of wet puddles - "høljer" - and higher situated, drier hummocks covered with heather.
The growth-rate and structure of the peat depends on the climatic conditions at the time of its formation. In this way a raised bog has acted as a self-registering climatograph for millennia. Under dry, warm conditions a dark-brown, nearly structureless peat was formed; this had a low growthrate. On the other hand, in a cool,
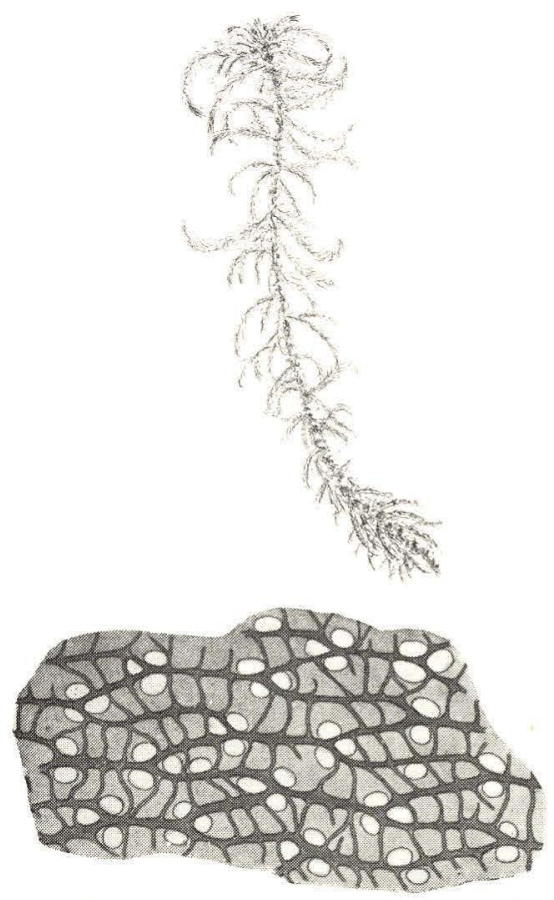

69. Sphagnum cuspidatum, the most important Sphagnum species in the wet "høljer" of a raised bog. Below, some of the peculiar large and light dead cells are shown greatly enlarged; they can store water which is sucked up through round holes (the light patches). The small, dark, living green cells can also be seen. (From O. Hagerup). 


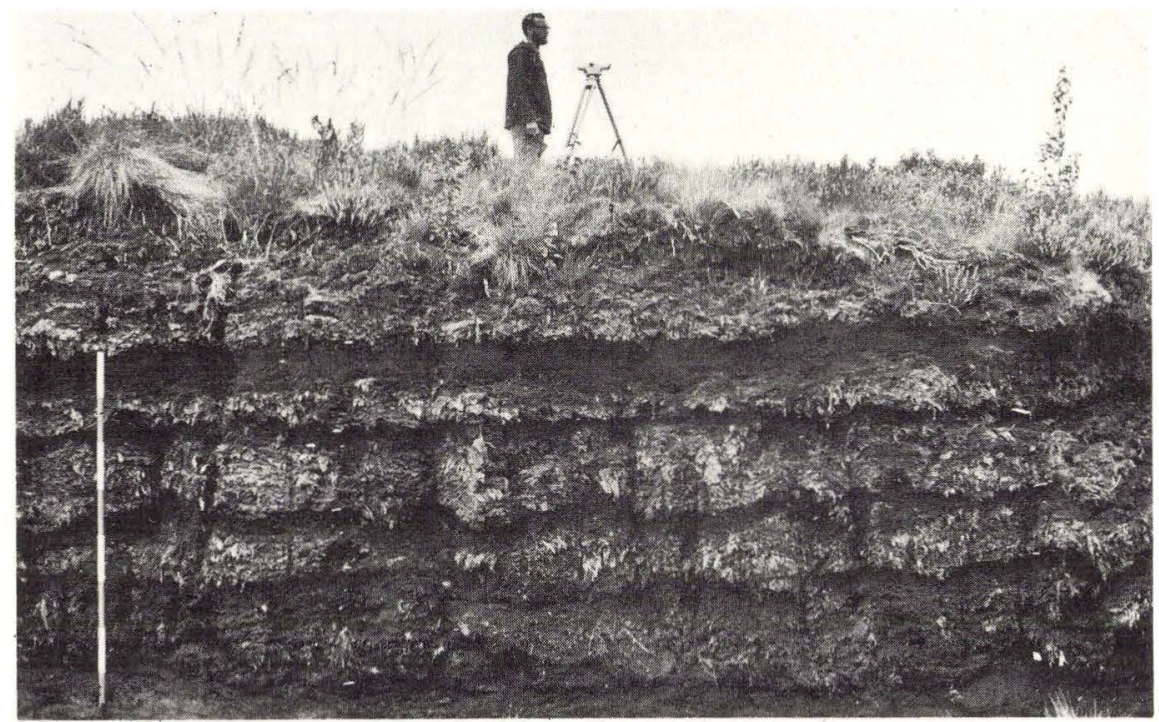

70. Profile through Fuglsø Bog on Djursland with clearly visible boundary horizons, which could be followed right through the bog. The top one-at the top of the levelling rod - corresponds to Gh II, A.D. 580 according to Carbon-14 dating. The lowest corresponds to Gh V, 2,140 B.C. Gh I was also found, but had been removed at this spot by peat-cutting. (D.G.U.).

damp climate the so-called "dogsmeat" is formed - a light, slightly decomposed peat of well-preserved Sphagnum shoots. In peat profiles one can see the dark peat at the lower part, whilst the dogsmeat is dominant further up. The transition from the dark peat type to the light can be so abrupt that one must assume that a threshold has been crossed, whereby the existing heather-rich vegetation pattern died out and was replaced by a new pattern where the more moisturedemanding Sphagnum species were dominant. The boundary horizon between the dark and the light peat is called a recurrence level ( $\mathrm{RY}$, from the Swedish expression); here, however, we will use the older name boundary horizon ("grænsehorizont", Gh).

Originally one discussed the boundary horizon, in the singular, since only one great climatic deterioration was thought to have taken place, which set the dividing line between the SubBoreal and the Sub-Atlantic period, at the boundary between the Bronze Age and the Iron Age. The Swedish scientist Granlund demonstrated, however, that there was a whole series of boundary horizons, five in all, of which the classical one, which was now indicated as Gh (RY) III, dated ca. 600 B.C., is probably the most widespread. There are two younger ones, Gh I ca. 1200 A.D., Gh II ca. 400 A.D., and two older, Gh IV ca. 1200 B.C. and Gh V ca. 2,300 B.C.

Now that the $\mathrm{C}-14$ method has made exact dating of the boundary horizons possible, their investigation has been taken up everywhere where suitable raised bogs are still to be found. Sweden is especially favourably placed in 
this respect in comparison with other north-west European countries where raised bogs have long ago been removed by peat-cutting. Granlund's results have been confirmed in principle by these new investigations and datings; a few new boundary horizons have been added, and it has been found that there are certain geographical differences, as one might expect. Thus there is a boundary horizon in Germany which lies between Gh II and Gh III, and which has no corresponding horizon in the far better investigated Mid-Sweden area. All of Granlund's 5 horizons have been demonstrated in Denmark, and the investigations are still continuing. Fig. 79 shows four boundary horizons in the same profile, an uncommon occurrence, since as a rule only one or two are clearly developed.

\section{What do the boundary horizons signify?}

It is clear that a boundary horizon indicates a transition to a moister environment, but increased moisture can be caused both by reduced evaporation, i.e. a fall in temperature, and by increasing precipitation.

As yet it has not been possible to separate these two components with certainty. However, since there is clear biological evidence of a falling trend in the summer temperature during the later part of the Post-Glacial period, the present author is inclined to consider the boundary horizons as being mainly influenced by a wave-like fall in temperature. A thorough investigation of the boundary horizons and, not least, of the alterations in the pattern of vegetation, will probably shed light on this problem. At present, work has been concentrated on the dating of the observed boundary horizons and on determinations of the changes which occur in the peat structure and the microfossil content.

There is reason to expect that in the near future we will be able to achieve a deeper understanding of the PostGlacial climatic development and its causes, through the cooperative efforts of geologists and physicists. We must hope that the most appropriate north European raised bogs will be preserved as research material for climatic history as well as the other branches of science which have found unique research possibilities in raised bogs.

\section{Glacial advances}

The deterioration in climate in the Sub-Atlantic period is also shown in the advance of the glaciers. The conditions in Alaska are the best investigated, and they indicate three glacial advances after the warm period. Since the ice advanced over wooded country here, it has been possible to C-14 date the glacial advances. The resulting dates agree so precisely with the datings of the boundary horizons Gh III, Gh II, and Gh I, that we can be certain that they are an indication of general climatic oscillations.

\section{The forest picture is altered}

\section{The disappearance of the lime forest}

We have described the lime as a dogged shade-tree which once having established itself was not easy to displace. Despite this the lime forest disappeared almost totally from Denmark. This had several causes.

The lime is a demanding tree from a climatic point of view. If the summer temperature is not sufficiently high the lime cannot complete the physiological processes that render it resistant to the winter cold. After the extremely cold summers of 1952 and 
1953 all the small shaded limes in Draved forest suffered severely; it was only due to lime's unique ability to regenerate that most of them managed to recover in the succeeding years. Where the young lime trees were better illuminated there was only slight damage, and on Lolland, which has a warmer climate, no damage at all was observed. The ripening of the lime seeds is also dependent upon favourable summer temperatures, and the renewal by seed plants is thus often relatively sparse.

The cool summers of the Beech period thus weakened lime in its competition with beech, which was not in the least affected by the lower summer temperature, rather the reverse since this resulted in higher air humidity, which beech enjoys.

The increasing soil deterioration also inhibited the lime on poor sandy soil in comparison with beech and oak, which make fewer demands on the soil.

In the more fertile and summerwarm areas of the country, however, it was first and foremost man who was the bane of the lime. All the changing types of farming from the Stone Age until nearly the present day have forced the lime back and favoured the mast trees, first oak and hazel, later beech. Whilst the folk singers extolled the "fairest of trees" the summertime's "green lime" with the "golden leaves" in the autumn, the peasants gave it its death blow.

\section{Ash and hazel are forced back}

Ash and hazel played a strikingly important role in the Younger Lime period. They were both encouraged by the man-made alteration of the forest to light scrub forest, and ash probably also spread onto the rich higher ground where lime and elm had previously dominated. In the Beech period ash and hazel are forced further and further back, whilst oak, the most important tree, held its ground.

\section{The expansion of beech}

Beech was already present in the Bronze Age, but only sparsely. It is possible that the farming of that time, with freely grazing cattle in the forests, hindered the dispersal of this shadetree, too. It began to gain ground in the Sub-Atlantic period, presumably being favoured by the climate. The advance occurred in stages, however, and it can be observed that each retreat of farming signified a new advance for beech.

But there can still be no doubt that the spread of beech was partly due to mankind. The rapid advances when cultural influences temporarily ceased are connected with the fact that the balance in the forest had been broken down. It would have been difficult for beech to invade a primeval forest of shade-trees; these would have had all the cards in their hand, so to speak for example, the regenerative growth would consist mainly of the trees which were already present. But on abandoned cultivated land and in grazed forest where there were only a few or no shade-trees, beech had all the opportunities.

\section{Hornbeam}

Hornbeam, which had at last reached this country, was also favoured indirectly by the human activities which gave it a chance to establish itself as soon as farming became less intense. Hornbeam is a shade-tree, but in competition with beech it is hampered by its lower height and shorter lifespan. It is also more demanding with respect to climate than beech, and the cool summers of the Beech period did not 


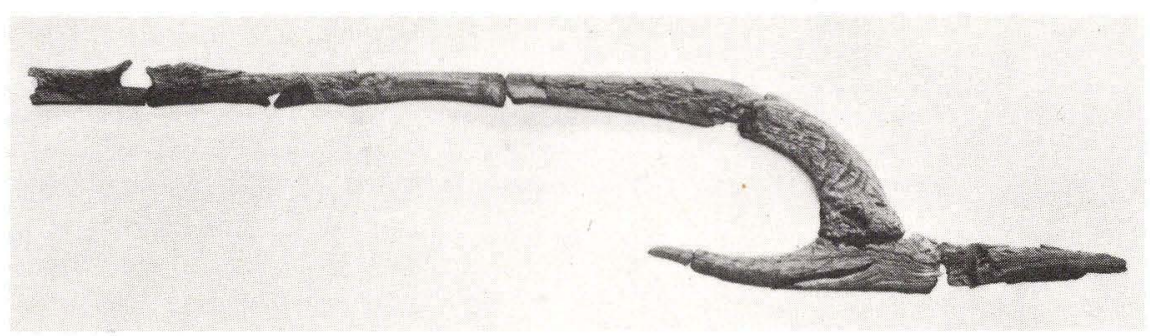

71. Primitive plough (ard) from the Pre-Roman Iron Age. Found in Døstrup Bog near Hobro. (Nat. Mus.).

suit it particularly well. It only achieved great significance on Bornholm, where it replaced beech as the climax tree, although beech presumably was not completely absent.

\section{The open land appears}

\section{The agriculture of the Iron Age}

Whilst we have only indirect evidence concerning the agriculture of the Stone and Bronze Ages from cereal impressions in pottery, finds of cereal pollen, and demonstration of ploughed furrows under burial mounds, we have a considerable knowledge of the agriculture of the Iron Age. This is partly due to the fact that field systems from the Iron Age are extremely well preserved in the Jutland heath areas, where Gudmund Hatt initiated a comprehensive investigation before the traces were destroyed by reclamation. Field systems have also been demonstrated in forests, but it takes a sharper eye to detect them there.

On the flat heaths the rectangular fields stand out clearly because they are surrounded by low banks, which formed on uncultivated strips between them. The dense vegetation here caught dust and sand blown off the fields, and rocks collected on the fields were thrown there. We know from dated bog finds that in the oldest part of the Iron Age, the so-called Pre-Roman (Celtic) period, the primitive plough, the "ard", was still in use in this country.

\section{Cultivated plants}

The most important Iron Age cereal was barley, both the naked and the hulled variety. Emmer, wheat, and spelt still occurred, but sparsely. Millet was still cultivated to a slight extent in the Pre-Roman period, 500 B.C.- 0 , but then it went out of use. In return, oats became commoner, and rye began to appear in the Roman Iron Age, 0400 A.D., although it was only sparse to begin with. It is believed that rye and oats originally occurred as weeds in emmer fields, but that they were gradually taken into cultivation in countries where they throve better than emmer and wheat. Both the cooler climate in the Iron Age and the increasing soil deterioration, especially in the sandy areas of Jutland, made the cultivation of oats and rye advantageous, since they are less demanding than the other cereals.

Spurrey, Spergula arvensis, is also an undemanding plant. It occurred first in the Pre-Roman Iron Age and was later commonly cultivated on the poor sandy fields of Jutland. Buckwheat, Fagopyrum sagittatum, is an equally undemanding plant, but this seems to 


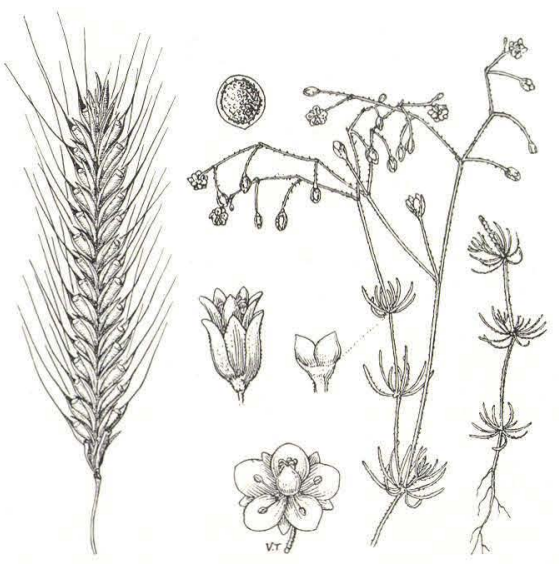

72. Rye and spurrey, which were first cultivated in the Iron Age. Both plants can grow on poor soil and can tolerate a cooler climate than the Stone Age cereal types. (From G. Hatt).

have been first cultivated in Viking times and later.

Flax, Linum usitatissimum, which was already present in the Late Bronze Age, was perhaps originally cultivated for the sake of its oily seeds - thus many flax seeds have been found in Celtic Iron Age food crusts and a mixture of barley, flax, and gold of pleasure has been found in provisions from the Older Roman Iron Age. Evidence of the use of flax as a textile plant first occurs in the Younger Roman Iron Age. Previously the nettle, Urtica dioeca, had been used for this purpose; it was still used for the same purpose in Germany during the First World War.

Woad, Isatis tinctoria, which grows wild on the margins of the Baltic Sea - on Bornholm, for example - was cultivated as a dye plant in the Roman Iron Age, as indicated by several finds in Jutland. Cæsar mentions how the Britons coloured their bodies blue with woad before going into battle.
Pollen diagrams give evidence of the expansion of agriculture

Denmark was still wooded in the Bronze Age, even though the forest for the most part was a light grazing forest with scrub pasture here and there. In the early Iron Age this picture was altered; both arable land and grass pasture now achieve a wide distribution.

A great increase of sheep's sorrel even in fertile areas is evidence of the great significance of agriculture. Sheep's sorrel, as previously mentioned, is typical of fallow fields; such land must have been very widespread. This agrees very well with Tacitus' account that the Germans "yearly change their cropfields". The cereal pollen curve to begin with is hardly higher than in the Younger Stone Age, but this can be explained by the fact that rye was still absent and barley has very poor pollen dispersal.

The sharp increase of the grass and ribwort plantain curves, together with the decline shown in the hazel curve, bears witness to the great extent of the grass pastures.

\section{Hay meadows appear}

A new feature of the landscape appeared in the Pre-Roman Iron Age when the iron scythe made it possible to mow grass. A characteristic decline in the curve for alder in several diagrams from this period indicates that alder swamps, which were not suitable for grazing owing to their soft ground, now became transformed into moist hay meadows. This culture-dependent type of vegetation, rich in flowers, survived right until our time, but it is disappearing now that more efficient agricultural methods have made it uneconomic.

Leaf-gathering, however, did not 


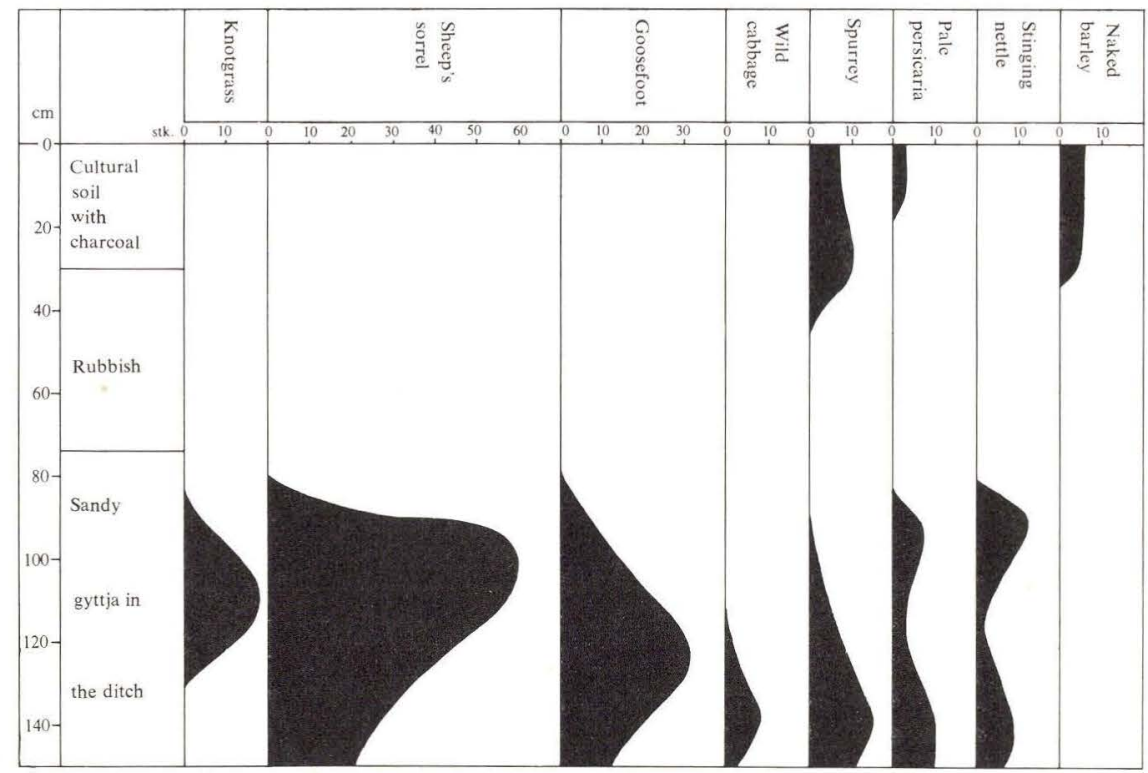

73. The frequency of various seeds and fruits in the ditch around the islet in Borre Bog. The defensive period is characterized by the "trodden plant", common knotgrass, the village period by cereals, and in between comes a layer rich with nettles. Immediately before the foundation of the village the ditch was partly filled in with rubbish. (From Inger Brandt).

cease after the introduction of meadow cultivation; on the contrary, an improved instrument was developed in the leaf knife with its angled blade for the cutting of twigs for cattle winter fodder.

\section{Borre Bog as a refuge in the Older Iron Age}

As an example of a peasant community from the Iron Age we can describe the settlement on an islet in Borre Bog in Himmerland. Thorough investigations have been carried out here by the National Museum and the Geological Survey of Denmark.

The setting was an already completely deforested landscape characterized by fields, extensive grass pasture and raised bogs. In a period of unrest during the Pre-Roman Iron Age the islet, which lay in a little outlier of a great raised bog, was turned into a fortified place of refuge. A deep moat was constructed whilst the uppermost layers of peat in the bog were also removed. The islet was then surrounded by open water with deep holes in the soft bottom, and approachable only by a narrow ford. Pollen and fruits in the moat bear witness to a heavy traffic of cattle and humans - the "trodden plants", common knotgrass and great plantain, were common. Spurrey, gold of pleasure, fat hen, pale persicaria, black bindweed, sheep's sorrel, and wild cabbage grew on small fields; some of them grew as weeds, but their seeds were also used as food (see p. 112).

When the troubled times were over the islet was abandoned and the manured ground became overgrown by nett- 


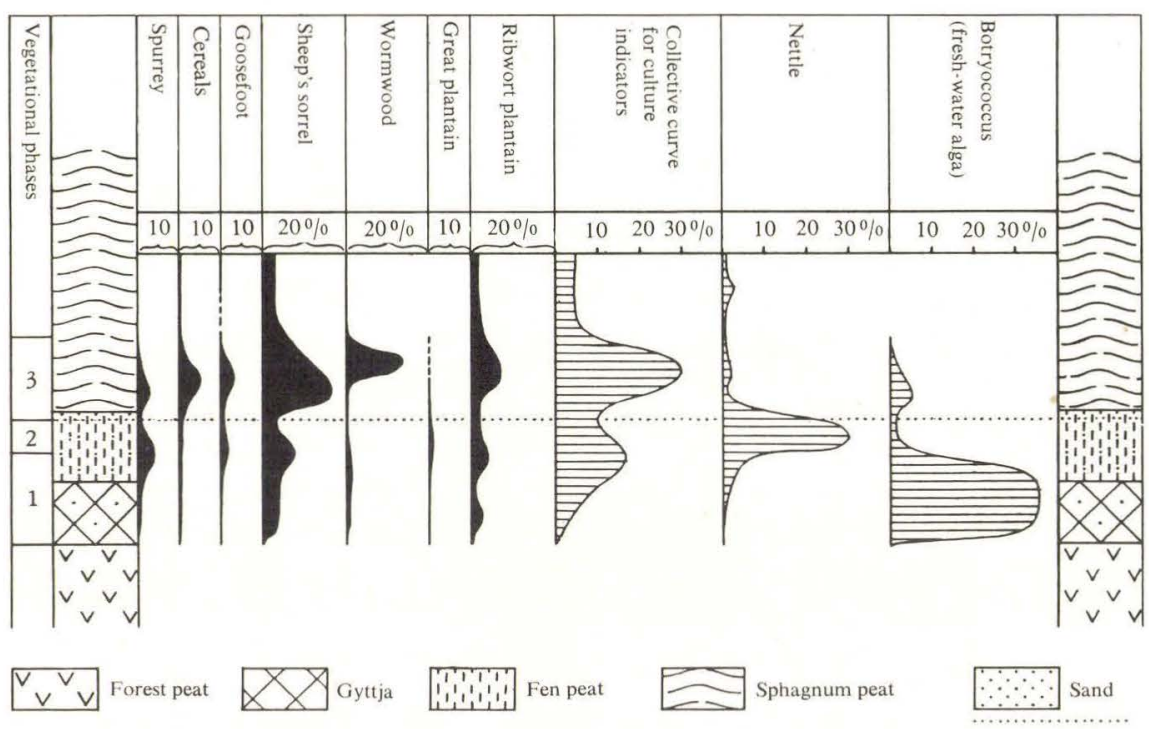

74. Section from a pollen diagram from Borre Bog, with the type of peat indicated below. The forest peat dates from the Pine period; it is overlain by gyttja formed after a lake was created around the islet by removal of peat from the Lime period. The diagram shows the frequency of various herbaceous plants whilst the islet functioned as a refuge, then stood deserted (nettle maximum!), and finally housed a village. (From Alfred Andersen).

les. These were presumably harvested and the fibres were used to make clothing.

\section{An Iron Age village on the Borre Bog islet}

After the islet had been deserted for a short time it was again resettled. A village was built, the moat filled in, and a fine broad cobbled road was built across the ford. Cattle were driven out and in over this road, and at harvest-time hay and crops were brought in along it.

The nettles disappeared, and the pollen flora is characterized by the nearby cereal fields (naked barley and wheat have been demonstrated). Cereal pollen now occurs so richly in the bog layers that it must originate from chaff which drifted into the bog at threshing time. Spurrey was still cul- tivated on the islet and flax has been found too. The cattle grazed on the nearby pasture, but the forest, where the swine could be fattened in good mast years, was more distant.

A peaceful village - but from the same bog and the same period a corpse has been found and dated by pollen analysis. It had been thrown into a peat cutting and is a gruesome illustration of Tacitus' accounts of the Germanic methods of punishment. Part of the large intestine of the executed man had been preserved and it contained large quantities of the seeds or fruits of spurrey, pale persicaria, sheep's sorrel, and fat hẻn, as well as a little gold of pleasure, black bindweed, and others, but no cereals. All the named species have also been found in the settlement on the islet. The large quantity of weed seeds indicates that many 
species of weeds with nutritious seeds were used as food.

Pollen diagrams indicate a period of depopulation in Jutland in the middle of the Iron Age

The density of the population in Denmark appears to have increased gradually through the Younger Stone Age, Bronze Age, and early Iron Age; this is especially obvious in the early Iron
Age when the landscape became increasingly open and was completely dominated by man and his domestic animals in many places. Drastic changes then occurred in the middle of the Iron Age, especially in Jutland and most of all in South Jutland pollen diagrams, changes which undeniably signify a strange depopulation. The same phenomenon can also be observed further to the south in the Cim-

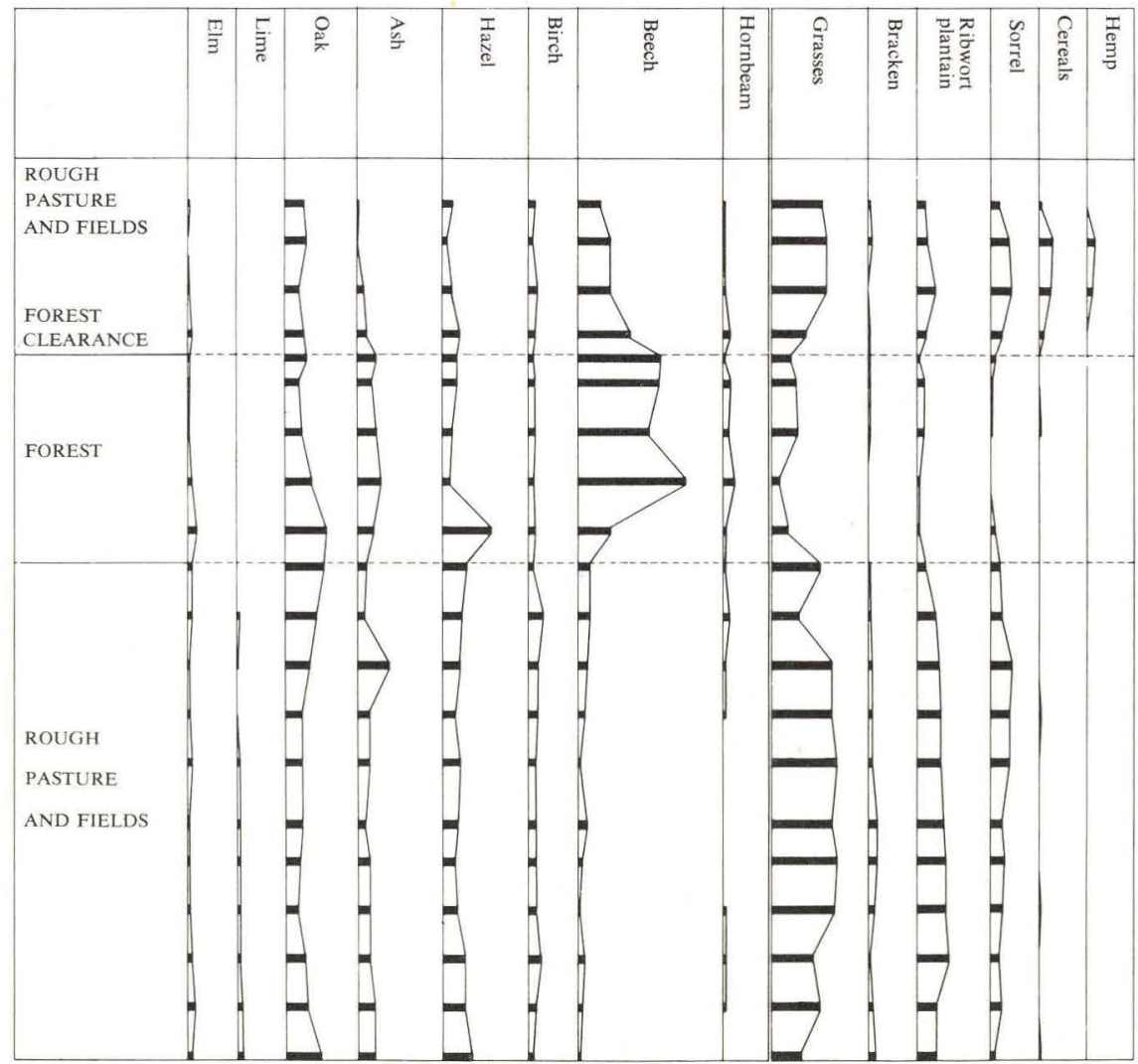

75. Upper part of a pollen diagram from Bundsø on Als. No other Danish pollen diagram shows such intensive and unbroken agricultural influence throughout the prehistoric period, from the landnam in the Younger Stone Age into the Early Iron Age, when rough pasture and fields characterized this part of Als. But suddenly the pollen of the important agricultural indicator plants disappears almost completely, and the pollen of forest trees becomes dominant. There can be no doubt that the area was deserted. The same phenomenon can be observed further south on the Cimbrian peninsula right down to Holland. (From Alfred Andersen). 
brian peninsula all the way down to Holland. It occurs most clearly and has been best investigated in a diagram from Bunds $\phi$, of which the upper part is reproduced in fig. 75 .

No other Danish pollen diagram shows so intense and unbroken agricultural influence through the whole of prehistory, from the landnam in the Younger Stone Age until the early Iron Age, when rough pasture, fields, and meadows completely dominated this part of the fertile island of Als. Then suddenly the pollen of plantain, sheep's sorrel, cereals and the other farming indicator plants disappears almost totally, and the pollen curves of grasses, bracken, and other herbaceous plants decline to the values which they had before the Stone Age landnam. There can be no doubt - the whole area was deserted. The question is: when did this depopulation occur, and what was the cause? Concerning the point in time, we know that it lies before the appearance of rye in this area, and that this cereal became very important immediately after the close of the cultural gap. In other diagrams the rye curve begins immediately before the depopulation, which thus could not have occurred before the Roman Iron Age.

\section{Archaeological evidence}

It is interesting to see what the archaeologists have recorded from this period. Johannes Brøndsted, in Politiken's History of Denmark, vol. 1, pp. 474-476, writes: "As mentioned, dwelling site and house finds cease in the last part of the Younger Roman period, in other words during the 4th century A.D. Furthermore there is no indication that the fields and field systems of which we know, were cultivated after this time" (translated from the Danish text).
Regarding an explanation of the deserted dwelling sites and fields Brøndsted writes: "A broad general reason must be sought, and it is natural to think of the climate." However, he continues: "A solution one can always turn to is the idea of a largescale emigration from Jutland in the 4th century, but it would be desirable to have greater support from the archaeological evidence than we have at present. The problem awaits an explanation." Other archaeologists have referred to the soil deterioration which may have occurred in Jutland, and it appears to the present author that in comparison with a change in climate, soil deterioration must be by far the most likely explanation for the desertion of the settlements in the sandy areas of Jutland. But this explanation can not be applied to the fertile island of Als, nor in Angeln, where an equally abrupt decline of agriculture has been found.

\section{A scientific explanation}

The most relevant explanation from a scientific point of view would be that the extensive exploitation of the soil had led to a crisis. The danger of intensive grazing is known all over the world, since it leads to a marked decline in the luxuriance of the grass vegetation. If this occurs simultaneously with a further increase in the population and the numbers of livestock, it leads inevitably to a catastrophe which can only be evaded by emigration. This crisis must necessarily have occurred in the closely populated poor sandy areas of Jutland, and if emigration ocurred into more fertile areas it would only cause overpopulation there too. An evaluation of the course of the pollen curves can lead to no other result: a crisis and an emigration were inevitable. 
In the 8th century A.D. Bede recorded in his history of the English Church that the Anglo-Saxon conquest of England at the beginning of the 5th century was carried out by three mighty Germanic peoples: the Saxons, the Angles, and the Jutes. According to English research workers the AngloSaxons were able to plough the heavy soil which previously had lain uncultivated. Thus there were opportunities for the settlers in this new country.

The pattern begins to develop, although many things still remain unclear; an excessive exploitation of the soil led to a crisis resulting in emigration, first in the poor areas of Jutland and later perhaps in the more fertile areas too. It is presumably the emigration to England that we find registered in the South Jutland pollen diagram (see fig. 75).

\section{The forest succession on the abandoned pasture and fields}

Bede writes in his chronicle that the land of the Angles was said to lie deserted after their emigration, and the diagram from Bunds $\phi$ definitely confirms this. It is interesting to be able to follow the succession on the deserted pasture and fields in the diagram.

We first observe an increase in the curves for oak and hazel, whilst the light-demanding tree birch disappears. Beech is slower to react, but then it advances, growing up over the hazel scrub and suppressing it in its shade. Oak is forced back from the high ground and the beech forest then reigns there supreme. Hornbeam, too, is favoured by the new conditions but its role is insignificant compared with beech. An interesting feature is the slow but considerable increase in ash, which gradually took over the damp, fertile meadow bottoms.
The easy and complete victory of beech is due to the fact that lime, the only tree which would have been a serious competitor, was completely absent in this area; it had long ago been wiped out by human interference.

\section{A new landnam occurs}

It is difficult to say how long the area around Bunds $\phi$ remained unpopulated, but eventually a new landnam occurred here as it did in other Jutland diagrams. The new clearance was carried out with great energy; pasture and fields quickly achieved just as wide an extent as before. Rye was now generally cultivated, and with it followed cornflower, which had not occurred in the country since the Late-Glacial period. A new cultivated plant whose pollen appears with great frequency was hemp.

Beech declined somewhat, as did ash and hornbeam. Oak managed better, but beech was still the dominant forest tree.

We shall not discuss here who could be thought to have carried out this landnam - that would be pure speculation. It should only be noted that hemp was cultivated by the Vikings; the only two definitely dated macroscopic finds of hemp in Scandinavia are both from the Viking period. It is well-known that hemp has played its part later as well.

\section{The soil deterioration increased}

\section{Leaching and mull-drift}

In the course of thousands of years the primeval forest had enriched the soil with a nutrient capital which was enormously great on clayey ground, but more scanty on sandy ground. As mentioned previously, the simulta- 


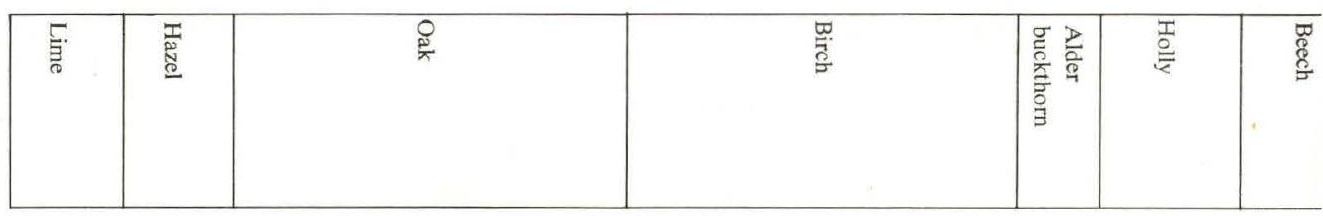

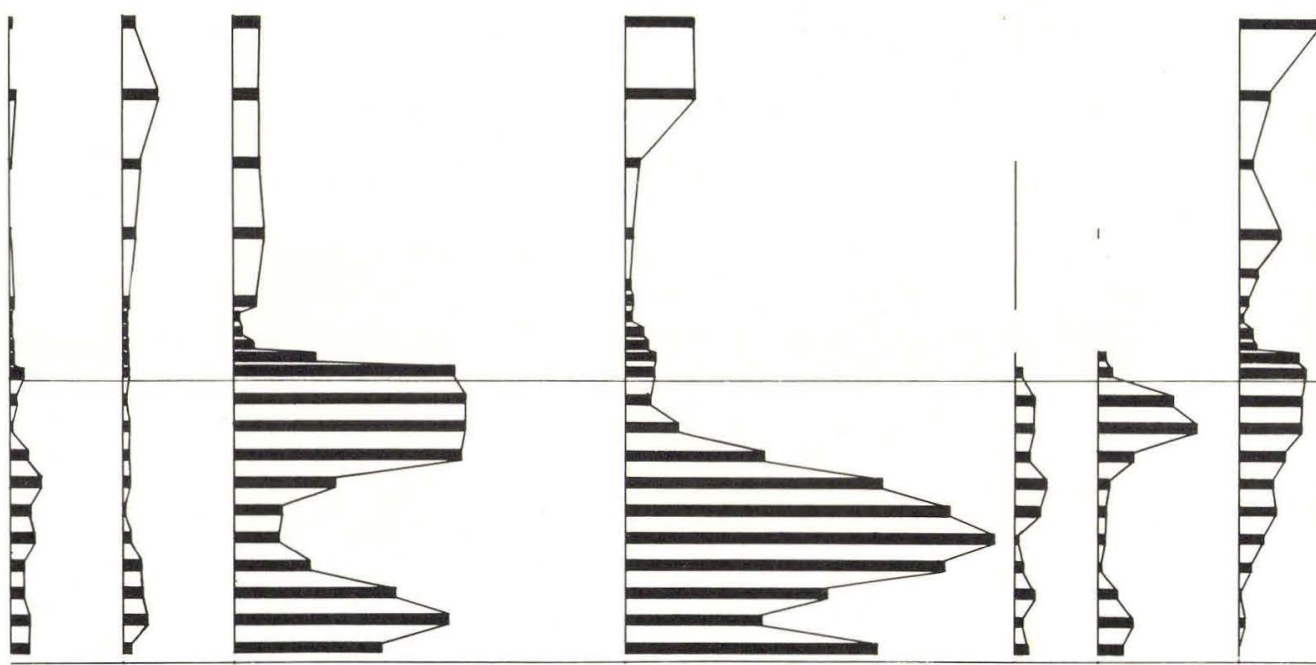

76. Pollen diagram showing how a heath arises from an oak forest as a result of fire clearance and grazing in the Viking period. It derives from the upper part of a thick layer of fossil mor in Draved forest. The burning-off is marked by a charcoal stripe

neous leaching, first of lime, and later of other nutrients too, led to a very slow deterioration of the mull on forested sandy soil.

The prehistoric forest clearances greatly accelerated this soil deterioration in sandy soil, regardless of whether it was used as rough pasture or as arable land. We have mentioned that excessive grazing in itself leads to a decline in grass production. In addition, the reduced density of vegetation increases the leaching of the soil and thus accelerates its deterioration still more.

Ploughing of arable land in windy weather will unavoidably result in erosion of mull, which also produces a dangerous reduction in the nutrient capital in the long run. Thus, as we have seen, a vicious circle was created in the Older Iron Age which could not be broken.

\section{Beech mor and heather mor}

Even before human intervention made itself felt, oak mor could develop on very poor soil, as we have seen. The formation of mor became more widespread as beech expanded over the country, since beech is more inclined to form mor than is oak. Beech mor is crumbly like oak mor to begin with, but it soon develops a tough structure as fungal hyphae weave the fallen beech leaves together into a felt-like 


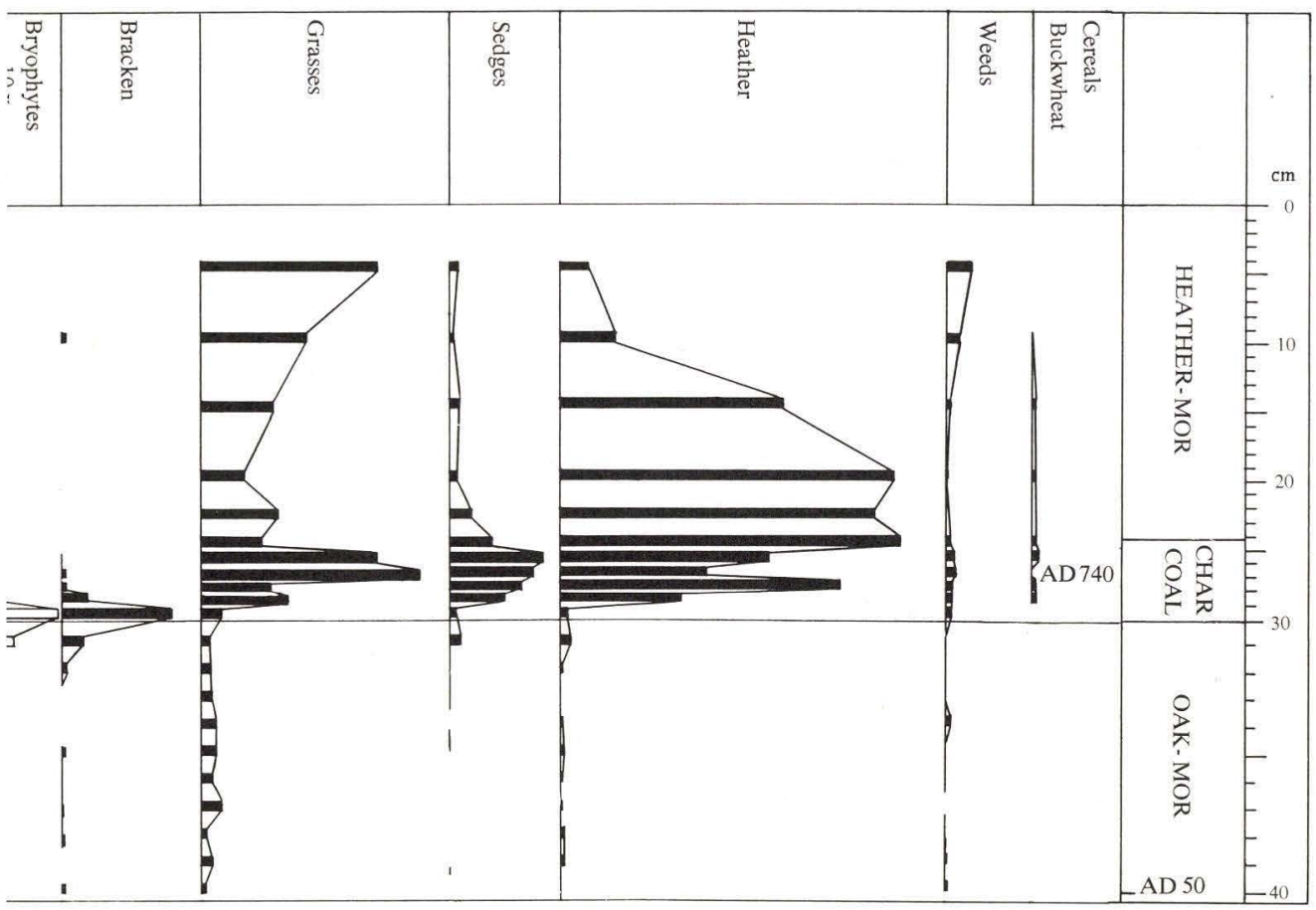

on the boundary between the almost structureless "oak mor" and the less decomposed, quickly growing heather mor.

cake. Beech leaves decompose very slowly on acid soil. The tough mor is unfavourable to plant growth and also hinders regeneration to a certain extent - at any rate where human intervention makes the forest more open and where the trees are not allowed to die and decay but are felled and utilized.

Heather also produces mor in large quantities. Dead heather is even more resistant to decomposition than are beech leaves, so heather mor makes a tough and infertile soil.

Both oak mor and beech mor are highly acidic and lead to the formation of a podsol profile (see p. 100) but this is particularly the case with heath- er, which quickly produces a tough, water-resistant hard pan.

\section{A heath occurs after forest clearance}

As mentioned previously, pollen diagrams from the fossil mor layers in Draved Forest show that the oak-lime primeval forest on the extensive flat dunes gradually developed into an oak forest with birch, holly and alder buckthorn. After a period with insig. nificant forest grazing a veritable landnam occurred in the Viking period; a charcoal layer can be observed in many places, and the pollen diagrams clearly register both the burning and the succeeding grazing.

In the charcoal layer we find a very 
short-lived maximum of moss spores and bracken, exactly as in the Stone Age landnam (see p. 87). Here, too, it is obvious that the felling only included the smaller trees and the shrubs; the older trees were allowed to remain. After the fire holly, alder buckthorn and rowan almost disappeared and the forest had become light, but the pollen frequencies of oak and beech were only slightly changed. The fire was thus not so severe as to kill the old beech trees; the composition of the high forest was hardly changed. The succeeding grazing, however, produced a total change in the vegetation on the areas where the mor layer was thickest. Here, but only here, the regeneration was prevented by livestock grazing; after the short-lived maximum of bracken, grass extended over the area, and then an open, treeless, grazed heath developed on the mor banks.

\section{The heaths of Jutland}

The origin of the Jutland heaths has been much discussed for over a century. The outstanding soil scientist P. E. Müller held the opinion that the hard pan formation on the Jutland heaths had occurred in the Late-Glacial period, and that the heath was thus successor to the Late-Glacial tundra. Others, however, believed that all the heaths of Jutland stand on old forest ground.

The latter opinion has been strongly supported by the pollen analytical investigations in heath areas, especially the diagrams of $H$. Jonassen from the great heath plains of northern Jutland. In the small Krag Lake in the middle of Karup heath about $10 \%$ heather pollen was found in gyttja sediments from the Older Lime period. This shows that the heath plain was mainly wooded. On the other hand, there must have been some heathcovered areas; these could have been raised bogs and also temporarily open patches in the forest, which in that case must have been a very poor, light and open oak forest rich in birch. A lake diagram is available from the not quite so poor Tinglev heath in South Jutland, and here the heather curve lies at only $1 \%$ over the same period.

The heather curve remained low throughout the Younger Stone Age, although, as mentioned, it could rise temporarily when arable land and pasture were abandoned. It is only in the Iron Age that the heath seriously began to expand in Jutland - perhaps after the previously discussed largescale abandonment of settlements in the Older Iron Age, but definitely following the grazing of partially cleared forest on mor soil, as we have seen. A new and even greater advance of the heaths occurred in historic time; for the greatest extent which it probably attained, just before heath reclamation was commenced, refer to Danmarks Natur, vol. 7.

\section{The utilization of heathland}

Heathland is not a natural vegetation type in Denmark; it was mainly created by man, and it has been of importance for the heathland peasant. Sheep found good food here, and heather peat was cut for fuel and probably also to supply humus to the sandy fields. Thus the original fossil mor, which could have given evidence of a succession from forest to rough pasture and heath, has almost completely disappeared from north-west Europe. And at the same time the nutrient capital contained in the mor layer disappeared. The leached sand is exteremely barren, and until very recently it was not possible to penetrate the harmful hard pan layer. 


\section{Dunes appear again}

Just as the over-intensive cultivation in the Iron Age resulted in mull-drift in the interior of Jutland, it also caused sand drift near the coasts. In the Lime period the forest appears to have extended right to the coast and thus to have protected the soil from the attack of the wind. The Post-Glacial dune-formation is a new phenomenon which culminated far up in historical time - see Danmarks Natur, vol. 3.

\section{The sea in the Beech period}

The rising of the land in north-east Denmark continued at a decreasing rate, and Denmark's coast-line approached its present shape. The salt content of the Baltic Sea decreased again; Litorina and other saltwater molluscs disappeared from the inner Baltic and were replaced by species which, like Limnaea, thrive in brackish water. The Baltic had reached the Limnaea stage. The well-known sand gaper, Mya arenaria, immigrated quite late in historical time - perhaps by ship from America.

\section{The historical perspective}

We have followed the natural history of Denmark from the last Glacial right up to historical time and attempted to understand the past in the light of those processes which can be observed in nature today. If we do the reverse and look at the living landscape of today with a historical perspective, we will achieve a deeper understanding of many characteristic features.

The map in fig. 77 shows the present distribution of a number of plants which are found as fossils in Ice Age sediments but which are rare today.

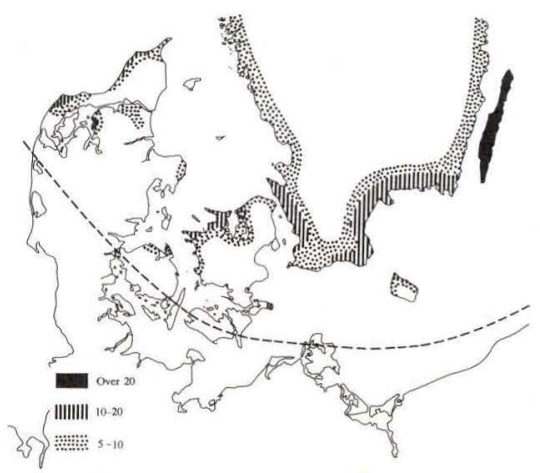

77. Refuges of Late-Glacial plant species. North of the stippled line the Stone Age beach ridges lie above the present sealevel.

It will be noticed that these plant species are concentrated in particular places, and we must assume that LateGlacial plants had refuges within these areas during the time of the primeval forest.

It is first and foremost the coast which has been the place of refuge, but only in that part of the country which has been elevated. The concentration is especially great where chalk comes to the surface along old beach cliffs, as at Hanstholm and L $\phi$ gst $\phi r$ as well as on High Møn, or where the rainfall is particularly low, as on the north-west Zealand coast. This latter area is interesting on account of its "steppe plants" - see Danmarks Natur, vol. 7.

The original refuges have presumably been limited to the beaches, with the exception of small outcrops of pure chalk; along the beaches the sea has continually created fresh slopes, shore benches, and so on, with new earth and abundant light for pioneer plants. The extremely interesting and varied flora of beach slopes will be discussed in detail in Danmarks Natur, vol. 4.

Entire plant communities and their 
animal life can also only be understood in a historical perspective, since they are relics of definite though now abandoned agricultural methods. This is true of heath, rough pasture, and hay meadows, which are all disappear- ing today, and which can only be preserved as historic monuments by the reintroduction of the methods that once created them. This subject, too, is discussed in the succeeding volumes of Danmarks Natur. 


\section{List of English Plant Names and their Latin Equivalents}

Alder, Alnus glutinosa

Aspen, Populus tremula

Barley, Six-rowed, Hordeum vulgare

Bearberry, Arctostaphylos uva-ursi

Bearberry, Black, Arctostaphylos alpina

Bindweed, Convolvulus

Bindweed, Black, Polygonum convolvulus

Birch, Betula pubescens

Birch, Dwarf, Betula nana

Birch, Silver, Betula pendula

Bird Cherry, Prunus padus

Bird's Foot Trefoil, Lotus corniculatus

Bittersweet, Solanum dulcamara

Bladderwort, Utricularia

Bracken, Pteridium aquilinum

Buckwheat, Fagopyrum sagittatum

Buckthorn, Rhamnus cathartica

Buckthorn, Alder, Frangula alnus

Buckthorn, Sea, Hippophaë rhamnoides

Burnet, Lesser, Sanguisorba minor

Buttercup, Ranunculus

Buttercup, Creeping, Ranunculus repens

Cabbage, Wild, Brassica oleracea

Clover, White, Trifolium repens

Club Moss, Selaginella selaginoides

Corn Flower, Centaurea cyanus

Crab Apple, Malus sylvestris

Crowberry, Empetrum nigrum

Dandelion, Taraxacum

Dog's Mercury, Mercurialis perennis

Dogwood, Cornus sanguinea

Elm, Smooth, Ulmus carpinifolia

Elm, Wych, Ulmus glabra

Emmer, Triticum dicoccum

Fat Hen, Chenopodium album

Fern, Royal, Osmunda regalis
Fern, Shield, Dryopteris

Field Pansy, Viola arvensis

Fir, Silver, Abies alba

Flax, Linum usitatissimum

Gold of Pleasure, Camelina sativa

Grape Vine, Vitis silvestris

Grass of Parnassus, Parnassia palustris

Guelder Rose, Viburnum opulus

Harebell, Campanula rotundifolia

Hawthorn, Crataegus

Hazel, Corylus avellana

Heath Grass, Sieglingia decumbens

Hemp, Cannabis sativa

Hemp-nettle, Galeopsis

Holly, Ilex aquifolium

Honeysuckle, Lonicera periclymenum

Hop, Humulus lupulus

Hornbeam, Carpinus betulus

Hornwort, Ceratophyllum demersum

Ivy, Hedera helix

Kidney-vetch, Anthyllis vulneraria

Knawel, Scleranthus annuus

Knotgrass, Polygonum aviculare

Knotgrass, Viviparous, Polygonum viviparum

Larch, Larix

Lime, Broad-leaved, Tilia platyphyllos

Lime, Small-leaved, Tilia cordata

Lyme-grass, Elymus arenarius

Maple, Field, Acer campestre

Maple, Norway, Acer platanoides

Marram-grass, Ammophila arenaria

Meadow Rue, Alpine, Thalictrum alpinum

Meadow-sweet, Filipendula ulmaria

Milk-vetch, Alpine, Astragalus alpinus

Milk-vetch, Purple, Astragalus danicus

Millet, Panicum miliaceum

Mistletoe, Viscum album

Moonwort, Botrychium lunaria 
Moss Campion, Silene acaulis Mountain Avens, Dryas octopetala Mugwort, Artemisia vulgaris Nettle, Stinging, Urtica dioeca Oak, Common, Quercus robur Oak, Sessile, Quercus petraea Oak, Pedunculate, Quercus robur

Oats, Avena sativa

Persicaria, Pale, Polygonum lapathifolium

Pine, Mountain, Pinus mugo

Pine, Scots, Pinus sylvestris

Plantain, Great, Plantago major

Plantain, Hoary, Plantago media

Plantain, Ribwort, Plantago lanceolata

Plantain, Sea, Plantago maritima

Polypody, Polypodium vulgare

Reed-mace, Typha latifolia

Rock-rose, Helianthemum nummularium

Rock-rose, Öland, Helianthemum oelandicum

Rowan, Sorbus aucuparia

Rye, Secale cereale

Sainfoin, Onobrychis viciifolia

Sawwort, Alpine, Saussurea alpina

Saxifrage, Purple, Saxifraga oppositifolia

Sedge, Fen, Cladium mariscus

Sedge, Pill, Carex pilulifera

Sheep's Bit, Jasione montana

Sloe, Prunus spinosa
Sorrel, Common, Rumex acetosa Sorrel, Mountain, Oxyria digyna Sorrel, Sheep's, Rumex acetosella Spelt, Small, Triticum monococcum Spindletree, Euonymus europaea Spruce, Common, Picea abies Spurge, Euphorbia Spurrey, Spergula arvensis Sweep's Brush, Luzula campestris Thrift, Armeria maritima Tormentil, Potentilla erecta Water-chestnut, Trapa natans Water Dropwort, Oenanthe aquatica Water-lily, Yellow, Nuphar luteum Water Milfoil, Whorled, Myriophyllum verticillatum

Wheat, Bread, Triticum aestivum Wheat, Club, Triticum compactum Whitebeam, Sorbus aria Whortleberry, Bog, Vaccinium uliginosum

Willow, Arctic, Salix polaris

Willow, Dwarf, Salix herbacea

Willow, Goat, Salix caprea

Woad, Isatis tinctoria

Wood-sorrel, Oxalis acetosella

Wormwood, Common, Artemisia vulgaris

Wormwood, Field, Artemisia campestris

Yew, Taxus baccata 


\section{List of English Animal Names and their Latin Equivalents}

Antelope, Saiga, Saiga tatarica

Auk, Great, Alca impennis

Aurochs, Bos taurus primigenius

Badger, Meles meles

Beluga, Delphinapterus leucas

Bittern, Botaurus stellaris

Burbot, Lota vulgaris

Capercaillie, Tetrao urogallus

Catfish, Silurus glanis

Cockles, Cardium

Cod, Gadus

Coot, Fulica atra

Cormorant, Phalacrocorax carbo

Crane, Grus grus

Deer, Red, Cervus elaphus

Deer, Roe, Capreolus capreolus

Diver, Black-throated, Gavia arctica

Duck, Long-tailed, Pagonetta glacialis (= Clangula hyemalis)

Duck, Pintail, Anas acuta

Duck, Tufted, Aythya fuligula

Eagle, White-tailed, Haliaeetus albicilla

Elk, Irish, Megaloceros giganteus

Fox, Arctic, Alopex lagopus

Gannet, Morus bassanus

Goosander, Mergus merganser

Goose, Grey Lag, Anser anser

Grebe, Great Crested, Podiceps cristatus

Guillemot, Uria aalge

Gull, Black-backed, Larus marinus

Gull, Black-headed, Larus ridibundus

Hare, Blue, Lepus timidus

Hedgehog, Erinaceus europaeus

Heron, Ardea cinerea

Jay, Garrulus glandarius

Kite, Milvus milvus

Lemming, Lemmus lemmus

Lynx, Lynx lynx

Mallard, Anas platyrhynchos
Marten, Martes foina

Marten, Pine, Martes martes

Merganser, Mergus serrator

Moorhen, Gallinula chloropus

Mussel, Common, Mytilus edulis

Osprey, Pandion haliaetus

Otter, Lutra lutra

Perch, Perca fluviatilis

Piddock, Oval, Zirphaea crispata

Pike, Esox lucius

Plover, Plurialis apricaria

Polecat, Putorius putorius

Porpoise, Phocaena phocaena

Ptarmigan, Lagopus mutus

Razorbill, Alca torda

Roach, Leuciscus rutilus

Rorqual, Balaenoptera physalus

Sand Gaper, Mya arenaria

Scallop, Pecten varius

Seal, Common, Phoca vitulina

Seal, Grey, Halichoerus grypus

Seal, Harp, Fagophilus groenlandica $(=$ Phoca groenlandica)

Seal, Ringed, Pusa hispida

Shrew, Sorex araneus

Suslik, Spermophilus rufescens ( = Citellus citellus $)$

Swan, Bewick's, Cygnus bewickii

Swan, Mute, Cygnus olor

Swan, Whooper, Cygnus cygnus

Tortoise, European Pond, Emys orbicularis

Whale, Blue, Sibbaldus musculus

Whale, Greenland, Balaena mysticetus

Whale, Killer, Orcinus orca

Whitefish, Coregonus lavaretus

Vole, Microtus arvalis

Wolverine, Gulo gulo

Woodpecker, Black, Dryocopus martius 


\section{More important Literature about the Late-Glacial and Post-Glacial Geology of Denmark}

Andersen, A. 1954: Two standard pollen diagrams from South Jutland. Danm. geol. Unders. II. række, 80, 188-209.

Andersen, F. S. 1938: Spätglaciale Chironomiden. Meddr dansk geol. Foren. 9, 320326.

Christensen, W. 1935: Jordens Fosforsyreindhold som Indikator for tidligere Kultur og Bebyggelse. Danm. geol. Unders. II. række, 57, 47 pp. English Summary.

Dau, J. H. C. 1823: Neues Handbuch über den Torf dessen Natur, Entstehung und Wiedererzeugung. Leipzig.

Dau, J. H. C. 1829: Allerunterthänigster Bericht an die Königliche Dänische Rentekammer über die Torfmoore Seelands. Kopenhagen und Leipzig.

Degerbøl, M. 1927: Über prähistorische, dänische Hunde. Vidensk. Meddr dansk naturh. Foren. 84, 17-71.

Degerbøl, M. 1932: Et Fund af Steppe-Antilope (Saiga tatarica (Pall.)) i Danmark. Summary: A find of the Saiga Antelope (Saiga tatarica (Pall.)) in Denmark. Meddr dansk geol. Foren. 8, 175-185.

Degerbøl, M. 1933: Danmarks Pattedyr i Fortiden i Sammenligning med recente Former. I. Summary: The prehistoric mammals of Denmark compared with recent forms. I. Vidensk. Meddr dansk naturh. Foren. 96, 356-641.

Degerbøl, M. 1945: Subfossile Fisk fra Kvartærtiden i Danmark. Summary: On subfossil fishes from the Quaternary in Denmark. Vidensk. Meddr dansk naturh. Foren. 108, 103-160.

Degerbøl, M. 1964: Some remarks on Lateand Post-Glacial vertebrate fauna and its ecological relations in northern Europe. J. Ecol. 52 (Suppl.), 71-85.

Degerbøl, M. \& Fredskild, B. 1970: The Urus (Bos primigenius Bojanus) and Neolithic domesticated cattle (Bos taurus domesticus Linné) in Denmark. Zoological and palynological investigations. Biol. Skr. K. dansk Vidensk. Selsk. 17(1), 234 pp.

Degerbøl, M. \& Iversen, J. 1942: On a find of a sheat-fish (Silurus glanis L.) from the Ancylus period in Denmark. Vidensk. Meddr dansk naturh. Foren. 105, 435-446.

Degerbøl, M. \& Iversen, J. 1945: The Bison in Denmark. Danm. geol. Unders. II. række, 73, $62 \mathrm{pp}$.

Degerbøl, M. \& Krog, H. 1951: Den europæiske Sumpskildpadde (Emys orbicularis L.) i Danmark. Summary: The European pond tortoise (Emys orbicularis L.) in
Denmark. Danm. geol. Unders. II. række, 78, $130 \mathrm{pp}$.

Degerbøl, M. \& Krog, H. 1959: The Reindeer (Rangifer tarandus L.) in Denmark. Biol. Skr. K. dansk. Vidensk. Selsk. 10(4), 1-165.

Fjerdingstad, E. 1954: The subfossil algal flora of the lake Bølling Sø and its limnological interpretation. Biol. Skr. K. dansk Vidensk. Selsk. 7(6), 56 pp.

Feyling-Hanssen, R. W., Jørgensen, J. A., Knudsen, K. L. \& Andersen, A.-L. 1971 Late Quaternary foraminifera from Vendsyssel, Denmark, and Sandnes, Norway. Bull. geol. Soc. Denmark, 21, 67-317.

Foged, N. 1965: En senglacial ferskvandsdiatoméflora fra Fyn. Meddr dansk geol. Foren. 15, 459-469.

Foged, N. 1969: Diatoms in a postglacial core from the bottom of the lake Grane Langsø, Denmark. Bull. geol. Soc. Denmark, 19, 237-256.

Hansen, K. 1950: The geology and bottom deposits of Lake Tystrup Sø, Zealand. Danm. geol. Unders. II. række, 76, $52 \mathrm{pp}$.

Hansen, K. 1956: The profundal bottom deposits of Gribsø. In Berg, K. \& Petersen, I.C. Studies on the humic, acid lake Gribsø. Folia limnol. scand. 8, 16-24.

Hansen, K. 1965: The Post-glacial development of Grane Langsø. Meddr dansk geol. Foren. 15, 446-458.

Hansen, S. 1965: The Quaternary of Denmark. In Rankama, K. (Editor): The geologic systems. The Quaternary, 1, 1-90. Interscience Publishers, Wiley and Sons, New York, London, Sydney.

Hartz, N. 1902: Bidrag til Danmarks senglaciale Flora og Fauna. Résumé: Recherches sur la flore et la faune glaciaires postérieures du Danemark. Danm. geol. Unders. II. række, $11,80 \mathrm{pp}$.

Hartz, N. 1912: Allerød-Gytje und AllerødMull. Meddr dansk geol. Foren. 4, 85-92.

Hartz, N. \& Milthers, V. 1901: Det senglaciale Ler i Allerød Teglværksgrav. Meddr dansk geol. Foren. no. 8, 31-60.

Hatting, T. 1963: On subfossil finds of Dalmatian pelican (Pelecanus crispus Bruch.) from Denmark. Vidensk. Meddr dansk naturh. Foren. 125, 337-351.

Helbæk, H. 1954: Prehistoric food plants and weeds in Denmark. Danm. geol. Unders. II. række, 80, 250-261.

Henriksen, K. L. 1933: Undersøgelser over Danmark-Skånes kvartære Insektfauna. Vidensk. Meddr dansk naturh. Foren. 96, 77-355. Deutsch. Zusammenfass. 
Iversen, J. se pp. 9-10.

Jessen, A. 1920: Stenalderhavets Udbredelse i det nordlige Jylland. Summary: The extension of the Stoneage Sea (Tapes-Litorina Sea) in northern Jutland. Danm. geol. Unders. II. række, 35, 112 pp.

Jessen, A. \& Nordmann, V. 1915: Ferskvandslagene ved Nørre Lyngby. Summary: The fresh-water deposits at Nørre Lyngby. Danm. geol. Unders. II. række, 29, 66 pp.

Jessen, K. 1920: Moseundersøgelser i det nordøstlige Sjælland. Summary: Bog-investigations in North East Sjælland. Danm. geol. Unders. II. række, 34, 269 pp.

Jessen, K. 1923: En undersøisk Mose i Rungsted Havn og de senglaciale Niveauforandringer i Øresund. Summary: A submerged peat-bog in the harbour of Rungsted and changes of sea-level in the Sound in the LateGlacial period. Danm. geol. Unders. IV. række, 1(18), $18 \mathrm{pp}$.

Jessen, K. 1935: Archaeological dating in the history of North Jutland's vegetation. Acta Arch. 5, 185-214.

Jessen, K. 1935: The composition of the forests in northern Europe in epipalæolithic time. Biol. Meddr K. dansk. Vidensk. Selsk. XII(1), 64 pp.

Jessen, K. 1937: Some west baltic pollen diagrams. Quartär, 1, 124-139.

Johansen, A. C. 1904: Om den fossile kvartære Molluskfauna i Danmark og dens Relationer til Forandringer i Klimaet. Landog Ferskvandsmolluskfaunaen. 141 pp. Gyldendalske Boghandel, Nordisk Forlag, København.

Johnsen, P. \& Krog, H. 1948: Potosia speciosissima Scop. subfossil in Denmark (Coleoptera Lamellicornia). Ent. Meddr 25, 252-262.

Jonassen, H. 1950: Recent pollen sedimentation and Jutland heath diagrams. Dansk bot. Ark. 13(7), 1-168.

Jørgensen, S. 1954: A pollen analytical dating of Maglemose finds from the bog Aamosen, Zealand. Danm. geol. Unders. II. række, 80 , 159-187.

Jørgensen, S. 1963: Early Postglacial in Aamosen. Vol. I-II. Danm. geol. Unders. II. række, $87,115 \mathrm{pp}$.

Krog, H. 1954: Pollen analytical investigation of a $\mathrm{C}^{14}$-dated Alleröd section from Ruds Vedby. Danm. geol. Unders. II. række, 80, 120-139.

Krog, H. 1968: Late-glacial and Postglacial shoreline displacement in Denmark. Proc. VII. Congr. int. Ass. Quatern. Res., U. S. A 1965, 421-435. Utah.

Krog, H. 1971: The early Post-Glacial development of the Store Belt as reflected in a former fresh water basin. Quaternaria, 14, 85-92.

Laursen, D. 1937: Et Profil gennem en Skalbanke fra Dosinia-Havet. Meddr dansk geol. Foren. 9, 127-136.

Marcussen, I. 1967: The freshwater molluses in the Late-Glacial and early Post-Glacial deposits in the bog of Barmosen, southern
Sjælland, Denmark. Meddr dansk geol. Unders. 17, 265-283.

Mathiesen, F. J. 1925: Om nogle arktiske Planterester fra Møens Klint. Meddr dansk geol. Foren. 6(27), 1-15.

Mertz, E. L. 1924: Oversigt over de sen- og postglaciale Niveauforandringer i Danmark. Résumé en francais. Danm. geol. Unders. II. række, 41, 49 pp.

Michelsen, O. 1967: Foraminifera of the LateQuaternary deposits of Læsø. Meddr dansk geol. Foren. 17, 205-263.

Mikkelsen, V. M. 1943: Bidrag til Lille Vildmoses Stratigrafi og Vegetationshistorie. Summary: Contributions to the stratigraphy and the vegetational history of Lille Vildmose (Jutland). Meddr dansk geol. Foren. 10, 329-364.

Mikkelsen, V. M. 1949: Præstø Fjord. The development of the Post-Glacial vegetation and a contribution to the history of the Baltic Sea. Dansk bot. Ark. 13(5), 171 pp.

Mikkelsen, V. M. 1954: Studies on the subatlantic history of Bornholm's vegetation. Danm. geol. Unders. II. række, 80, 210-229.

Mikkelsen, V. M. 1963: Beech as a natural forest tree in Bornholm. Bot. Tidsskr. 58, 253-280.

Nilsson, T. 1948: On the application of the Scanian Post-Glacial zone system to Danish pollen-diagrams. Biol. Skr. K. dansk. Vidensk. Selsk. V, 5, 53 pp.

Nordmann, V. 1903: Østersens (Ostrea edulis L.) Udbredelse i Nutiden og Fortiden i Havet omkring Danmark. Meddr dansk geol. Foren. Nr. 9, 45-60.

Nordmann, V. 1905: Danmarks Pattedyr i Fortiden. Danm. geol. Unders. III. række, $5,133 \mathrm{pp}$.

Nygaard, G. 1956: Ancient and recent flora of diatoms and chrysophyceae in Lake Gribsø. In Berg, K. \& Petersen, I. C. : Studies on the humic, acid lake Gribsø. Folia limnol. scand. 8, 32-94.

Poulsen, E. M. 1944: Entomostraceans from a Late-Glacial lacustrine deposit at Næstved, Denmark. Meddr dansk geol. Foren. 10, 405-416.

Rosenkrantz, A. \& Henriksen, K. 1921: De senglaciale Lag i Vintappermosen ved Kongens Lyngby og deres Insektfauna. Meddr dansk geol. Foren 6(6), 1-23.

Steenstrup, J. J. S. 1841: Geognostisk-geologisk Undersögelse af Skovmoserne Vidnesdam- og Lillemose i det nordlige Sjælland, ledsaget af sammenlignende Bemærkninger, hentede fra Danmarks Skov- Kjær-og Lyngmoser Ialmindelighed. $104 \mathrm{pp}$. Kjöbenhavn.

Sørensen, R. P. 1972: Iagttagelser i jyske indsande. Dansk geol. Foren. Årsskr. f. 1971, 5-26.

Thomsen, M. \& Krog, H. 1949: Cerambyx cerdo L. (= heros Scop.) fra subboreal Tid i Danmark. Vidensk. Meddr dansk naturh. Foren. 111, 131-148.

Troels-Smith, J. 1937: Pollenanalytisk Datering af Brabrand-Fundet. Mit deutscher $\mathrm{Zu}$ - 
sammenfassung. Danm. geol. Unders. IV. række, 2(16), $24 \mathrm{pp}$.

Troels-Smith, J. 1942: Geologisk Datering af Dyrholm-Fundet. Arkæol.-Kunsth. Skr. K. dansk. Vidensk. Selsk. 1(1), 137-212.

Troels-Smith, J. 1954: Ertebøllekultur-Bondekultur. Aarb. Nord. Oldkynd. Hist. 1953, 5-62. English summary.

Troels-Smith, J. 1960: Ivy, mistletoe and elm. Climate indicators - fodder plants. Danm. geol. Unders. IV. række, 4(4), 32 pp.

Vaupell, C. 1851: De nordsjællandske Skovmoser. 57 pp. Hos Universitetsboghandler C. A. Reitzel, Kjöbenhavn.

Vaupell, C. 1857: Bögens Indvandring i de danske Skove. 63 pp. Forlagt af C. A. Reitzels Bo og Arvinger, Kjöbenhavn.

Villumsen, A. 1973: Geochemical and sedimentological investigations of the Rosenholm depression. Danm. geol. Unders. II. række, $100,66 \mathrm{pp}$.

Whiteside, M. C. 1970: Danish chydorid Cladocera: Modern ecology and core studies. Ecol. Monogr. 40, 79-118.

Winge, H. 1903: Om jordfundne Fugle fra Danmark. Vidensk. Meddr naturh. Foren. Kjøbenhavn. 1903, 61-109.

Winge, H. 1904: Om jordfundne Pattedyr fra Danmark. Vidensk. Meddr naturh. Foren. Kjøbenhavn, 1904, 193-304. 